\title{
EHRA/EAPCl expert consensus statement on catheter-based left atrial appendage occlusion - an update
}

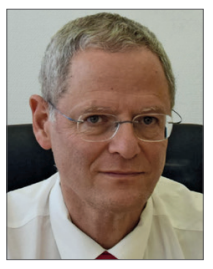

Michael Glikson ${ }^{1 *}$; Rafael Wolff ${ }^{1}$; Gerhard Hindricks²; John Mandrola ${ }^{3}$; A. John Camm4; Gregory Y.H. Lip ${ }^{5,6}$; Laurent Fauchier ${ }^{7}$; Tim R. Betts ${ }^{8}$; Thorsten Lewalter ${ }^{9,10}$; Jacqueline Saw ${ }^{11}$; Apostolos Tzikas ${ }^{12}$; Leonid Sternik ${ }^{13}$; Fabian Nietlispach ${ }^{14}$; Sergio Berti ${ }^{15}$; Horst Sievert ${ }^{16,17,18,19}$; Stefan Bertog ${ }^{16} ;$ Bernhard Meier ${ }^{20}$

The authors' affiliations can be found in the Appendix paragraph.

Document Reviewers:

Radoslaw Lenarczyk (review coordinator): First Department of Cardiology and Angiology, Silesian Centre for Heart Disease, Zabrze, Poland; Jens Erik Nielsen-Kudsk: Department of Cardiology, Aarhus University Hospital, Skejby, Aarhus, Denmark; Jai-Wun Park: Senior Consultant, Cardiology, Charite Universitätsmedizin Campus Benjamin Franklin, Berlin, Germany; Roland Tilz: University Heart Center Luebeck, Medical Clinic II, Division of Electrophysiologie, University Hospital Schleswig-Holstein, Germany and DZHK (German Center for Cardiovascular Research), Partner Site Hamburg/Kiel/Lübeck, Berlin, Germany; Zbigniew Kalarus: SMDZ in Zabrze, Medical University of Silesia, Katowice, Poland, and Department of Cardiology, Silesian Center for Heart Diseases, Zabrze, Poland; Serge Boveda: Clinique Pasteur, Cardiology Department, Toulouse, France; Thomas Deneke: Rhön-Clinic Heart Center Campus Bad Neustadt, Bad Neustadt, Germany; Frank R. Heinzel: Department of Cardiology, Charité University Medicine, Campus Virchow-Klinikum, Berlin, Germany; Ulf Landmesser: Campus Benjamin Franklin, Charité Universitätsmedizin Berlin, Berlin, Germany; David Hildick-Smith: Sussex Cardiac Centre, Brighton and Sussex University Hospitals NHS Trust, Brighton, United Kingdom

This paper also includes supplementary data published online at: https://eurointervention.pcronline.com/doi/10.4244/EIJY19M08_01

\section{Chapter 1. Background and pathophysiology of thrombus formation in the left atrium}

The rationale for the quest to close the left atrial appendage (LAA) for stroke prevention is composed of three elements: the concept that atrial fibrillation (AF) causes strokes, the concept that strokes are associated with thrombus formation in the LAA, and that these thrombi cause strokes by embolisation to the cerebral circulation.

There are strong data supporting an association between AF and stroke. The Framingham study following 5,070 patients over 34 years demonstrated an approximately fivefold higher stroke risk in individuals with $\mathrm{AF}$ than in those without ${ }^{1}$. Though this does not prove a causal relationship, it is important to mention that this risk remained even after adjustment for other risk factors such as hypertension, coronary artery disease, congestive heart failure, and age.

Another element to support LAA closure is that there must be proof that thrombus formation occurs predominantly in the LAA. One would imagine that there are abundant data to support the concept that, in AF, thrombus formation occurs predominantly in the LAA; however, in almost all texts discussing the pathophysiology of stroke in AF there are few publications cited to support this concept.

Blackshear et al included 1,288 patients with non-valvular AF who underwent either transoesophageal echocardiography (TOE) or autopsy ${ }^{2}$. Thrombus formation was reported in 222 patients, $91 \%$ of which was located in the LAA. It was further supported by a more comprehensive meta-analysis by Mahajan et al who demonstrated that $89 \%$ of thrombi in the left atrium (LA) were located in the $\mathrm{LAA}^{3}$. This was corroborated by a study in the realm of degenerative aortic stenosis by Parashar et $\mathrm{al}^{4}$. In this study, all left atrial thrombi resided in the LAA. It is worth mentioning that the LAA is the most common site of intracardiac thrombi not only in patients with AF but also in patients in sinus rhythm ${ }^{5}$.

More direct evidence is now available proving that a large proportion of strokes in AF are the result of thrombus in the LAA. The PROTECT AF and PREVAIL studies (described later in this document) provide evidence for the protective effect of LAA closure on thromboembolic events (Chapter 5), although some have debated the evidence (Chapter 6) ${ }^{6}$.

Editorial, see page 1117

\footnotetext{
*Corresponding author: Shaare Zedek Medical Center, POB 3235, Jerusalem 9103102, Israel.

Tel. Administrative office: 972-(0)2-6555975.Fax: 972-(0)2-6555437.E-mail address: mglikson@szmc.org.il

This article has been co-published with permission in EP Europace and EuroIntervention. All rights reserved. (C) 2019 the European Heart Rhythm Association and the European Association of Percutaneous Cardiovascular Interventions. The articles are identical except for minor stylistic and spelling differences in keeping with each journal's style. Either citation can be used when citing this article.
} 
In order to justify LAA closure it is important to show that, when thrombus occurs in the LAA, it can embolise in the cerebral circulation. To demonstrate this, a thrombus embolising to the brain would have to be caught in the act. Parekh et al describe real-time imaging capture of LAA thrombus embolisation during TOE with subsequent stroke after a delay of 4 hours of the witnessed embolisation, possibly due to initial retention at a non-occlusive location with subsequent fragmentation and delayed more distal embolisation ${ }^{7}$. The fact that LAA closure prevents thromboembolic events as detailed above is also indirect proof for embolisation from LAA as a cause of embolic events.

\section{PATHOGENESIS OF THROMBOSIS}

The concept that AF confers a prothrombotic or hypercoagulable state was first proposed in $1996^{8}$. Thrombus formation in the LA as well as LAA was reported. As in any vascular compartment, it is probably the result of flow abnormalities or stasis, changes in the inner layer of the atrium and LAA and abnormalities in haemostasis (Virchow triad) ${ }^{9,10}$.

An atrial myopathy may underlie the pathophysiology of AF and its complications ${ }^{11}$. Indeed, atrial remodelling occurs during AF with left atrial and LAA dilatation ${ }^{12}$. Atrial size in patients with AF has been reported as a risk factor for stroke on univariate analysis ${ }^{13}$, although it was not an independent predictor on multivariate analysis. Left atrial enlargement may promote stasis, thus increasing the thrombotic risk. This finding correlates with high stroke rates seen in patients with $\mathrm{AF}$ and mitral stenosis ${ }^{14}$ compared to relatively lower than expected rates in those with $\mathrm{AF}$ and significant mitral regurgitation ${ }^{15}$. Spontaneous echocardiographic contrast (SEC or smoke) seen during echocardiographic imaging, a surrogate for stasis, is an independent predictor for strokes in $\mathrm{AF}^{16}$. Likewise, a reduction in LAA peak flow velocities indicative of stasis is an independent risk factor for stroke in patients with $\mathrm{AF}^{17,18}$. Flow velocities also appear to be lower in patients with sinus rhythm and LAA thrombus (e.g., with mitral stenosis) ${ }^{5}$. Also, mitral inflow parameters (E-wave velocity) and tissue Doppler velocities (e') as well as their ratio, when consistent with increased filling pressures (high E/e' ratio, low e' velocities), are associated with thrombus formation in patients with non-valvular $\mathrm{AF}^{19}$. High filling pressures are associated with stasis.

Stasis also probably contributes to thrombus formation elsewhere in the LA including in the left atrial septal pouch in case of a caudally fused foramen ovale, a structure that has been implicated as a source of cerebral embolism ${ }^{20-22}$.

Abnormalities of the endocardium and wall of the LAA potentially promoting thrombogenesis have been described (Table 1) (9,10. $^{\text {. }}$

In addition to atrial remodelling and stasis, there is mounting evidence for the presence of a prothrombotic state in AF, first described in the 1990s (Table 2) ${ }^{30}$.

It is not clear what promotes the prothrombotic state. A number of mechanisms have been implicated including inflammation, growth factors, nitric oxide, and the renin-angiotensin-aldosterone system $^{9,10}$. Some inflammatory mediators have been found to be elevated in patients with AF. Evidence supports both the role of inflammatory state in promoting $\mathrm{AF}$, as well as the role of $\mathrm{AF}$ in promoting inflammation (Table 3).

Another possible cause of a prothrombotic state could be growth factors such as vascular endothelial growth factor (VEGF) that stimulates the expression of tissue factor on the surface of the endothelial membrane. Indeed, an increased VEGF level has been reported in patients with $\mathrm{AF}$ and is associated with an increased level of tissue factor ${ }^{58}$.

In addition, nitric oxide produced by the nitric oxide synthase in the endothelium has antithrombotic properties ${ }^{59,60}$. Low endocardial shear stress (as is present during AF) may lead to a reduction in nitric oxide production ${ }^{61}$. In this context, lower expression of nitric oxide synthase has been shown in animals with $\mathrm{AF}^{62}$. The mechanisms underlying this may be multifactorial ${ }^{63}$.

Table 1. Endocardial changes in AF.

\begin{tabular}{|c|c|c|}
\hline Type of study & Main observations & Reference \\
\hline Autopsy/biopsy & $\begin{array}{l}\text { 1. Endocardial damage occurs in the LAA of MV disease patients. Changes are more } \\
\text { prominent in MS versus MR pathology }{ }^{23,24} \text {. } \\
\text { 2. In AF patients who died from cerebral embolism "LAA rough endocardium" was } \\
\text { seen macroscopically which contained oedematous and fibrous thickening } \\
\text { combined with fibrin deposits } \\
\text { 3. Significant LAA endocardial thickening with fibrous and elastic tissue } \\
\text { (endocardial fibroelastosis causing a reduction in pectinate muscle volume was } \\
\text { found in chronic AF patients) } \\
\text { 4. In lone AF patients, atrial biopsies revealed myocyte hypertrophy, necrosis and } \\
\text { mononuclear cell infiltration }\end{array}$ & 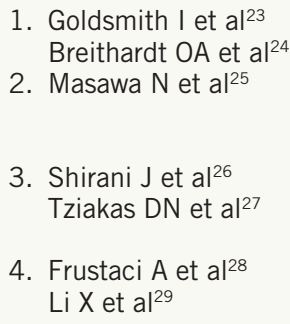 \\
\hline Clinical & $\begin{array}{l}\text { 1. Increased plasma fibrinogen, vWF and D-dimer levels were found in patients with } \\
\text { chronic AF suggesting increased intravascular thrombogenesis }{ }^{30} \text {. } \\
\text { 2. Patients with AF exhibit increased levels of metalloproteinases and corresponding } \\
\text { inhibitors as well as TGF- } \beta^{25,31} \text {. }\end{array}$ & $\begin{array}{l}\text { 1. Lip GY et al }{ }^{30} \\
\text { 2. Masawa } \mathrm{N} \text { et } \mathrm{al}^{25} \\
\text { Marin } \mathrm{F} \text { et } \mathrm{al}^{31}\end{array}$ \\
\hline MRI & $\begin{array}{l}\text { 1. Using gadolinium enhancement, MRI showed areas of LAA scarring in AF } \\
\text { patients. The presence of LAA scar was associated with thrombus formation }{ }^{32} \text {. }\end{array}$ & 1. Akoum $\mathrm{N}$ et al ${ }^{32}$ \\
\hline
\end{tabular}


Table 2. Evidence for prothrombotic state in AF.

\begin{tabular}{|c|c|c|}
\hline Type of study & Main observations & Reference \\
\hline Clinical & $\begin{array}{l}\text { 1. High levels of prothrombotic parameters were found in AF patients (including } \\
\text { fibrinogen }{ }^{33} \text {, prothrombin fragments I and II, D-dimer, thrombin-antithrombin } \\
\text { complexes }^{34} \text {, platelet micro-particles }{ }^{35}, \beta \text {-thromboglobulin, and von Willebrand } \\
\text { factor }^{36} \text { ). } \\
\text { 2. D-dimers' level was found to be an independent predictor of LAA thrombi }{ }^{37} \text { and } \\
\text { thromboembolic events }{ }^{38,39} \text {. } \\
\text { 3. Increased vWF levels were found to predict thrombus formation independently in } \\
\text { AF patients }{ }^{40} \text { and were associated with stroke and death }{ }^{41} \text {. } \\
\text { 4. Gene polymorphisms of the coagulation system (fibrinogen }{ }^{42,43} \text { ), (factor XIII } I^{44} \text { ) and } \\
\text { platelet function (integrin alpha } 2^{45} \text { ) have been implicated as potential risk } \\
\text { factors for an increased stroke risk in patients with AF. }\end{array}$ & 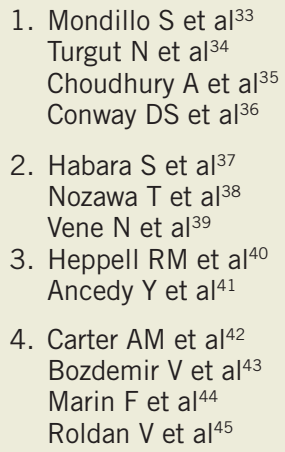 \\
\hline
\end{tabular}

Table 3. Evidence for inflammation in AF.

\begin{tabular}{|c|c|c|}
\hline Type of study & Main observations & Reference \\
\hline Clinical & $\begin{array}{l}\text { 1. Increased levels of inflammatory markers (CRP, sICAM I and fibrinogen) were } \\
\text { associated with a higher risk of developing AF } \\
\text { 2. AF itself may trigger inflammation. CRP and IL- } 6 \text { levels dropped following } \\
\text { successful AF ablation }{ }^{47} \text {. } \\
\text { 3. Inflammation promotes prothrombotic state in AF patients (IL- } 6 \text { and CRP have } \\
\text { been shown to increase acute phase proteins including fibrinogen, C-reactive } \\
\text { protein and serum amyloid) })^{48-53} \text {. } \\
\text { 4. Elevated TNF- } \alpha \text { levels were found in AF patients }{ }^{54} \text {. } \\
\text { 5. CRP levels correlate with the risk of SEC or LAA thrombus formation }{ }^{53} \text {. } \\
\text { 6. High level of cytokine was associated with a risk of ischaemic stroke in AF } \\
\text { patients }{ }^{54} \text {. } \\
\text { 7. Elevation of CD40 ligand (released by platelets) which promotes tissue factor } \\
\text { expression and increases thrombosis was found in patients with atrial } \\
\text { fibrillation }{ }^{55-57} \text {. }\end{array}$ & 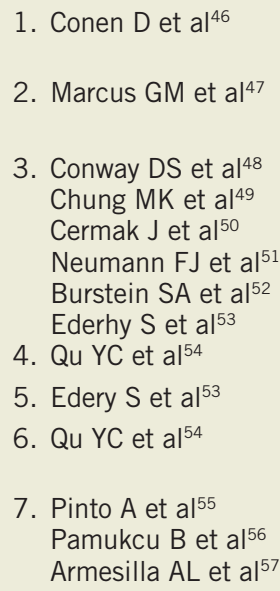 \\
\hline
\end{tabular}

CD40: cluster of differentiation 40; IL-6: interleukin 6; LAA: left atrial appendage; SEC: spontaneous echo contrast; sICAM I: soluble intercellular adhesion molecule-1; TNF- $\alpha$ : tumour necrosis factor alpha

Finally, increased expression of angiotensin-converting enzyme has been demonstrated in atrial tissue from patients with $\mathrm{AF}^{64}$. Angiotensin has a number of proinflammatory, profibrotic and potentially prothrombotic properties that could promote atrial remodelling as well as thrombus formation.

Many of the abovementioned mechanisms are not temporally related to episodes of $\mathrm{AF}$ and therefore $\mathrm{AF}$ and stroke may occur at different times.

In conclusion, though a causal relationship of AF and stroke is difficult to prove, AF is a very strong, independent, stroke risk factor. In patients with non-valvular AF, the overwhelming majority of thrombi are located in the LAA. Embolisation of thrombotic material from the LAA has been witnessed and is the likely underlying mechanism for many (but not all) strokes. Stasis, changes in the atrial geometry, and specific LAA morphologies (discussed in Chapter 3) including the inner surface, on a macroscopic and microscopic level, and an unfavourable haemostatic milieu potentially caused by inflammation, growth factors, diminution of nitric oxide or activation of the renin-angiotensin-aldosterone system are all likely to contribute to thrombus formation and thereby stroke risk (Figure 1).

\section{Chapter 2. Types of current LAA occlusion device}

Requirements for an ideal LAAO device are:

- Ease of use: adaptability of the device to the large variety of LAA anatomies

- Safety: low rate of procedural complications; low rate of device thrombus

- Efficacy: complete exclusion of the LAA from circulation; reduction of stroke rate

Current catheter-based devices for LAAO (Figure 2) are based on three different principles:

1. Plug: endovascular delivery of a device lobe or umbrella obstructing the neck of the LAA (WATCHMANTM [Boston Scientific, Marlborough, MA, USA], WaveCrest ${ }^{\circledR}$ [Biosense Webster, Diamond Bar, CA, USA]), thereby preventing blood flow into the body of the LAA. LAA exclusion relies on sealing/endocardialisation of the device lobe/umbrella ${ }^{65,66}$.

2. Pacifier principle: endovascular delivery of a device with a lobe or umbrella and an additional disc to seal the ostium of the LAA from the left atrial side. LAA exclusion relies on sealing/endocardialisation of the device lobe/umbrella 


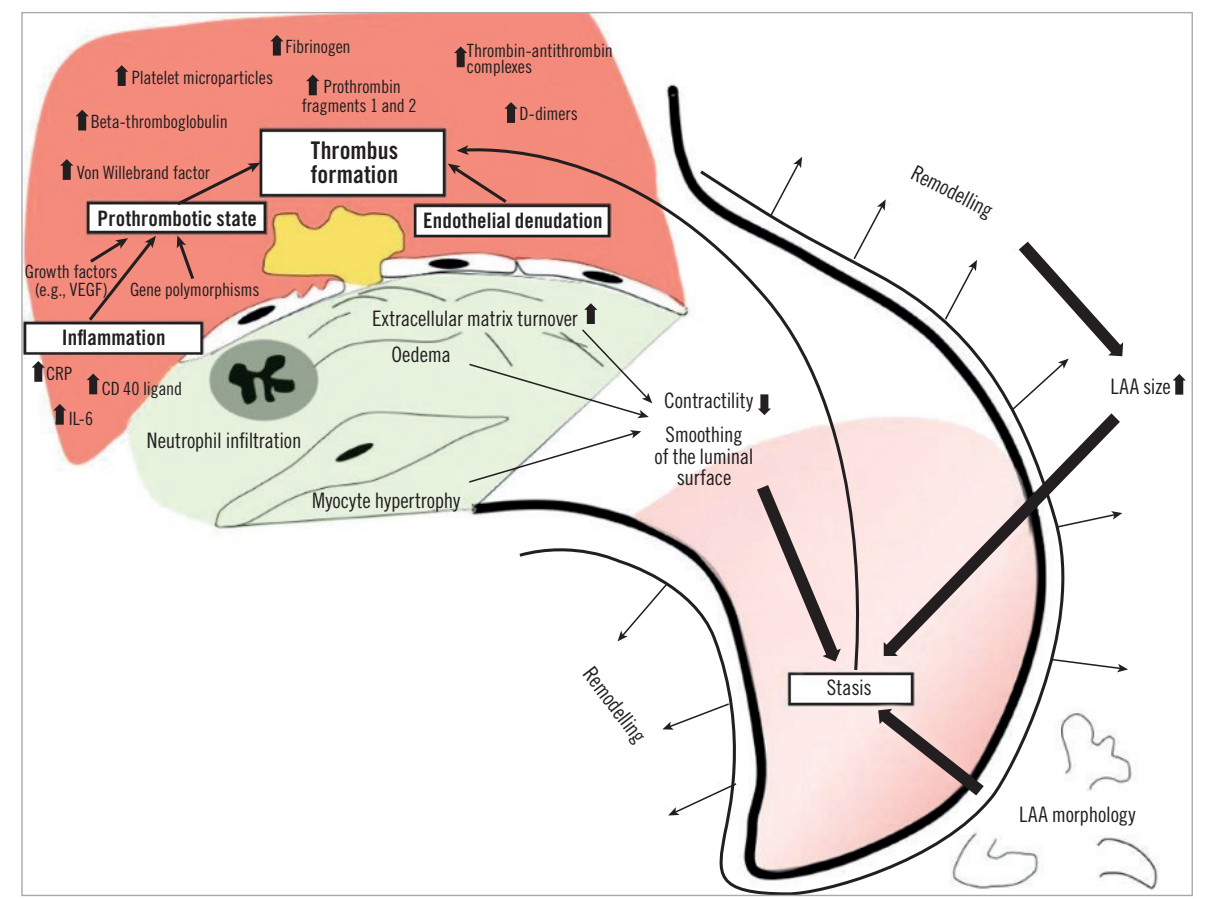

Figure 1. LAA thrombus formation pathophysiology. CD: Cluster of differentiation; CRP: C-reactive protein; IL: interleukin; LAA: left atrial appendage; VEGF: vascular endothelial growth factor

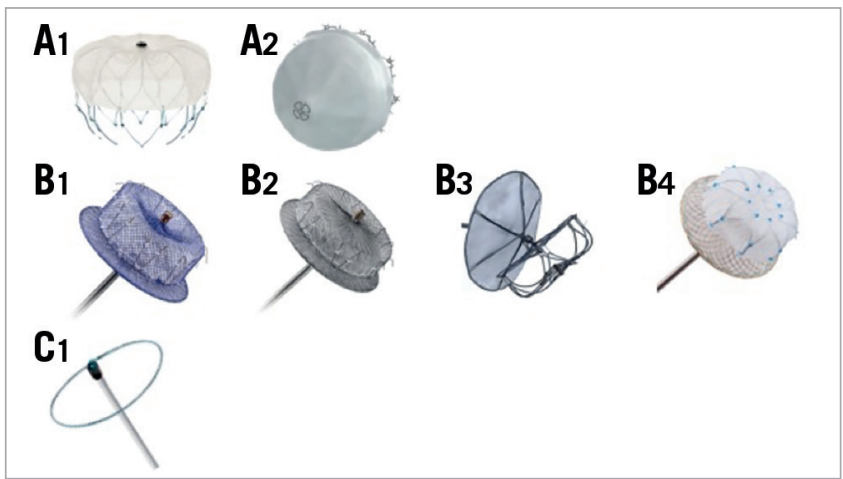

Figure 2. Commercially available, CE-mark approved devices. A1) WATCHMAN (Boston Scientific). A2) WaveCrest (Biosense Webster). B1) Amulet (Abbott Vascular). B2) AMPLATZER Cardiac Plug (Abbott Vascular). B3) Ultraseal LAA Occluder (Cardia). B4) LAmbre (Lifetech). C1) LARIAT (SentreHEART).

(AMPLATZER ${ }^{\mathrm{TM}}$ Cardiac Plug [ACP], Amulet ${ }^{\mathrm{TM}}$ [both Abbott Vascular, Santa Clara, CA, USA]) and/or the sealing disc (ACP, Amulet, Ultraseal [Cardia, Inc., Eagan, MN, USA], LAmbre ${ }^{\mathrm{TM}}$ [Lifetech, Shenzhen, China] $)^{67-69}$.

3. Ligation: LARIAT ${ }^{\circledR}$ (SentreHEART, Inc., Redwood City, CA, USA) to snare and ligate the body of the LAA using an endocardial and epicardial approach. LAA exclusion relies on complete ligation of the neck of the $\mathrm{LAA}^{70}$.

Table 4 lists commercially available CE mark-approved devices. Endovascular devices are nitinol based and deployed through a dedicated sheath either by retracting the sheath or by pushing the device out or a staged combination of the two. Anatomical contraindications are rare; implantation is technically feasible in $>95 \%$ of patients. These procedures are typically performed under general anaesthesia or deep sedation with TOE guidance. Operators with respective experience may use intracardiac echocardiography $(\mathrm{ICE})^{71}$ or fluoroscopy alone ${ }^{72}$, both allowing local anaesthesia and an awake patient.

Epicardial ligation devices do not leave any foreign material in contact with the blood stream. Preprocedural planning including computed tomography (CT) scanning is routine, as exclusion criteria regarding orientation, size, shape and width of the LAA lead to rejection of about $25 \%$ of patients for the procedure. Procedures are performed under general anaesthesia and with TOE guidance. There are no randomised data concerning anticoagulation regimen following the procedure. Antiplatelet therapy regimen may change based on patient history and comorbidities. Most operators typically prescribe dual antiplatelet therapy (DAPT) for a few weeks, followed by single antiplatelet therapy. In exceptional circumstances, some operators do not prescribe any antiplatelet therapy.

Device choice relies mostly on operator experience and preference, while some anatomies require selection of a specific device. Randomised controlled trials (RCT) comparing the WaveCrest with the WATCHMAN device (WAVECREST2 trial; NCT03302494) and the Amulet with the WATCHMAN device (Amulet IDE; NCT02879448) are recruiting.

Further devices are: (1) the LAmbre device which has obtained CE mark approval (nitinol-based "top-hat-shaped" device), and is commercially available in several countries. (2) The second-generation WATCHMAN device (WATCHMAN FLX) was introduced in 
Table 4. Commercially available CE mark-approved devices.

\begin{tabular}{|c|c|c|c|c|c|c|c|c|}
\hline Device & Delivery & Lobe & Sealing & Anchoring & Sizes & LAA sizes & Advantages & Caveats \\
\hline \multicolumn{9}{|l|}{ 1. Plugs } \\
\hline $\begin{array}{l}\text { WATCHMAN } \\
\text { (CE mark } \\
2005 \\
\text { FDA 2015) }\end{array}$ & $\begin{array}{l}14 \text { Fr delivery } \\
\text { system. } \\
\text { Single- or } \\
\text { double-curve } \\
\text { configuration. }\end{array}$ & $\begin{array}{l}\text { Jellyfish- } \\
\text { shaped } \\
\text { nitinol wire } \\
\text { frame. } \\
\text { Recapturable. }\end{array}$ & $\begin{array}{l}160 \mu \mathrm{m} \text { PET } \\
\text { fabric sealing } \\
\text { skirt at atrial } \\
\text { side of device } \\
\text { lobe. }\end{array}$ & $\begin{array}{l}10 \text { fixation } \\
\text { anchors distal } \\
\text { to sealing } \\
\text { skirt. }\end{array}$ & $\begin{array}{l}\text { Device } \\
\text { diameter: } \\
\text { 21-33 mm. }\end{array}$ & $\begin{array}{l}17-31 \mathrm{~mm} \text { at } \\
\text { proximal } \\
\text { landing zone. }\end{array}$ & $\begin{array}{l}\text { Reproducible } \\
\text { results; } \\
\text { supported by } \\
\text { solid scientific } \\
\text { data (2 RCTs). }\end{array}$ & $\begin{array}{l}\text { Requires deep } \\
\text { intubation of } \\
\text { LAA with } \\
\text { delivery sheath } \\
\text { for } \\
\text { deployment. }\end{array}$ \\
\hline $\begin{array}{l}\text { WaveCrest } \\
\text { (CE mark } \\
\text { 2013) }\end{array}$ & $\begin{array}{l}12 \text { Fr delivery } \\
\text { system. } \\
\text { Single curve } \\
(60,75,90) \\
\text { or double } \\
\text { curve }\end{array}$ & $\begin{array}{l}\text { Nitinol frame } \\
\text { can be folded } \\
\text { out after } \\
\text { device } \\
\text { placement. } \\
\text { Recapturable. }\end{array}$ & $\begin{array}{l}\text { Outer (towards } \\
\text { LA) ePTFE } \\
\text { sealing skirt. } \\
\text { Inner (towards } \\
\text { the LAA) } \\
\text { polyurethane } \\
\text { layer. }\end{array}$ & $\begin{array}{l}20 \text { anchors } \\
\text { distal to } \\
\text { sealing skirt. }\end{array}$ & 22-32 mm. & 14-32 mm. & $\begin{array}{l}\text { Anchor } \\
\text { deployment } \\
\text { independent } \\
\text { from position of } \\
\text { sealing cap. } \\
\text { Allows } \\
\text { injections distal } \\
\text { to the device. }\end{array}$ & \\
\hline
\end{tabular}

\section{Pacifiers}

\begin{tabular}{|c|c|c|c|c|c|c|c|c|}
\hline $\begin{array}{l}\text { ACP } \\
\text { (CE mark } \\
\text { 2008) }\end{array}$ & $\begin{array}{l}9 \mathrm{Fr}, 10 \mathrm{Fr} \text {, } \\
\text { and } 13 \mathrm{Fr} \\
\text { delivery } \\
\text { sheath. } \\
\text { Double curve } \\
\left(45^{\circ} \times 45^{\circ}\right)\end{array}$ & $\begin{array}{l}\text { Nitinol mesh } \\
\text { filled with } \\
\text { polyester } \\
\text { fabric. } \\
\text { Recapturable. }\end{array}$ & $\begin{array}{l}\text { Lobe inside } \\
\text { the LAA and } \\
\text { disc at the } \\
\text { ostium. }\end{array}$ & $\begin{array}{l}12 \text { anchors } \\
\text { on the lobe. }\end{array}$ & $\begin{array}{l}16-30 \mathrm{~mm} \\
\text { (lobe). }\end{array}$ & $12-28 \mathrm{~mm}$. & $\begin{array}{l}\text { Scientifically } \\
\text { documented in } \\
\text { large registries. } \\
\text { Documented } \\
\text { safety for } \\
\text { fluoroscopy-only } \\
\text { approach. }\end{array}$ & $\begin{array}{l}\text { First-genera- } \\
\text { tion device. } \\
\text { Less stability } \\
\text { than Amulet. }\end{array}$ \\
\hline $\begin{array}{l}\text { Amulet } \\
\text { (CE mark } \\
\text { 2013) }\end{array}$ & $\begin{array}{l}12 \mathrm{Fr} \text { and } \\
14 \mathrm{Fr} \text { delivery } \\
\text { sheath. } \\
\text { Double curve } \\
\left(45^{\circ} \times 45^{\circ}\right) \text {. }\end{array}$ & $\begin{array}{l}\text { Nitinol mesh } \\
\text { filled with } \\
\text { polyester } \\
\text { fabric. } \\
\text { Recapturable. }\end{array}$ & $\begin{array}{l}\text { Lobe inside } \\
\text { the LAA and } \\
\text { disc at the } \\
\text { ostium. }\end{array}$ & $\begin{array}{l}12-20 \\
\text { anchors on } \\
\text { the lobe. }\end{array}$ & $\begin{array}{l}16-34 \mathrm{~mm} \\
\text { (lobe). }\end{array}$ & $11-31 \mathrm{~mm}$ & $\begin{array}{l}\text { Scientifically } \\
\text { documented in } \\
\text { large registries. } \\
\text { Documented } \\
\text { safety for } \\
\text { fluoroscopy-only } \\
\text { approach. }\end{array}$ & \\
\hline $\begin{array}{l}\text { Ultraseal } \\
\text { (CE mark } \\
\text { 2016) }\end{array}$ & $\begin{array}{l}10 \mathrm{Fr} \text { and } \\
12 \mathrm{Fr} \text { delivery } \\
\text { sheath. } \\
\text { Single }\left(45^{\circ}\right) \\
\text { or double } \\
\text { curve } \\
\left(45^{\circ} \times 45^{\circ}\right) \text {. }\end{array}$ & $\begin{array}{l}\text { Uncovered, } \\
\text { bare nitinol } \\
\text { struts simply } \\
\text { for anchoring, } \\
\text { not for } \\
\text { sealing. } \\
\text { Recapturable. }\end{array}$ & $\begin{array}{l}\text { Polyvinyl } \\
\text { alcohol foam } \\
\text { and polyester } \\
\text { fabric covered } \\
\text { disc (sail) at } \\
\text { the ostium. }\end{array}$ & $\begin{array}{l}12 \text { anchors at } \\
\text { the lobe. }\end{array}$ & $\begin{array}{l}16-32 \mathrm{~mm} \\
\text { (lobe). }\end{array}$ & $12-26 \mathrm{~mm}$ & $\begin{array}{l}\text { Disc and lobe } \\
\text { are connected } \\
\text { by flexible joint, } \\
\text { allowing } \\
\text { self-orientation } \\
\text { of the disc at } \\
\text { the LAA ostium. }\end{array}$ & $\begin{array}{l}\text { Sealing } \\
\text { depends solely } \\
\text { on disc. }\end{array}$ \\
\hline $\begin{array}{l}\text { LAmbre } \\
\text { (CE mark } \\
\text { 2016) }\end{array}$ & $\begin{array}{l}8 \mathrm{Fr} \text { and } \\
10 \mathrm{Fr} \text { delivery } \\
\text { sheath. } \\
\text { Double curve } \\
\left(45^{\circ} \times 30^{\circ}\right) \text {. }\end{array}$ & $\begin{array}{l}\text { PET-covered } \\
\text { nitinol } \\
\text { umbrella. } \\
\text { Recapturable. }\end{array}$ & $\begin{array}{l}\text { PET-filled } \\
\text { nitinol disc at } \\
\text { the LAA } \\
\text { ostium and } \\
\text { PET-covered } \\
\text { umbrella } \\
\text { inside the } \\
\text { LAA. }\end{array}$ & $\begin{array}{l}8 \text { anchors at } \\
\text { outer side of } \\
\text { umbrella. } \\
8 \text { "soft } \\
\text { hooks" at tip } \\
\text { of umbrella. }\end{array}$ & $\begin{array}{l}16-36 \mathrm{~mm} \\
\text { (umbrella). }\end{array}$ & & $\begin{array}{l}17 \text { sizes. Disc } \\
\text { extending } \\
\text { umbrella from } \\
4-16 \mathrm{~mm} \text {. } \\
\text { Allows } \\
\text { implantation in } \\
\text { a variety of } \\
\text { anatomies. }\end{array}$ & $\begin{array}{l}\text { Sealing } \\
\text { depends } \\
\text { mostly on } \\
\text { disc. }\end{array}$ \\
\hline
\end{tabular}

\section{Ligation device}

\begin{tabular}{|c|c|c|c|c|c|c|c|}
\hline $\begin{array}{l}\text { LARIAT } \\
\text { (CE mark } \\
\text { 2015) }\end{array}$ & $\begin{array}{l}13.5 \mathrm{Fr} \\
\text { epicardial } \\
\text { delivery } \\
\text { sheath for } \\
\text { delivery of } \\
\text { magnet and } \\
\text { suture/snare. }\end{array}$ & $\begin{array}{l}8.5 \mathrm{Fr} \\
\text { transseptal } \\
\text { EndoCATH } \\
\text { (inflatable } \\
\text { balloon and } \\
\text { magnet). }\end{array}$ & $\begin{array}{l}\text { Epicardial polyester suture. } \\
\text { Endocardial placement of } \\
\text { magnet-tip wire in the LAA. } \\
\text { Introduction of an epicardial } \\
\text { magnet-tip wire. The magnets } \\
\text { form a rail for epicardial } \\
\text { advancement of a snare to } \\
\text { suture the base of the LAA. }\end{array}$ & $\begin{array}{l}40 \mathrm{~mm} \\
\text { suture loop } \\
\text { for snaring. }\end{array}$ & $\begin{array}{l}\text { LAAs up to: } \\
40 \mathrm{~mm} \\
\text { width, } \\
20 \mathrm{~mm} \\
\text { height. } \\
70 \mathrm{~mm} \\
\text { length. }\end{array}$ & $\begin{array}{l}\text { No foreign } \\
\text { material in } \\
\text { contact with } \\
\text { blood. } \\
\text { Potential } \\
\text { electrical } \\
\text { isolation of LAA. }\end{array}$ & $\begin{array}{l}\text { Induces } \\
\text { inflammation } \\
\text { (pericardial } \\
\text { effusion). } \\
\text { Several } \\
\text { anatomical } \\
\text { exclusion } \\
\text { criteria } \\
\text { (preprocedural } \\
\text { CCTA } \\
\text { mandatory) }\end{array}$ \\
\hline
\end{tabular}

ACP: AMPLATZER Cardiac Plug; CE: Communauté Européenne; CCTA: cardiac computed tomography angiography; Fr: French; LA: left atrium; LAA: left atrial appendage; PET: polyethylene terephthalate; ePTFE: expanded polytetrafluoroethylene; RCT: randomised controlled trial 
2015 and has received CE mark approval. The device was withdrawn and is now available again in a modified version. (3) The Sideris plug patch (bioabsorbable device with polyurethane cover [Custom Medical Devices, Bakersfield, CA, USA]) and the Prolipsis plug patch (a re-designed Sideris patch second-generation device [Occlutech, Helsingborg, Sweden]). There are other investigational devices being developed and tested such as the LeFort device (umbrella-shaped nitinol device [Lepu Medical Technology, Beijing, China]), the pfm device (Christmas tree-shaped pacifier device [pfm medical AG, Cologne, Germany]), the SeaLA Occluder (umbrellashaped nitinol plug device [Hangzhou Valued Medtech Co., Ltd, Hangzhou, China) and the Sierra Ligation System (epicardial ligation device [Aegis Medical Innovations Inc., Vancouver, BC, Canada]).

\section{Chapter 3. Non-fluoroscopic imaging for left atrial appendage closure IMAGING INTRODUCTION}

The LAA is a blind-ended pouch with a highly variable structure consisting of lobes and trabeculations from pectinate muscles. The LAA length ranges from $20-60 \mathrm{~mm}$ and the width from $16-59 \mathrm{~mm}^{73}$. The LAA orifice is most often oval-shaped ( $69 \%)$, but can be footshaped $(\sim 10 \%)$, triangle-shaped $(\sim 8 \%)$, waterdrop-shaped $(\sim 8 \%)$ or round $(\sim 6 \%)^{74}$. The LAA can have a varying number of lobes, most commonly two: these are defined as outpouchings from the main body with a lumen $\geq 2 \mathrm{~mm}$ in diameter ${ }^{73}$. There can also be an accessory LAA (consisting of pectinate muscles) and atrial diverticula (outpouching consisting only of a muscle layer) that occur in $10-27 \%$ of the general population ${ }^{75}$. There are several morphological LAA classifications. The most commonly adopted one consists of four shapes ${ }^{76}$ : chicken-wing ( $48 \%$; presence of a significant bend), windsock ( $\sim 19 \%$; single dominant lobe without a significant bend), cactus ( $\sim 30 \%$; dominant central lobe with multiple secondary lobes), and cauliflower ( $\sim 3 \%$; short LAA without a dominant lobe that branches into several lobes) (Figure 3). The shape of the LAA may affect stroke risk. In particular, the presence of extensive trabeculations is correlated to higher risk ${ }^{77}$. Furthermore, the LAA

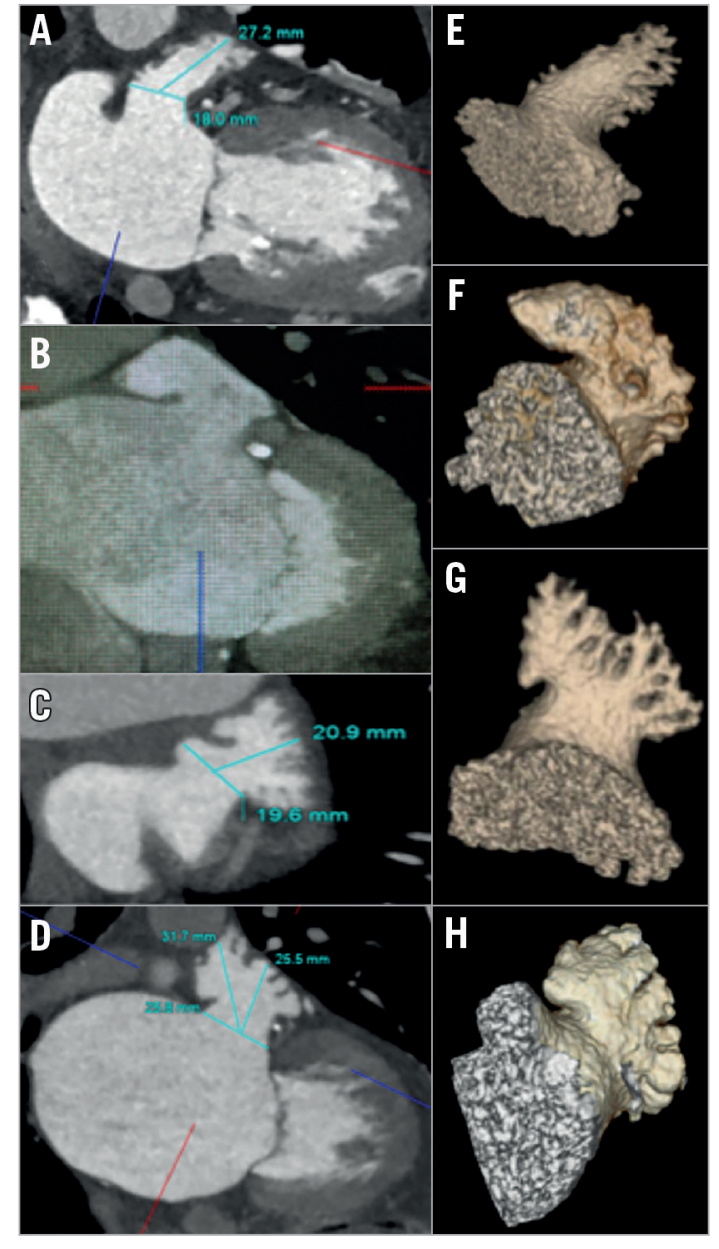

Figure 3. LAA shapes. A) - D) MPR CCTA images. E) - H) 3D volume-rendered images. Windsock ( $A \& E)$, retroflex chicken-wing $(B \& F)$, cactus $(C \& G)$, and cauliflower $(D \& H)$.

shape can increase the technical challenge for percutaneous LAA closure. Therefore, imaging is essential to pre-plan equipment selection and implantation strategy, to guide procedural device implantation, and also for device surveillance post implantation (Table 5).

Table 5. Roles of imaging in different LAA closure procedural stages.

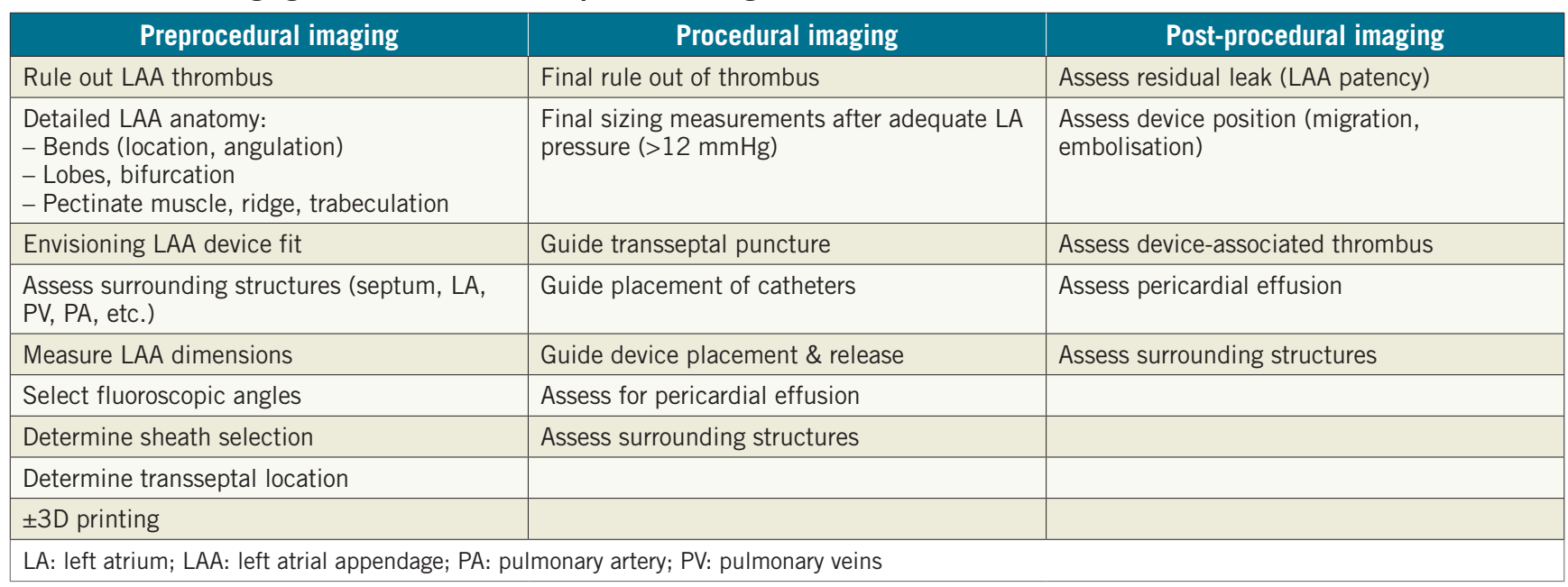




\section{PREPROCEDURAL IMAGING}

TOE and/or cardiac computed tomography angiography (CCTA) are both well suited for preprocedural imaging. Although TOE has been the traditional gold-standard preprocedural imaging for LAAO, there are several advantages with CCTA including superior spatial resolution, detailed three-dimensional (3D) characterisation of the LAA anatomy, accurate sizing, and non-invasive acquisition. The key elements for preprocedural interrogation are ruling out LAA thrombus, characterisation of LAA anatomy (Figure 3E-Figure 3H) and surrounding structures, and LAA measurements. In addition, imaging (especially with CCTA) can aid selection of sheaths, transseptal location, and optimal fluoroscopic angles during the procedure. The advantages of TOE (aside from not requiring X-ray or contrast medium) include being widely available and being the default procedural imaging guidance in most centres for LAA closure; thus, it can be performed in the catheterisation laboratory just before venous access, avoiding an additional preprocedural imaging session with the associated cost, sedation, radiation, and contrast administration. However, detecting anatomical exclusions on the table (e.g., thrombus, unsuitable anatomy) would mean case cancellation, after expending resources on general anaesthesia, nursing coverage, and laboratory time.

LAA thrombus: TOE is excellent for ruling out LAA thrombus, but CCTA has also made significant strides with protocol adaptations (e.g., delayed imaging, dual-enhanced scan, prone positioning, dualenergy source) that can achieve positive predictive values and specificities $>90 \%$, and negative predictive values and sensitivities close to $100 \%{ }^{78}$. If the baseline CCTA shows good contrast opacification of the LAA without thrombus, then TOE is not necessary. LAA shape: detailed characterisation of the LAA body and orifice shapes helps to facilitate device selection and sizing (Figure 3). The presence of angulation (chicken-wing bend), proximal bifurcation into lobes, location of trabeculations and pectinate muscles/ridges can influence the site of device implantation and the device type selection. Thus, "envisioning fit" of the chosen device can be predetermined, and the orifice measurements taken at that specific location on CCTA or TOE (Figure 4, Figure 5). With CCTA, the shape of the LAA should be visualised with oblique multiplanar reconstructions (MPR) (Figure 3A-Figure 3D) and 3D volume-rendered images (Figure 3E-Figure $3 \mathrm{H}$ ), which are used to determine device implant location. The MPR images also allow assessments of the proximity to adjacent structures such as the left upper pulmonary vein (LUPV) and mitral annulus, which can come into contact with the discs of pacifier devices. The angulations of the proximal (neck) and distal body of the LAA are easily determined from coronal and sagittal planes on CCTA (Figure 6), which can help with sheath selection and location of a transseptal puncture (TSP). With TOE, the probe is usually positioned at the mid oesophagus with slight retroflection $\left(50-70^{\circ}\right)$ and multiple imaging planes are obtained by changing the omniplane angulation. A full $0-135^{\circ}$ sweep should be

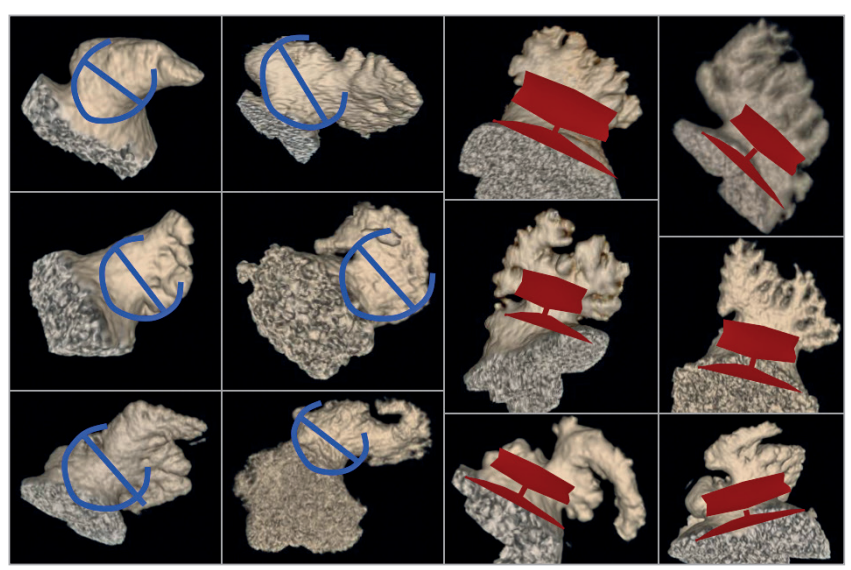

Figure 4. $3 D$ volume-rendered CCTA images showing examples of LAA shapes and envisioning of implant locations with WATCHMAN (blue schematic) and Amulet (red schematic) implants.

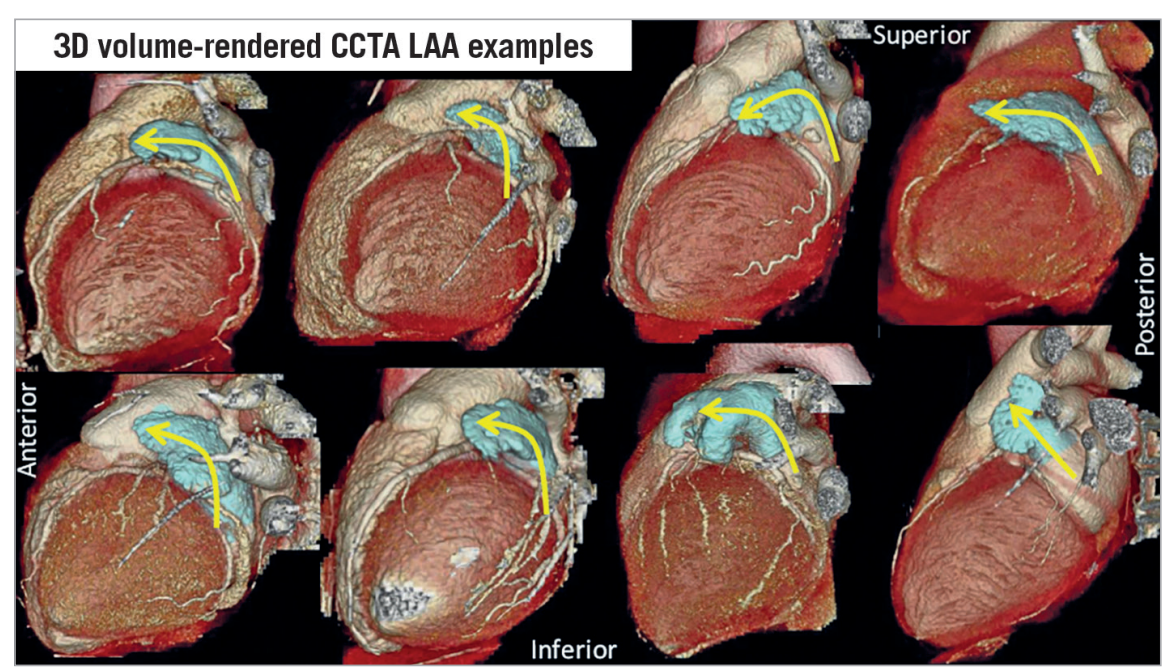

Figure 5. 3D volume-rendered CCTA examples showing the LAA in relation to the surrounding structures, and the angulations of the proximal and body of the LAA. 


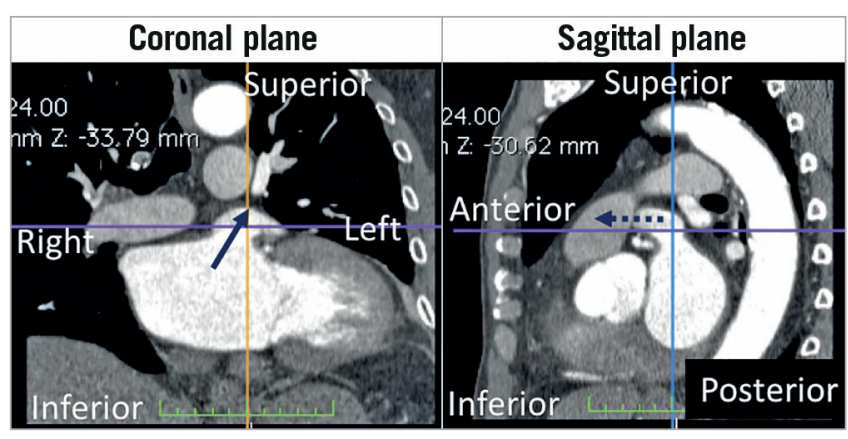

Figure 6. LAA CCTA in coronal and sagittal projections showing the proximal (neck) of the LAA directing superior, leftward and anterior (arrow), and the body of the LAA directing left and anterior in the mid level (dotted arrow).

performed to interrogate the LAA shape, with measurements taken in at least four views: $0,45,90$ and $135^{\circ}$.

LAA measurements: measurements of the LAA for device sizing can be different for devices, and manufacturer instructions for use should be adhered to. For example, with the WATCHMAN (Boston Scientific, Marlborough, MA, USA) device, the ostium of the LAA is measured from the circumflex coronary artery to a superior point $1-2 \mathrm{~cm}$ within the pulmonary vein ridge, and the deepest feasible LAA depth is then measured from that point (Figure 7AFigure 7D). For the Amulet (Abbott Vascular, Santa Clara, CA, USA) device, the most proximal aspect of the LAA (from the inferior edge of LAA origin to the LUPV ridge superiorly) and the landing zone (12 mm inside the most proximal point) should be measured (Figure 7E-Figure 7H). However, nuances in the LAA shape at the implant site (e.g., trabeculation, angulation, pectinate ridge) can affect where the device should be implanted, and thus this ostial measurement has to vary accordingly. Measurements on CCTA should be taken at the cardiac phase with the largest LAA dimension, which is usually at late atrial diastole corresponding to $30-40 \%$ of the RR interval ${ }^{79}$. An oblique view of the LAA ostium is first obtained on MPR, selecting a plane where the circumflex coronary artery, the pulmonary vein ridge, and the LAA are clearly depicted. An orthogonal cross-section of this plane is then obtained, adjusting the crosshairs to be coaxial with the wall. Finally, the orthogonal "en face" double-oblique view is obtained to allow measurements of the maximum and minimum dimensions of this ostium (Figure 7 for WATCHMAN and Amulet measurements). The depth of the LAA is also assessed on MPR, which may sometimes require maximal intensity projections to visualise the entire body of the LAA given the frequent angulations and lobulations. For TOE measurements, both the LAA orifice and depth should be measured in at least four angles $\left(0,45,90\right.$ and $\left.135^{\circ}\right)$, at the cardiac phase with largest dimension (end-systole) (Figure 8). 3D-TOE facilitates assessment of the shape of the LAA orifice, and measurement of the maximum and minimum diameters, as well as mean diameters, which is increasingly used for sizing purposes, especially for highly elliptical shapes (Figure 9).

Comparison of measurements: several small studies have compared LAA measurements from CCTA to TOE and fluoroscopy (Table 6) ${ }^{80-85}$. Overall, CCTA produced the largest LAA measurements and more accurately predicted device $\operatorname{sizes}^{85}$, due to the superior multiplanar 3D imaging with CCTA, allowing visualisation of maximal dimensions. CCTA maximal LAA diameter measurements were on average 1-3 mm larger than 2D-TOE, and 2-4 mm larger than fluoroscopy measurements ${ }^{82-85} .3 \mathrm{D}-\mathrm{TOE}$ measurements

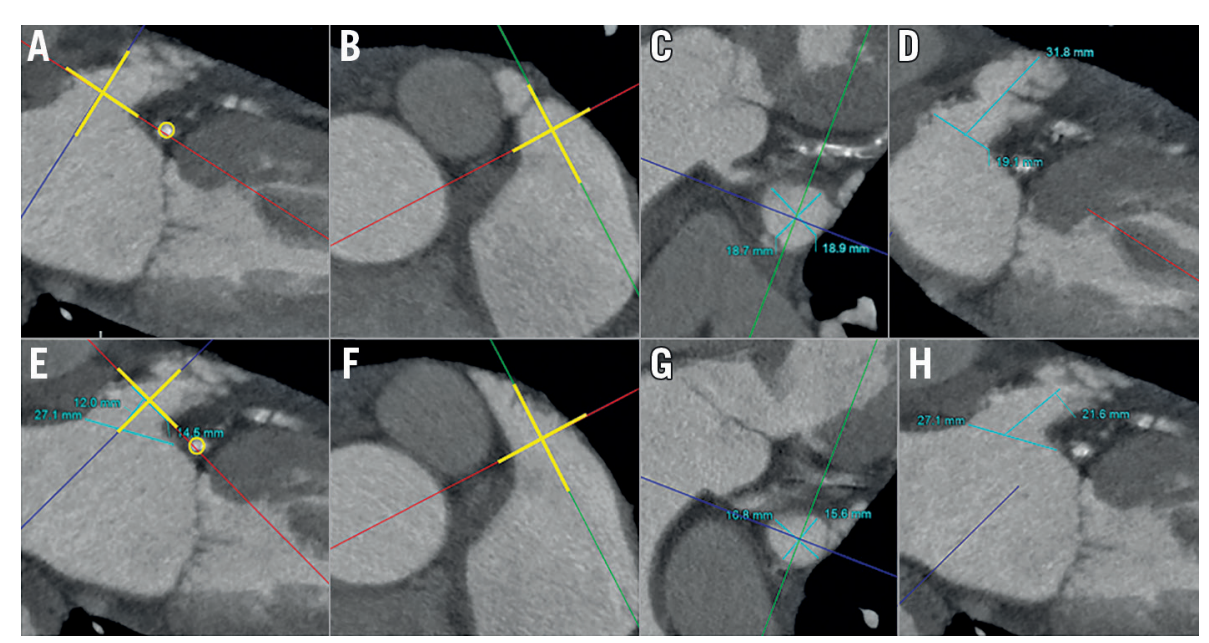

Figure 7. Measurements of the LAA ostium for the WATCHMAN device on MPR CCTA images (A-D) and measurements of the LAA landing zone for the Amulet device on MPR images (E-H). A) Oblique coronal plane to adjust the crosshairs (yellow lines) to be co-axial at the LAA ostium (circumflex coronary artery circled in yellow). B) Crosshairs further adjusted in an orthogonal plane to be co-axial (yellow lines) at the LAA ostium. C) Double-oblique $3^{\text {rd }}$ orthogonal plane with en face view of the LAA orifice for measurements of the long and short axis of the LAA. D) Measurement of the maximum depth of the LAA. E) Oblique coronal plane to adjust crosshairs (yellow lines) to be co-axial at the landing zone $12 \mathrm{~mm}$ within the LAA orifice. F) Crosshairs in orthogonal plane adjusted co-axial (yellow lines) at the landing zone. G) Double-oblique $3^{\text {rd }}$ orthogonal plane with en face view of the LAA landing zone for measurements. H) Measurement of the depth of the LAA for the Amulet device. 


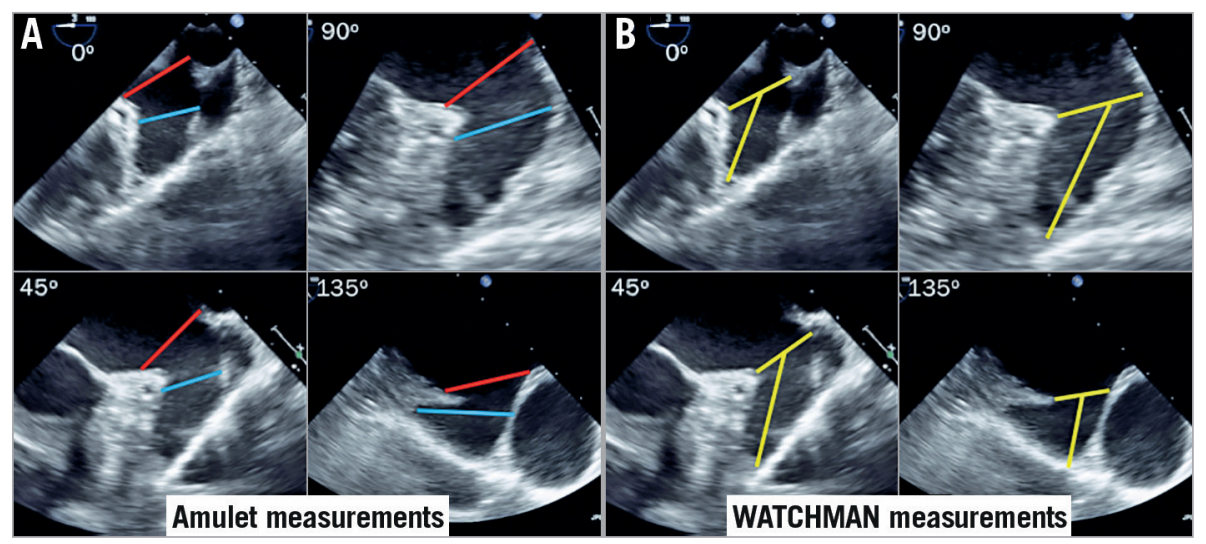

Figure 8. TOE measurements for the Amulet and WATCHMAN devices. A) TOE measurements at four angles for the Amulet device at the echocardiographic orifice (red lines) and at the landing zone $12 \mathrm{~mm}$ inside the orifice (blue lines). B) TOE measurements at four angles for the WATCHMAN device for the orifice diameter and depth.

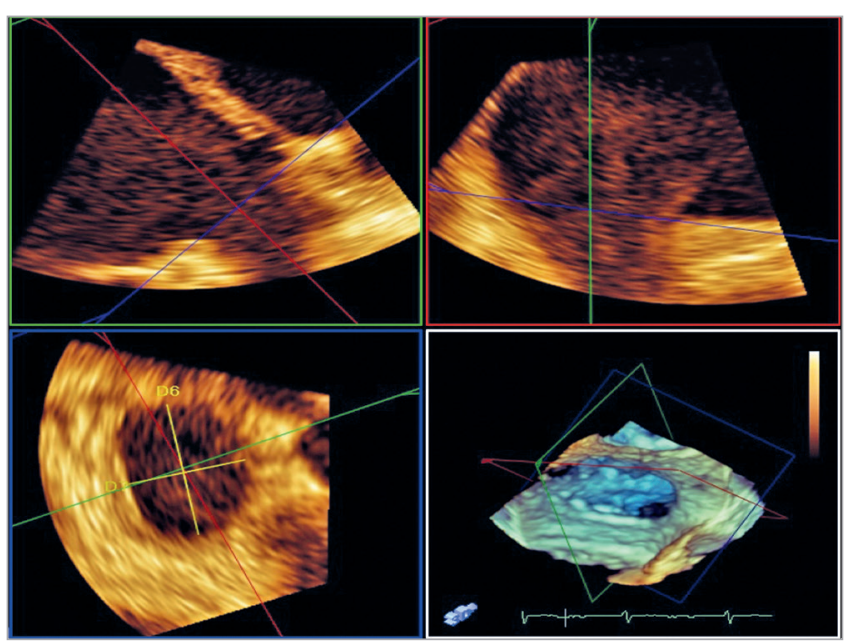

Figure 9. 3D-TOE assessments of the ostium of the LAA.

provided larger measurements than 2D-TOE, but remained smaller by $\sim 2 \mathrm{~mm}$ compared to CCTA assessments ${ }^{83,86}$. Of note, volume loading is critical to ensure proper measurements since the LAA is thin-walled and distensible. A saline bolus of 500-1,000 $\mathrm{ml}$ can increase the LAA orifice dimensions and depths by $\sim 2 \mathrm{~mm}^{87}$, and increase the perimeter and area by $4 \%$ and $8 \%$, respectively ${ }^{86}$. Therefore, the imaging modality used and volume status of the patients should be considered when sizing LAA devices. Equipment and procedural preplanning: CCTA 3D volume-rendered images are helpful to select fluoroscopic angles that best visualise the implant angle for the selected device. The right anterior oblique view with cranial projection typically shows the orifice and proximal segment of the LAA well, which is useful when implanting the Amulet. For the WATCHMAN, angles that visualise the body and distal lobe of the LAA are ideal (usually a right anterior oblique view with caudal projection), which helps to guide access sheath placement in the appropriate lobe. The direction of the mid to distal segment of the LAA body should be assessed to guide sheath selection for the WATCHMAN. As shown in Figure 3, the neck (proximal) portion of the LAA is invariably angled superiorly and anteriorly. However, the mid to distal body of the LAA angulation is highly variable, and can be grouped into three general directions: (A) superior-anterior directed (most common), (B) mid-to-inferior anteriorly directed (less frequent), or (C) retroflex (superior, rightward, posteriorly directed tip) (infrequent). The best-suited WATCHMAN sheaths are double-curve for (A), single-curve for (B) and anterior-curve for (C). The location of the TSP can also be selected based on the angulations of

Table 6. Comparison of measurements with CCTA versus TOE.

\begin{tabular}{|c|c|c|c|}
\hline Author, year & \#Cases & CT machine & CT measurements \\
\hline Budge $2008^{80}$ & $53 \mathrm{AF}$ ablation & 16-slice & Segmented CCTA $2.5 \mathrm{~mm}$ larger than 2D-TOE \\
\hline Lopez-Minguez $2014^{81}$ & 37 ACP & 64-slice, non-synchronised & Superior-inferior axis CCTA $0.95 \mathrm{~mm}$ larger than 2D-TOE \\
\hline Saw $2016^{82}$ & 50 LAA closure & $\begin{array}{l}\text { 320-detector or dual source } \\
\text { 128-slice }\end{array}$ & MPR CCTA $1.8 \mathrm{~mm}$ larger than 2D-TOE, $4.2 \mathrm{~mm}$ larger than fluoro \\
\hline Wang $2016^{83}$ & 53 WM & 128-slice + 3D printing & 3D-CCTA $2.7 \mathrm{~mm}$ larger than 2D-TOE, $2.3 \mathrm{~mm}$ larger than 3D-TOE \\
\hline Rajwani $2017^{84}$ & 73 LAA closure & Dual source 128 -slice & MPR CCTA $3 \mathrm{~mm}$ larger than 2D-TOE \\
\hline Goitein $2017^{85}$ & 36 LAA closure & 256-slice & $\begin{array}{l}\text { 3D-CCTA diameter } 5 \mathrm{~mm} \text { larger and perimeter } 13 \mathrm{~mm} \text { larger than } \\
\text { 2D-TOE }\end{array}$ \\
\hline
\end{tabular}

2D: two-dimensional; 3D: three-dimensional; ACP: AMPLATZER Cardiac Plug; AF: atrial fibrillation; CCTA: cardiac computed tomography angiography; LAA: left atrial appendage; MPR: multiplanar reconstruction; TOE: transoesophageal echocardiography; WM: WATCHMAN 
the LAA. For most LAA, where the body is superior-anterior directed, a standard inferoposterior puncture of the fossa ovalis is recommended to provide a direct vector towards the superioranterior LAA. For mid-inferiorly directed appendages, a mid-level and posterior puncture will facilitate advancing a single-curve sheath to the distal tip of the inferiorly directed lobe (Figure 10). 3D printing: there is increasing interest in 3D model printouts of the LAA from CCTA or TOE images ${ }^{87}$. A small randomised study showed that CCTA with 3D prints can improve the efficiency of device and guide catheter utilisation, and procedural time ${ }^{88}$. Although these prints are not necessary for all LAA implants, they may be useful for novice operators and/or challenging anatomies. Larger models, where the interatrial septum, the entire LA and LAA are included, can help with preplanning TSP site and sheath selection.

\section{PROCEDURAL IMAGING}

Fluoroscopy and TOE are the preferred modalities for procedural imaging for LAA closure. Intracardiac echocardiography (ICE) is gaining popularity and has become standard in some centres, given the convenience of minimal sedation. Some perform LAA closure with fluoroscopy guidance alone, but this practice has been limited to a few experienced centres and cannot be recommended for wide use by others. In extreme cases that can have neither TOE nor CT prior to or during the procedure, these centres have been using distant contrast injection to the LAA during the procedure to exclude LAA thrombus. This practice is also limited to a few expert centres and cannot be recommended for wide use by others.

Procedural imaging should confirm the lack of LAA thrombus and confirm sizing measurements with the appropriate volume loading conditions (mean LA pressure $>12 \mathrm{mmHg}$ ).

For TSP, TOE/ICE provides live visualisation of the transseptal needle and sheath position in relation to the fossa ovalis. With TOE, the supero-inferior (bicaval) and the antero-posterior (short-axis) views are essential to guide inferior-posterior punctures. With ICE, the probe is positioned in the right atrium, rotated clockwise and retroflex tilted to visualise the fossa in a craniocaudal angulation. Visualisation of the posterior fossa ovalis is achieved by clockwise rotation.

During the remainder of the procedure, TOE/ICE helps to guide sheath placement and device implantation according to manufacturer recommendations for optimal implant criteria. It is essential to interrogate the device in at least four angles $\left(0,45,90\right.$ and $\left.135^{\circ}\right)$ with TOE prior to release, ensuring appropriate compression, minimal peri-device leak $(<3 \mathrm{~mm})$, and stable tug/tension tests. With ICE, the best imaging is achieved with the probe in the LA, either through a double-TSP or through a single-TSP (both access sheath and ICE probe through the same TSP). The ICE probe can be retroflexed, rotated clockwise/counter-clockwise and tilted left/ right while facing the LAA to visualise the device and peri-device leak with colour Doppler. The probe can also be advanced into the LUPV to view the LAA in a long-axis view. Small non-randomised series have shown ICE-guided LAA closure to be feasible with good procedural outcomes ${ }^{89}$.

\section{POST-PROCEDURAL IMAGING}

A transthoracic echocardiogram should be performed prior to discharge to ensure that the device has remained in position in the LAA and to exclude pericardial effusion. It is challenging to visualise both the WATCHMAN and AMPLATZER devices on transthoracic echocardiography; the AMPLATZER device may be seen as a hallmark figure of 8 (Figure 11). After discharge, device surveillance is recommended 6 to 12 weeks post LAA closure with either TOE or CCTA, primarily to assess for device-related thrombus (DRT) and peri-device leak. The incidence of DRT has been reported at $2-4 \%$ for most endovascular devices (Table 7$)^{90-98}$ and

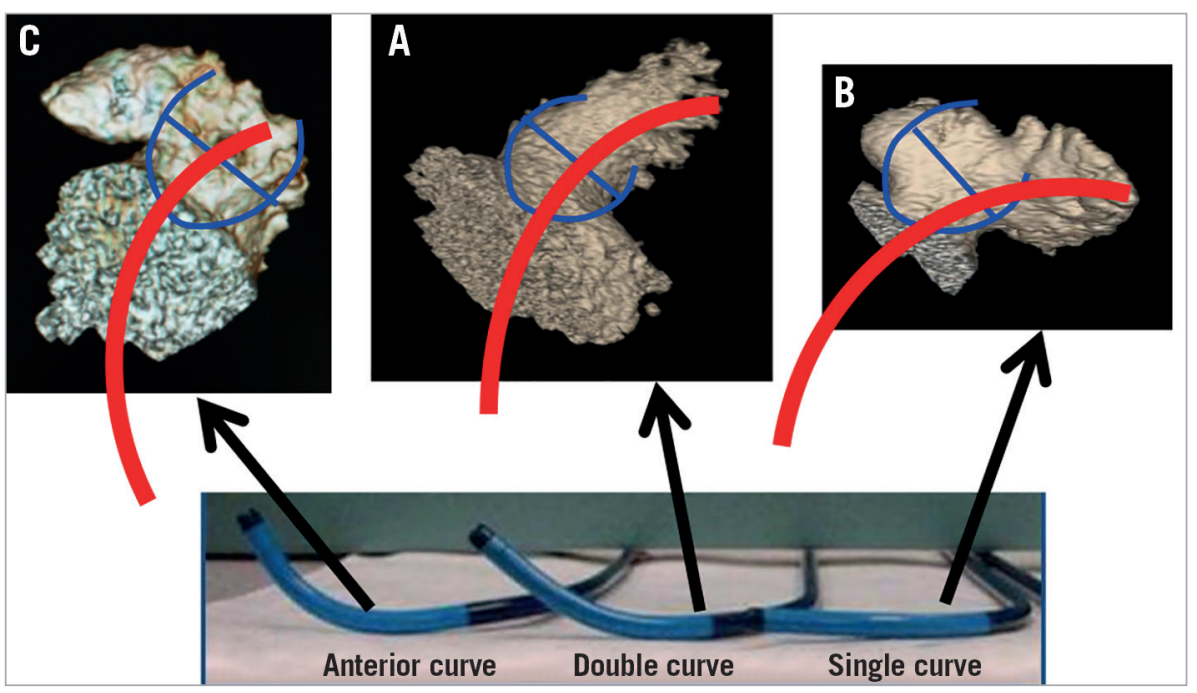

Figure 10. Selection of the WATCHMAN sheaths according to the angulations of the LAA. A) Double-curve sheath for the superior-anterior directed LAA. B) Single-curve sheath for the LAA directed mid level to inferior. C) Anterior-curve sheath for a retroflex chicken-wing LAA (directed superiorly and rightwards). 


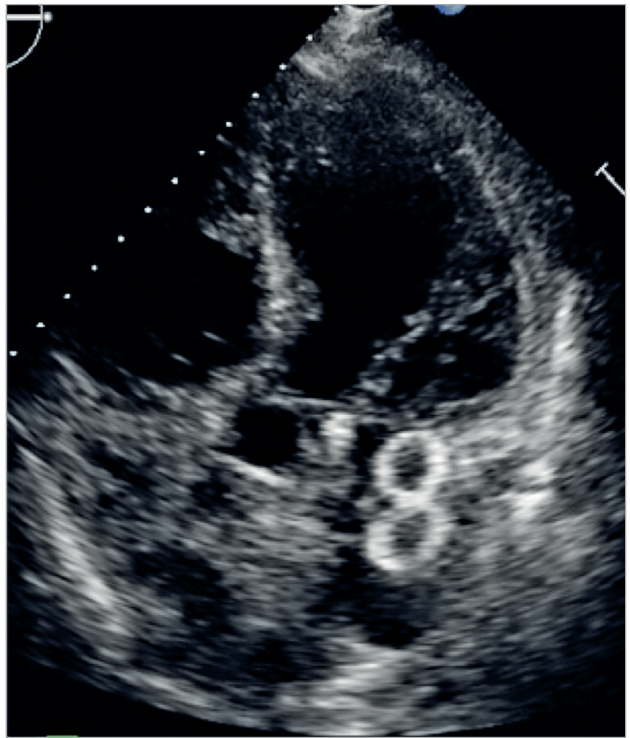

Figure 11. Transthoracic echocardiogram image of an implanted Amulet device, which appears as a "figure of 8 ".

can be detected on TOE and CCTA ${ }^{99}$. The occurrence of DRT was demonstrated to be an independent predictor of stroke/TIA (HR 4.4, 95\% CI: 1.05 to 18.43 ), and thus should be managed accordingly with anticoagulation therapy ${ }^{100}$. There are patient-related (e.g., poor left ventricular ejection fraction [LVEF], poor compliance with antithrombotic therapy, smoking, spontaneous echo contrast, history of thromboembolism) and implant-related (e.g., deep implantation, incomplete LAA occlusion) factors that can increase the risk of DRT ${ }^{92,93,101}$. The appearance of DRT can be quite varied, and it can sometimes be challenging to differentiate normal endocardialisation on the atrial surface of the device versus actual thrombus formation on the device. Although there is no uniform definition or classification of DRT for LAA closure devices, it has been suggested that protruding thrombi (especially those that are mobile) are more susceptible to embolisation. These types of DRT require reinforced anticoagulation to resolve the thrombus ${ }^{102}$. Very late
( $>12$ months post implantation) DRT have also been reported, and therefore repeat imaging at 12 months or later may be considered, especially if patients present with thromboembolism ${ }^{101}$.

The mechanism of residual leak can also be assessed on CCTA, differentiating from leaking through the fabric (incomplete endocardialisation) or peri-device leak (which can be due to ostial LAA gaps, or incomplete seal from an off-axis device ${ }^{99}$. With the WATCHMAN, any peri-device leak on TOE was observed in $\sim 32 \%$ of cases in the PROTECT study at 1 year ${ }^{103}$; however, in a contemporary real-world registry (EWOLUTION), the incidence of severe leak $>5 \mathrm{~mm}$ occurred in only $1 \%$ of cases ${ }^{96}$. For the ACP device, any leak occurred in $12.5 \%$ of cases, but severe leak $>5 \mathrm{~mm}$ was only observed in $0.6 \%$ in the ACP multicentre registry $^{21}$. For the Amulet device, $>3 \mathrm{~mm}$ peri-device leak was observed in $1.8 \%$, but there was no leak $>5 \mathrm{~mm}$ in the Amulet post-marketing registry ${ }^{97}$. The presence of any peri-device leak was not shown to correlate to clinical events ${ }^{22,103}$. The threshold of $5 \mathrm{~mm}$ leak was derived from the PROTECT study for continuation of oral anticoagulation; however, this has not been validated with outcomes or other devices. Even though there have been anecdotal case reports of treating large peri-device leaks with long-term oral anticoagulation or additional LAA/AMPLATZER occluders, the clinical benefit of these approaches remains to be proven.

\section{RECOMMENDATIONS FOR LAA CLOSURE IMAGING:}

Table 8 summarises the recommendations for LAA closure imaging according to expert consensus. Preprocedural imaging should be performed with either CCTA or TOE to rule out pre-existing LAA thrombus and anatomic suitability for LAA closure (software for semi-automatic analysis of pre-LAAO CT is available). Procedural imaging should be performed with either TOE or ICE guidance, and in exceptional circumstances may be performed with fluoroscopy alone by experts if pre-imaging was done with CCTA or TOE. LAA closure should not be performed with fluoroscopy alone without pre-screening with CCTA, TOE, or ICE, or a distant contrast medium injection should be performed upon arrival in the left atrium to rule out LAA thrombus. Post-procedural imaging to

Table 7. Incidence of device-related thrombus (DRT) and strokes.

\begin{tabular}{|c|c|c|c|c|c|}
\hline Study & $\mathbf{N}$ & Device & DRT & TOE time & Associated stroke \\
\hline PROTECT $^{90}$ & 478 & WATCHMAN & $4.2 \%$ & - & $3 / 20(15 \%)$ \\
\hline ASAP $^{91}$ & 150 & WATCHMAN & $4.0 \%$ & mean 164 days & $1 / 6(16.7 \%)$ \\
\hline ACP Multicentre ${ }^{92}$ & 339 & $\mathrm{ACP}$ & $3.2 \%$ & mean 7 months & $0 \%$ \\
\hline Lempereur et al ${ }^{93}$ & 2,118 & WATCHMAN, ACP, Amulet & $3.9 \%$ & - & $\begin{array}{c}\text { TIA } 2.4 \% \\
\text { Stroke } 4.9 \%\end{array}$ \\
\hline Lakkireddy et al ${ }^{94}$ & 712 & LARIAT & $2.5 \%$ & - & - \\
\hline Pillarisetti et al ${ }^{95}$ & $\begin{array}{l}259 \\
219\end{array}$ & $\begin{array}{c}\text { LARIAT } \\
\text { WATCHMAN }\end{array}$ & $\begin{array}{l}1.6 \% \\
3.7 \%\end{array}$ & - & - \\
\hline EWOLUTION ${ }^{96}$ & 1,025 & WATCHMAN & $3.7 \%$ & & $0 / 28(0 \%)$ \\
\hline Amulet $\mathrm{PMR}^{97}$ & 1,088 & Amulet & $1.5 \%$ & Mean 67 days & $1 / 10(10 \%)$ \\
\hline PROTECT, PREVAIL, CAP, CAP2 ${ }^{98}$ & 1,739 & WATCHMAN & $3.7 \%$ & 45 days and 12 months & $17 / 65(26.2 \%)$ \\
\hline
\end{tabular}


Table 8. Scientific rationale of recommendations for LAA closure imaging.

\begin{tabular}{|l|l|l|}
\multicolumn{1}{|c|}{ Recommendations } & $\begin{array}{c}\text { Consensus } \\
\text { statement } \\
\text { instruction }\end{array}$ & Symbol \\
\hline $\begin{array}{l}\text { Preprocedural imaging should be } \\
\text { performed with either CCTA or TOE to } \\
\text { rule out pre-existing LAA thrombus } \\
\text { and anatomic suitability for LAA } \\
\text { closure }\end{array}$ & "Should do this" & \\
\hline $\begin{array}{l}\text { Procedural imaging should be } \\
\text { performed with either TOE or ICE } \\
\text { guidance }\end{array}$ & "Should do this" & \\
\hline $\begin{array}{l}\text { Post-procedural imaging should be } \\
\text { performed at 6-24 weeks post } \\
\text { implantation to assess for DRT }\end{array}$ & "Should do this" \\
\hline $\begin{array}{l}\text { Post-procedural imaging may be } \\
\text { repeated after } 12 \text { months post } \\
\text { implantation to assess for DRT }\end{array}$ & "May do this" & \\
\hline $\begin{array}{l}\text { Presence of DRT on the atrial side of } \\
\text { the device should be treated with } \\
\text { intensified anticoagulation to resolve } \\
\text { thrombus }\end{array}$ & "Should do this" \\
\hline $\begin{array}{l}\text { CCTA: cardiac computed tomography angiography; DRT: device-related } \\
\text { thrombus; ICE: intracardiac echocardiography; TOE: transoesophageal } \\
\text { echocardiography }\end{array}$ & \\
\hline
\end{tabular}

assess for DRT should be performed at 6-12 weeks post implantation and may be repeated after 12 months. Presence of DRT on the atrial side of the device should be treated with intensified anticoagulation to resolve thrombus.

\section{Chapter 4. Implantation technique, step-by-step, tips and tricks FEMORAL VEIN ACCESS AND TSP}

Intravenous or oral antibiotic prophylaxis is administered once prior to and also after the procedure, with the choice of antibiotic depending on the institutional preference and allergy history of the patient (usually cephalosporin or vancomycin or clindamycin [for patients allergic to penicillin or cephalosporin]). Femoral venous access is obtained. Generally, given the more favourable orientation of the transseptal sheath and, later, the delivery system with respect to the interatrial septum, right is preferred over left femoral venous access. It is important to bear in mind that, in trials and registries, vascular access complications (e.g., requiring transfusion or further intervention/surgery) have been relatively common and therefore meticulous care during access is strongly recommended. Consideration should be given to fluoroscopic guidance (e.g., by applying a vascular clamp to mark the lower third of the femoral head) or direct ultrasound-guided access. The latter minimises the risk of inadvertent arterial puncture. A micropuncture needle can be used for access, potentially minimising the bleeding risk after an inadvertent arterial puncture. A skin incision of $\sim 7 \mathrm{~mm}$ and, optionally, subcutaneous track formation (e.g., with a Kelly clamp) facilitate transseptal and, later, access sheath entry into the femoral vein. Though it has not been demonstrated to improve outcomes or reduce vascular access complications, consideration can also be given to pre-close (e.g., with a Perclose ProGlide $^{\circledR}$ Suture-Mediated Closure System [Abbott Vascular, Santa Clara, CA, USA]) the vascular access site with a suture that allows suture tightening and immediate haemostasis after sheath removal at the termination of the case. If the Perclose ProGlide device is used for pre-closure, after wire removal and before foot plate deployment, gently pushing on the skin overlying the vein to generate blood return helps to confirm adequate intravenous positioning. The operator should consider carefully inserting a $16 \mathrm{Fr}$ sheath to reduce subcutaneous tissue friction and thereby improve access sheath torque transmission, particularly in obese patients with long distances from the skin surface to the venous entry site. TSP can be performed with traditional transseptal systems such as an SL-1 sheath and Brockenbrough (BRK)-1 needle; however, other systems may work equally well. In cases where a hypermobile or thickened, leathery septum makes puncture difficult, use of energy (either by a dedicated radiofrequency [RF] catheter [e.g., Baylis Medical, Burlington, MA, USA] or by touching the proximal end [arrow] of the BRK needle with an activated Bovie knife or RF catheter [15-20 Watt, duration: 1 second]) can facilitate puncture. Alternatively, the stylet provided with the needle or the back end of a 0.014-inch or 0.018-inch wire can be advanced through the BRK needle to enhance puncture success or a dedicated wire (e.g., SafeSept ${ }^{\mathbb{R}}$; Pressure Products Medical Supplies, San Pedro, CA, USA) can be used. A manifold or power injector with a pressure transducer should be connected to the transseptal needle or RF needle to allow continuous pressure monitoring and confirm left atrial position after puncture (the V-wave is typically more prominent than the a-wave in the left atrial pressure tracing whereas the opposite is true for the right atrial pressure tracing). As the transseptal system is pulled down from the superior vena cava into the right atrium, there is frequently a sudden jump and another when the system engages the fossa ovalis. To confirm engagement of the fossa, and when connected to a manifold, small amounts of contrast can be injected to visualise tenting on fluoroscopy (paint and poke technique). Tenting should also be confirmed by echocardiographic imaging (regardless of whether TOE or ICE is used) (Supplementary Figure 1, Movie 1). Guidance by TOE (or ICE) is very helpful to visualise the puncture location. The puncture location may vary depending on the anatomy and orientation of the left atrial appendage (LAA) but is most frequently at a posterior and inferior location (Supplementary Figure 2) as most LAAs are oriented anterolaterally (Supplementary Figure 3, Movie 2, Movie 4) and superiorly (Supplementary Figure 4, Movie 3, Movie 4). The key is to achieve coaxial alignment with the access sheath and delivery system and the proximal segment of the LAA (Supplementary Figure 5, Movie 4). To achieve a posterior location, the arrow on the base of the BRK needle near the groin typically points to a 5-6 pm position, assuming that noon is pointed towards the ceiling and $6 \mathrm{pm}$ towards the floor (Supplementary Figure 6). More posterior locations are reached by more clockwise rotation (Supplementary Figure 6) of the BRK needle and sometimes also 
by slightly withdrawing the transseptal system (Supplementary Figure 7, Movie 5). Slight withdrawal of the transseptal system will also direct the tip to a more inferior location. In some cases of a very anteriorly oriented LAA, the puncture may have to be at the most posterior part of the fossa ovalis (Supplementary Figure 8, Supplementary Figure 9), whereas in more unusual LAAs that have a lateral orientation or posterior orientation (e.g., reverse chicken-wing configuration) the puncture site may be better in the mid fossa to anterior (Supplementary Figure 10, Supplementary

Figure 11), rather than posterior. When the orientation of the LAA is favourable (e.g., lateral or posterior orientation) and a patent foramen ovale (PFO) or an atrial septal defect (ASD) is present, it is reasonable to access the left atrium and appendage through the (more anteriorly located) PFO or the ASD. However, this may create an access issue due to malalignment in the case of a tight PFO with a long tunnel and necessitate a separate puncture. During transseptal sheath manoeuvring, real-time TOE, in the bicaval view, helps to assure an inferior puncture location (Supplementary Figure 12), and, in the transoesophageal shortaxis view, clarifies a posterior location (Supplementary Figure 13). $\mathrm{X}$-plane imaging allows visualisation of both the bicaval (in fact showing the superior vena cava and the coronary sinus) and transoesophageal short-axis views simultaneously. In addition, 3D-TOE imaging can confirm both inferior and posterior puncture locations (Supplementary Figure 1, Movie 1). Once an interatrial septal puncture has occurred, the sheath and dilator are carefully advanced over the needle into the left atrium and the needle is removed, taking care to cover the proximal hub of the introducer with the thumb after removal and hold the proximal hub between the patient's legs or lateral to the leg as low as possible to prevent air entry (particularly in those with a low left atrial pressure). During removal of the introducer, consideration should be given to continuous slow aspiration through the dilator (via a Luer lock syringe) to avoid air entrapment into the transseptal sheath during this process. After dilator removal, the sheath is aspirated and flushed with heparinised saline and connected to the pressure transducer to assess the mean left atrial pressure. Occasionally, resistance is encountered during the attempt of crossing with the transseptal sheath (usually at the transition between the dilator and the sheath). This can usually be overcome by applying mild forward tension and slight rotation in either direction. If, despite these manoeuvres, the transseptal sheath does not cross, options are to use one of the stiffest available wires (Backup wire or E-wire [Boston Scientific, Marlborough, MA, USA] or Lunderquist $^{\mathbb{B}}$ wire [Cook Medical, Bloomington, IN, USA]) or balloon dilatation of the TSP site with a $4 \mathrm{~mm}$ balloon (Movie 6, Movie 7). As the balloon deflates, the transseptal sheath usually tracks over the balloon into the left atrium without difficulty (Movie 7). In such a case of resistant interatrial septum, it is crucial to introduce a J-tipped guidewire deeply into the pulmonary vein (usually left superior) or an Inoue shaped (large pigtail tip) wire in the left atrium or ventricle prior to any further, more aggressive attempt to overcome the septum. This may help to avoid inadvertent injury to the posterior wall of the atrium, caused by a dilator tip during sudden "jump in" through the septum deeply into the atrial cavity, facilitated by an excessive tension/ rotation applied. It has been demonstrated that the LAA ostium diameter can increase considerably after fluid administration in patients with low baseline pressure ${ }^{104}$. Hence, fluid challenge (e.g., $250 \mathrm{ml}$ to $1,000 \mathrm{ml}$, depending on left ventricular systolic function and/or prior history of congestive heart failure) in those with left atrial pressures $<11-12 \mathrm{mmHg}$ should be considered to allow measurement of the maximal ostial diameter and thereby optimise device sizing (i.e., avoid device embolisation or peridevice leaks due to undersizing). It is important to remember to administer heparin (e.g., 100 units $/ \mathrm{kg}$ ) before or upon transseptal crossing for a target activated clotting time (ACT) of $>250 \mathrm{~s}$ (some operators favour $>300 \mathrm{~s}$ ). The timing of heparin administration varies according to the operator. Some administer the full dose prior to TSP, others wait until puncture has occurred or administer half the dose prior to puncture (e.g., after transfemoral venous access) and the other half after TSP. Regardless of strategy, it is of great importance to achieve a therapeutic ACT level as soon as possible after transseptal crossing because of the low flow state in the left atrium and thrombogenicity of the equipment (sheath, wires, and device).

\section{WATCHMAN DEVICE}

Once the transseptal sheath is across the interatrial septum, a J-tipped 0.035-inch wire with a stiff body but soft tip (e.g., Amplatz Extra-Stiff $3 \mathrm{~cm}$ soft-tipped J-wire [Cook Medical, Bloomington, IN, USA], a Backup wire or an E-wire, or a Lunderquist wire) can be advanced into the left upper pulmonary vein or the left atrium or ventricle to allow exchange of the transseptal sheath for the WATCHMAN access sheath (WAS). To facilitate positioning of the wire in the left upper pulmonary vein, the transseptal sheath can be turned slightly clockwise for a more posterior orientation. In some cases, selective cannulation of the left upper pulmonary vein can prove difficult. Consideration may then be given to simply advancing a wire with a pigtail curve (e.g., the Safari ${ }^{T M}$ extra-small wire [Boston Scientific, Marlborough, MA, USA], ProTrack ${ }^{\mathrm{TM}}$ wire [Baylis Medical, Burlington, MA, USA] or TORAYGUIDETM guidewire [Toray, Tokyo, Japan) into the left atrium that can be used as an atraumatic rail to exchange the transseptal sheath for the WAS. Once the WAS tip has crossed the interatrial septum by $2-3 \mathrm{~cm}$, the dilator is pulled into the sheath and, subsequently, the wire removed. Then the dilator is slowly removed while aspirating via a Luer lock syringe to avoid air entrapment. The WAS is aspirated and flushed with heparinised saline and an angled 5 Fr or 6 Fr pigtail catheter (preferably with marker bands) is advanced via the access sheath into the left atrium and oriented to the (usually superiorly and anteriorly oriented) LAA. A common mistake when trying to position the pigtail catheter into the left atrium is that the tip of the access sheath is too far into the left atrium, thereby limiting the manoeuvrability of the pigtail catheter. If this is the case, the WAS can be retracted 
until the tip remains $2-3 \mathrm{~cm}$ in the left atrium (confirmation by TOE or ICE). The best fluoroscopic angulation to engage the LAA and position the pigtail tip as well as, eventually, the WAS is the right anterior oblique (RAO) caudal, but this can be modified depending on the best implant angle that may have been determined by computed tomography (CT) imaging. It is important to position the pigtail catheter tip into the deepest (usually anterior and also the largest) lobe to gain adequate depth for the WAS. Cineangiography in two orthogonal views (RAO caudal [e.g., 30/20] and RAO cranial [e.g., 30/20]) is performed (Figure 12, Figure 13, Movie 8, Movie 9). Some operators choose to perform cineangiography in the RAO/CAU view only. The best views determined by $\mathrm{CT}$ or magnetic resonance imaging (MRI) may deviate from the aforementioned generic RAO/CAU and RAO/ CRA views. In this context, please recognise that large appendages can frequently not be adequately filled by hand injection and the availability of a power injector can be very helpful (typical setting would be $9 \mathrm{ml} / \mathrm{s}$ for a total of $9 \mathrm{ml}$ ). The 30/20 RAO/CAU and 30/20 RAO/CRA views usually correspond to the mid-oesophageal $135^{\circ}$ and $45^{\circ}$ views on TOE imaging, respectively. The RAO/CRA view typically delineates the ostium and neck of the

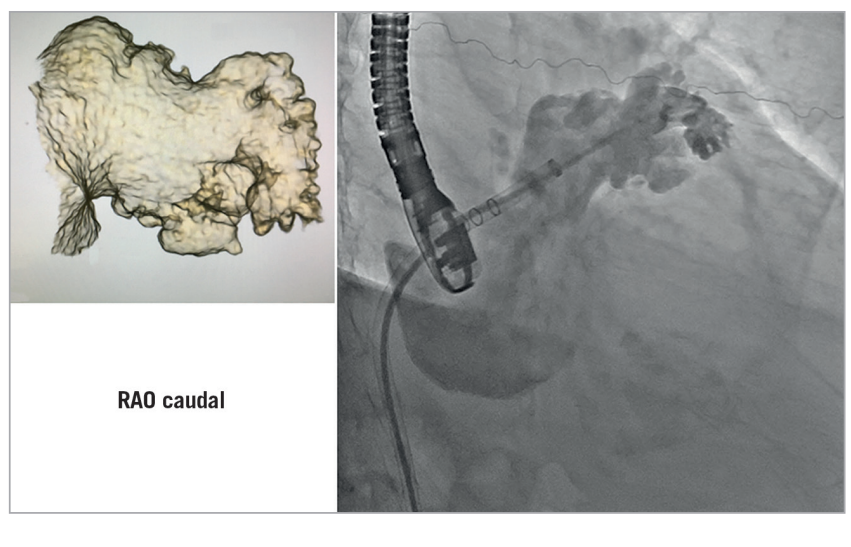

Figure 12. Illustration of how a $3 D$ reconstruction of the $L A A$ can help with preparation of how the LAA will lay out fluoroscopically. LAA: left atrial appendage; RAO: right anterior oblique

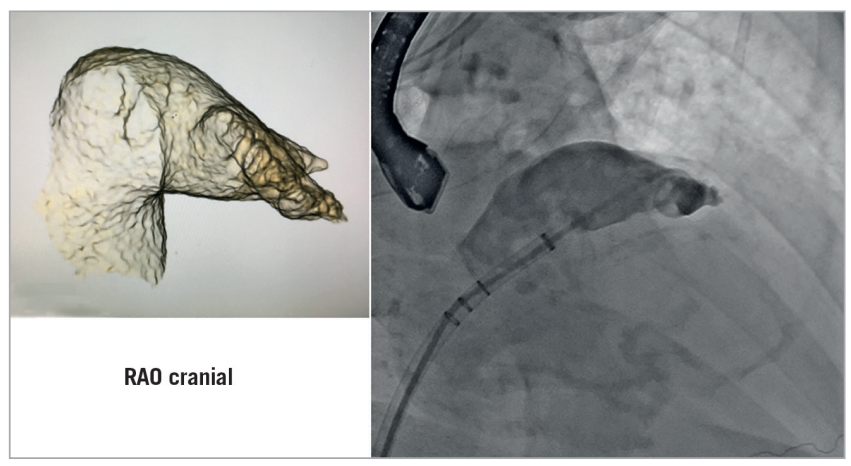

Figure 13. Illustration of how a $3 D$ reconstruction of the $L A A$ can help with preparation of how the LAA will lay out fluoroscopically. LAA: left atrial appendage; RAO: right anterior oblique
LAA better, whereas the RAO/CAU view demonstrates the mid to distal segment of the LAA and its side pouches better. After cineangiography, the maximum (regardless of the phase of the cardiac cycle and measured in the frame that provides the largest diameter) ostial diameter and depth are measured and compared to echocardiographic and/or CT imaging. Sizes rarely differ by more than $2 \mathrm{~mm}$ provided similar views are compared. It is important to rely on the largest size measured regardless of the imaging modality, provided measurements are made at the appropriate location and imaging quality is good. Sizing is performed according to the recommended sizing chart (Supplementary Figure 14), keeping in mind that the minimum recommended compression is $8 \%$. If the LAA depth is adequate and deployment of a larger device is not compromised by prominent pectinate muscles, oversizing by $\sim 20-25 \%$ may reduce the likelihood of peri-device leaks. The WAS (outer diameter $14 \mathrm{Fr}[4.7 \mathrm{~mm}$ ], inner diameter $12 \mathrm{Fr}$ [4.0 mm], length: $75 \mathrm{~cm}$ ) (Supplementary Figure 15, Movie 10) is then advanced over the pigtail catheter into the LAA with the tip as far distal as can safely be achieved, keeping in mind that the distal marker band is $5 \mathrm{~mm}$ proximal to the WAS tip (i.e., the distalmost marker band should not be any closer to the appendage wall than $5 \mathrm{~mm}$ ) (Figure 14, Movie 11). Cineangiography can be performed and, if the WAS is too deep, it can be retracted such that the marker band corresponding to the anticipated device size aligns with the LAA ostium. It is important to keep in mind that the WAS has four marker bands (Figure 14, Figure 15). The previously mentioned distal band, located $5 \mathrm{~mm}$ from the WAS tip, is important in guiding sheath engagement depth and helping to prevent dangerously deep engagement, and three more proximal markers correspond to the most proximal aspect of the loaded device and should align with the LAA ostium prior to device delivery (Figure 16). These three marker bands correspond with the $21 \mathrm{~mm}, 27 \mathrm{~mm}$ and $33 \mathrm{~mm}$ devices; for the $24 \mathrm{~mm}$ and $30 \mathrm{~mm}$ devices an imaginary line is located between the $21 \mathrm{~mm}$ and $27 \mathrm{~mm}$ and $27 \mathrm{~mm}$ and $33 \mathrm{~mm}$ marker bands, respectively (Figure 14). Sometimes, to gain depth and obtain more coaxial sheath alignment, counter-clockwise tension on the WAS is needed (particularly in more anteriorly oriented LAAs). Once a device size has been chosen, it is advisable to leave the pigtail catheter in the LAA until the device is prepared and ready for insertion because the pigtail catheter prevents inadvertent further advancement of the WAS into the LAA. When the device is ready for insertion, it is handed to the operator who should confirm that the device feet are at the distal marker band of the delivery catheter, but not beyond (Figure 15). The pigtail catheter is then removed with care taken that the WAS does not protrude any further into the LAA during this manoeuvre. The delivery catheter (with the device inside) is then inserted through the valve into the WAS (Movie 12). There are two important aspects for safe performance of this manoeuvre. First, the WAS valve has to be opened (by counter-clockwise turning) and should be held as low as possible to allow adequate back bleeding and prevent air entrapment and, second, during insertion of the delivery catheter into the valve, 


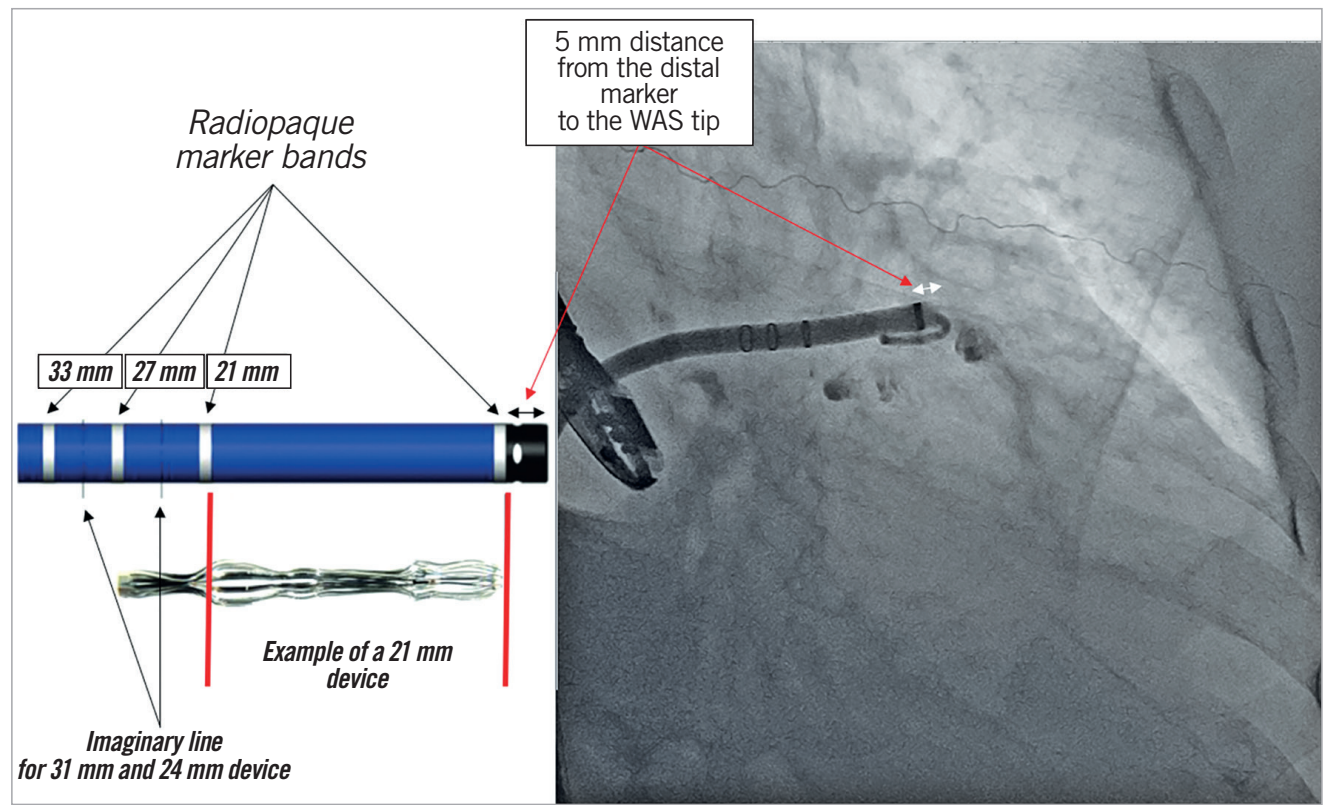

Figure 14. Illustration of the WATCHMAN access sheath with its markers and demonstration of the sheath fluoroscopically. WAS: WATCHMAN access sheath

forward flow of heparinised saline should occur through the delivery catheter to create a fluid-to-fluid connection during insertion (Movie 12). When inserting the delivery catheter (and device), the WAS may lose some of its necessary anterior orientation. In this case, it can help to have an assistant maintain the counter-clock-

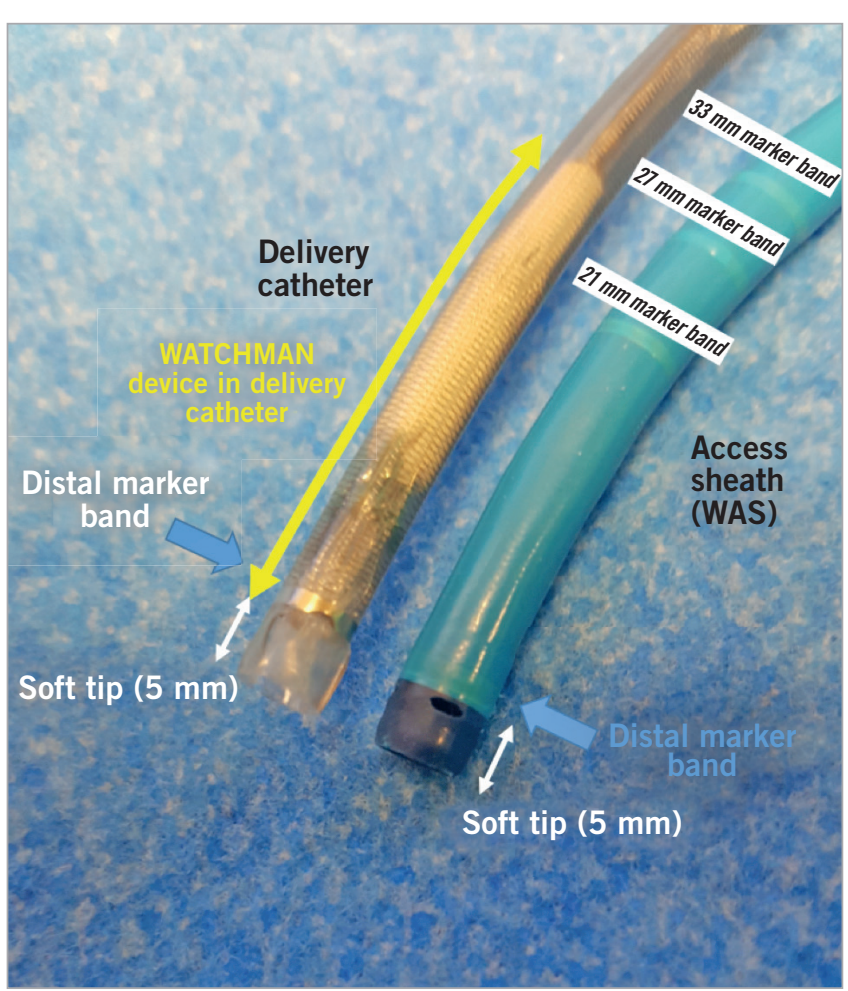

Figure 15. Illustration of the WATCHMAN access sheath and delivery catheter. WAS: WATCHMAN access sheath wise torque of the sheath while advancing the delivery catheter. The delivery catheter is then advanced such that the distal marker band of this catheter aligns with the distal marker band of the WAS (Movie 12). At this point, while maintaining the position of the delivery catheter and device, the WAS is pulled back until a "click" is felt (Movie 12, Movie 13). This locks the WAS and delivery catheter together such that both are now one unit. Keep in mind that the WAS marker bands are now more proximal and are

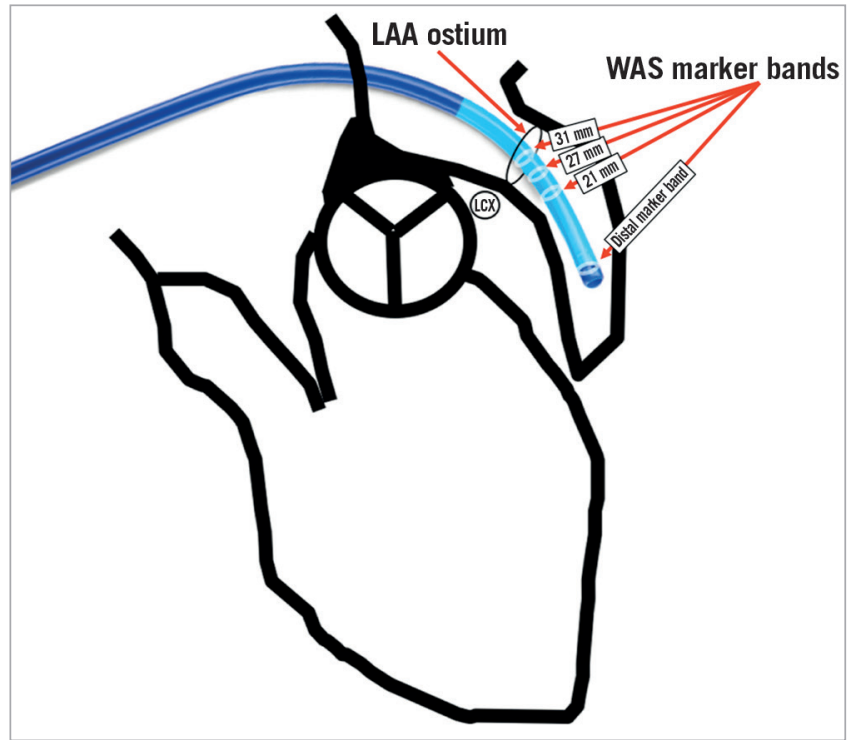

Figure 16. Demonstration of the WATCHMAN access sheath including radiopaque marker bands in relation to the LAA. LAA: left atrial appendage; LCX: left circumflex coronary artery; WAS: WATCHMAN access sheath 
no longer a reliable guide during deployment. The device is now ready for deployment. Deployment is usually performed in the $\mathrm{RAO} / \mathrm{CAU}$ view that best delineates the more distal LAA segment and depth and thereby helps to avoid inadvertent advancement of the delivery system or device. While maintaining device position by fixing the proximal end (cable), the WAS and delivery catheter are now very slowly pulled back allowing the feet to unfold (Movie 14). At this point, it is important to ask the patient to take slow shallow breaths (if the procedure is performed under local anaesthesia) or to ask the anaesthesiologist to hold ventilations if the patient is under general anaesthesia. This minimises diaphragmatic and LAA movement during deployment. Further, it is helpful to have an assistant draw the distalmost aspect of the LAA on the screen with a marker pen to help guide the operator to avoid any inadvertent advancement of the device and delivery system. The deployment is optimally carried out slowly while avoiding any pushing or repositioning relative to the LAA ostium. Once the feet have exited and the device begins to flower, it is important to maintain very subtle forward tension for the remainder of the deployment to prevent device migration towards the left atrium. Once the device has fully unfolded, the echocardiographer will check four components of deployment (PASS criteria: $\mathrm{P}=$ position, $\mathrm{A}=$ anchor, $\mathrm{S}=$ size, $\mathrm{S}=$ seal). Regarding anchoring, a tug test is performed during which, while maintaining WAS/delivery catheter position (with the catheter tip $\sim 2-4 \mathrm{~cm}$ from the device hub), the delivery cable is tugged backwards and attention is directed to movement of the device and LAA in unison (i.e., without independent device movement) (Movie 15). Regarding the position, more than half of the device length should be distal to the LAA ostium. To facilitate LAA visualisation during this manoeuvre, contrast can be injected. Next, correct device sizing should be confirmed. In all conventional TOE views $\left(0,45,90\right.$ and $\left.135^{\circ}\right)$ and/or with fluoroscopy, the largest diameter of the shoulder is measured. This should be at least $8 \%$ smaller than the original device size (i.e., there should be at least $8 \%$ compression). Finally, it should be confirmed in all the aforementioned echocardiographic views that there is no relevant peri-device leak. Contrast cineangiography can be obtained but is not mandatory if all echocardiographic criteria are met. The device is then released by turning the delivery cable counter-clockwise 3-5 turns while avoiding any forward tension (Movie 16). As the device is released, it is important to retract the tip of the delivery cable into the delivery catheter/access sheath to prevent any left atrial injury. The delivery system is then removed and femoral venous access haemostasis is obtained either by manual pressure, tightening of previously deployed sutures, or by a figure of 8 stitch.

It should be mentioned that some operators, after advancing the pigtail via the transseptal sheath into the LAA, exchange the pigtail for a soft, J-tipped stiff wire (e.g., Amplatz Extra-Stiff wire, $3 \mathrm{~cm}$ soft-tipped) and over this wire exchange the transseptal sheath for the WAS. If this technique is pursued, avoid any movement and undue forward tension while exchanging the transseptal sheath for the WAS to minimise the risk of LAA injury.
Further, though most currently use TOE for procedural guidance, some operators use only ICE during the procedure, avoiding the discomfort of the TOE probe. Multiplanar imaging with the currently available ICE probes is not possible but adequate imaging quality can be obtained by operators experienced with ICE. To compensate for the lack of multiplane imaging, the ICE probe, in addition to the right atrium, can be positioned into the coronary sinus, left main pulmonary artery and directly into the left atrium or left upper pulmonary vein to allow positioning closer to the LAA. If ICE is chosen as the imaging modality, and left atrial imaging is pursued, after TSP, while leaving a wire in the left atrium or left upper pulmonary vein, the transseptal sheath can be withdrawn back into the right atrium and the ICE catheter can be advanced (with the wire as a guide) via the orifice created by the TSP into the left atrium. The transseptal sheath and dilator can then be re-advanced over the wire into the left atrium.

\section{DEVICE RECAPTURE}

If, after deployment, it is noted that the device position is inadequate, the device can be partially or fully recaptured. Partial recapture is performed if the device position is too distal in the LAA. In this case, the WAS/delivery catheter is gently re-advanced up to the device and, while backward tension is applied to the delivery knob, the WAS/delivery catheter is slowly advanced over the device to, but not beyond, the fixation barbs (resistance can usually be felt when approaching the fixation barbs). At this point, the system can be retracted slightly to the desired location and a second deployment can be attempted. If the WAS/delivery catheter is advanced beyond the fixation barbs, the manufacturer recommends removal of the device out of concern for fixation barb injury. If, after deployment, it is determined that the device size is inappropriate, full recapture in the manner previously described is performed. Of note, if the device position is too proximal (too far in the left atrium), generally it is not recommended to recapture and advance the system partially as advancement without a leading pigtail or $\mathrm{J}$-wire is more traumatic and increases the perforation risk.

\section{ADDITIONAL TIPS}

Tip 1. Though not mandatory, especially for less experienced operators, it is helpful to familiarise oneself with the $3 \mathrm{D}$ anatomy of the appendage because it can be difficult to understand by fluoroscopic and echocardiographic imaging alone. The LAA can be well reconstructed with CT-angiographic imaging (Figure 12,

Figure 13, Movie 8, Movie 9). It can help to delineate the orientation of the LAA, number of lobes and which lobe is dominant. Importantly, it can also be helpful in determining the best implant angle.

Tip 2. Familiarisation of which images' fluoroscopic angles correspond best with TOE imaging. It is especially important to recognise how the RAO/CAU view corresponds with the $135^{\circ}$ mid-oesophageal TOE view (Movie 17).

Tip 3. Engagement of the LAA and coaxial alignment. The LAA is usually anteriorly and superiorly oriented. To facilitate engagement 
and coaxial alignment, the double-curve access sheath, most frequently used, has two curves in two planes. Under most circumstances, this allows alignment without much sheath manipulation. However, sometimes the sheath needs to be rotated counter-clockwise to facilitate anterior orientation (Movie 17). Alternatively, an anterior curve sheath can be used with a more pronounced secondary bend or the fossa ovalis can be re-punctured more posteriorly to achieve optimal alignment with the anteriorly directed LAA. In cases of laterally or posteriorly oriented LAAs, a less counterclockwise rotation or a single-curve access sheath or mid fossa puncture can be considered.

Tip 4. Understand the equipment. Keep in mind that the distal tip of both the WAS and the delivery catheter protrudes $5 \mathrm{~mm}$ beyond the distal marker band. This means that there are $5 \mathrm{~mm}$ of sheath and/or catheter beyond the distal marker that may not be visible on fluoroscopy or cineangiography (Figure 14, Movie 11).

\section{AMULET DEVICE}

The same principles for femoral venous access and TSP as outlined above for the WATCHMAN device also apply to the Amulet device. Likewise, anticoagulation, at the latest after TSP maintaining an ACT $>250-300$ seconds throughout the procedure, and an oral or intravenous antibiotic (depending on the institution's preference and the patient's allergy history) are administered once prior to and again after the procedure. An AMPLATZER ${ }^{\text {TM }}$ TorqVue ${ }^{\mathrm{TM}}$ delivery sheath (Abbott Vascular) (Supplementary Figure 16) is used to access the left atrium. It has two $45^{\circ}$ out-ofplane bends. Some operators adjust the sheath configuration according to the left atrial and appendage morphology by bending the sheath and dilator based on fluoroscopy ${ }^{2}$. Once across the interatrial septum, the wire and dilator are removed and a pigtail catheter is inserted via the TorqVue sheath into the LAA. The TorqVue sheath may also be inserted directly into the LAA, preferably with the dilator still inside, but retracted proximal to the proximal bend. This facilitates torquing without distorting the sheath curves and prevents kinking. Cineangiography of the LAA is performed (in the aforementioned RAO/CAU or RAO/CRA views) and measurements of the landing zone (i.e., the anticipated position of the lobe) and the ostium are made. It is important to emphasise that, depending on the anticipated device size used, the landing zone is measured $\sim 1.0 \mathrm{~cm}$ (for the $25 \mathrm{~mm}$ or smaller device) or $\sim 1.2 \mathrm{~cm}$ (for the $28 \mathrm{~mm}$ or larger device) distal (more towards the apex of the LAA) to the ostium (Figure 17). In addition, the length of the landing zone is measured, particularly in cases of a chickenwing LAA when, if this length is insufficient, the implantation strategy may differ from the usual technique to a "sandwich" technique described below. The sizing chart provided by the manufacturer outlines recommendations assuming that the measurements are made by 2D-TOE or cineangiography (Supplementary Figure 17). However, when CT angiography is available, it is reasonable to choose the device size based on the calculated mean diameter or perimeter, particularly when the LAA landing zone and ostium have very elliptical shapes. This strategy may prevent

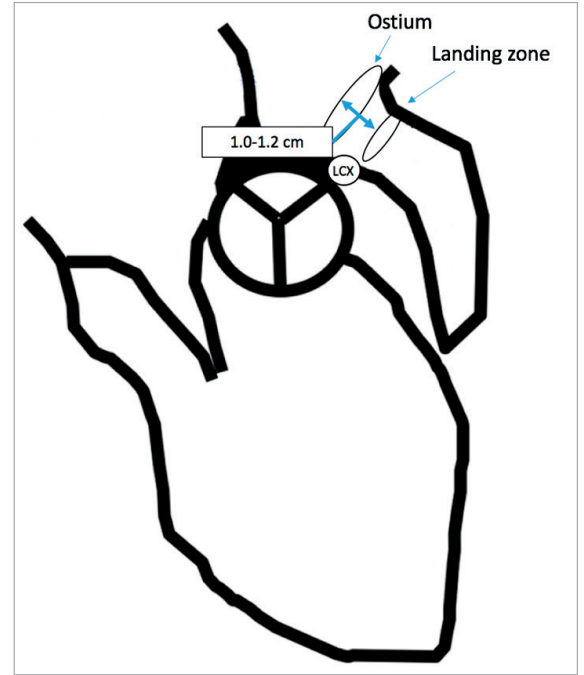

Figure 17. Illustration of the landing zone and ostium of the appendage for the purpose of Amulet implantation. The landing zone (grey area, location of where the lobe sits) is typically $1.0-1.2 \mathrm{~cm}$ distal to the ostium, depending on the device size.

gross oversizing. While maintaining a pigtail catheter in the LAA, the delivery sheath can be advanced into the LAA landing zone and the pigtail catheter then removed. The Amulet is supplied loaded in the loading catheter (Figure 18) and requires thorough flushing with heparinised saline until no air is visible in the loading catheter (Supplementary Figure 18, Movie 18). Through the side port of the Y-connector, either by hand injection or via a power injector, heparinised saline is injected exiting the loading catheter tip. Simultaneously, backflow of the delivery sheath is allowed to create a fluid-to-fluid connection as the loading catheter and delivery sheath are connected to minimise air entrapment and embolisation (Figure 19, Movie 19). Once connected, the valve on the loading catheter is opened slightly by counter-clockwise turning and the device is advanced by pushing the delivery cable forward while holding the sheath and loading catheter in place (Figure 20,

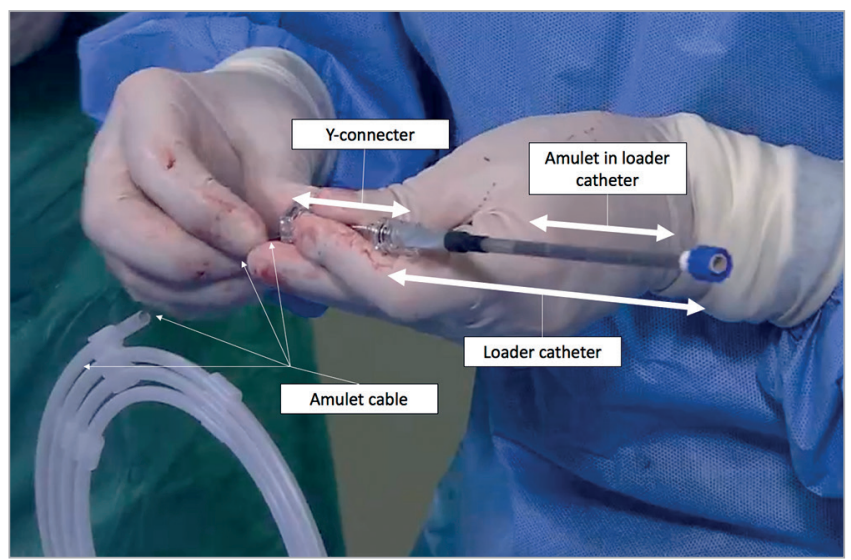

Figure 18. Demonstration of the loader catheter with the Amulet loaded and the Amulet cable as well as the Y-connector. 


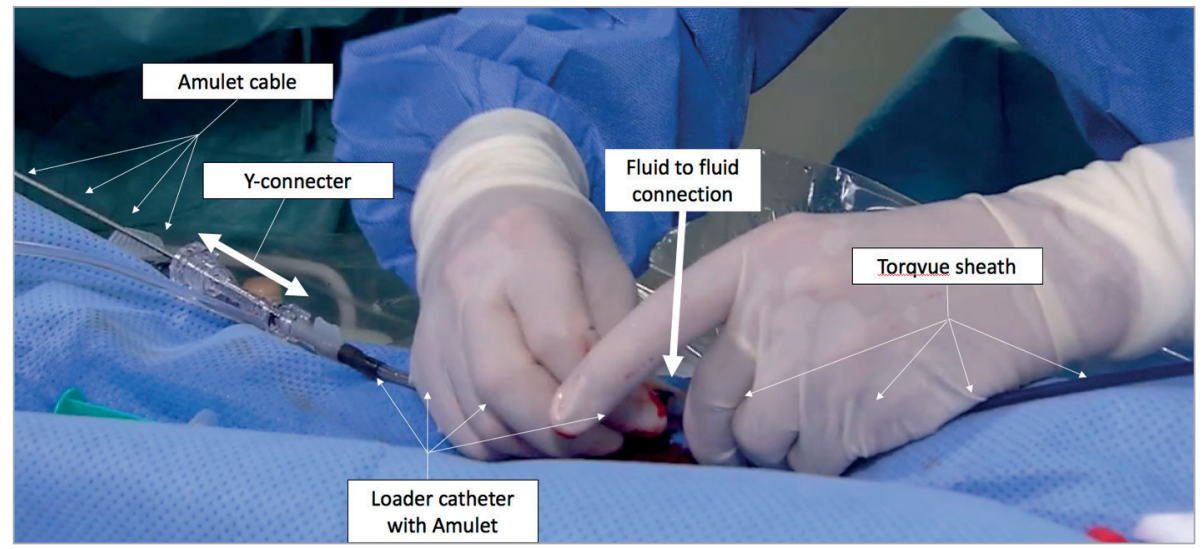

Figure 19. Fluid-to-fluid connection of the loading system with the TorqVue sheath (patient's head to the right).

Movie 20). Special attention should be paid to avoid turning of the delivery cable (counter-clockwise) while advancing it in order to avoid inadvertent premature disconnection of the device from the cable. To assure secure connection, prior to deployment, the cable can be pulled back 1-2 $\mathrm{cm}$ while paying attention to the device to make sure that it is still connected. The device is advanced to the sheath tip. For deployment, under most circumstances, good visualisation of the landing zone and ostium is most important, and therefore the RAO/CRA view may be preferred. Then the delivery cable is fixed with the right hand and the sheath slowly pulled back to allow partial deployment such that the device assumes a "ball" configuration, i.e., it has a round configuration (Figure 21, Supplementary Figure 19, Movie 21). This creates an atraumatic tip and, at this point, the sheath and device, as a unit, can be advanced or withdrawn if located too proximal to or distal from the landing zone. Frequently, counter-clockwise rotation of the sheath to allow more coaxial alignment of the delivery system and device with the LAA landing zone is needed. When the position is deemed optimal (i.e., the ball is in the landing zone), instead of further sheath retraction, the delivery cable is then pushed forward while fixing the position of the sheath (Figure 21, Supplementary

Figure 19, Movie 21). This does not cause further advancement of the device but rather allows the device to unfold (laterally) into a triangle and, subsequently, tyre configuration and the device is now anchored in the LAA via the lobe. If, instead of the aforementioned manoeuvre, the delivery cable is fixed and the sheath retracted, the device will migrate slightly proximal (towards the ostium) and may end up too far into the left atrium. Finally, the sheath is retracted with slight pulling tension on the delivery cable to allow the disc to unfold (Movie 22). After checking for reasonable positioning, first, a tug test is performed keeping the sheath tip $\sim 2 \mathrm{~cm}$ from the device and gently tugging (pulling) on the delivery cable until the disc is "football"-shaped (Movie 23). Some operators recommend continuous tension in this configuration for $\sim 30$ seconds to 2 minutes to assure a secure anchoring. Then tension is released and attention is paid to the position and shape of the lobe which optimally should have a "tyre" configuration that suggests that it is slightly compressed, and it should optimally be perpendicular to the landing zone axis causing the anchors to engage the LAA wall (Supplementary Figure 20). Second, at least half to two thirds of the lobe should be distal to the left circumflex coronary artery. Third, there should be slight separation of the disc from the lobe and, finally, the disc should have a slightly concave shape (Supplementary Figure 20) such that it is

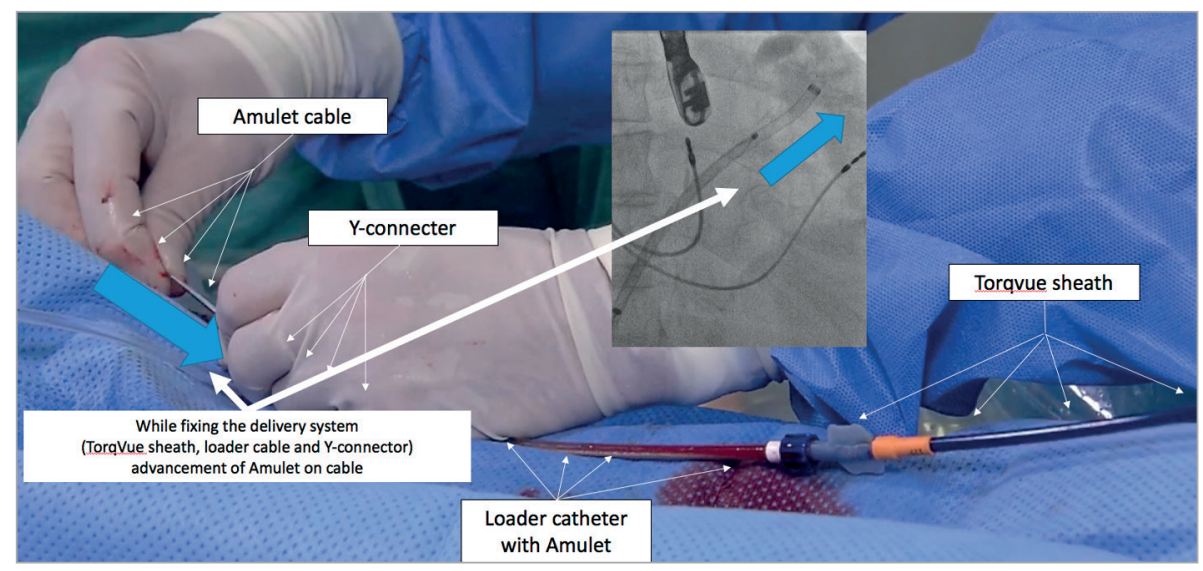

Figure 20. Advancing the Amulet device via the delivery cable (patient's head to the right). 


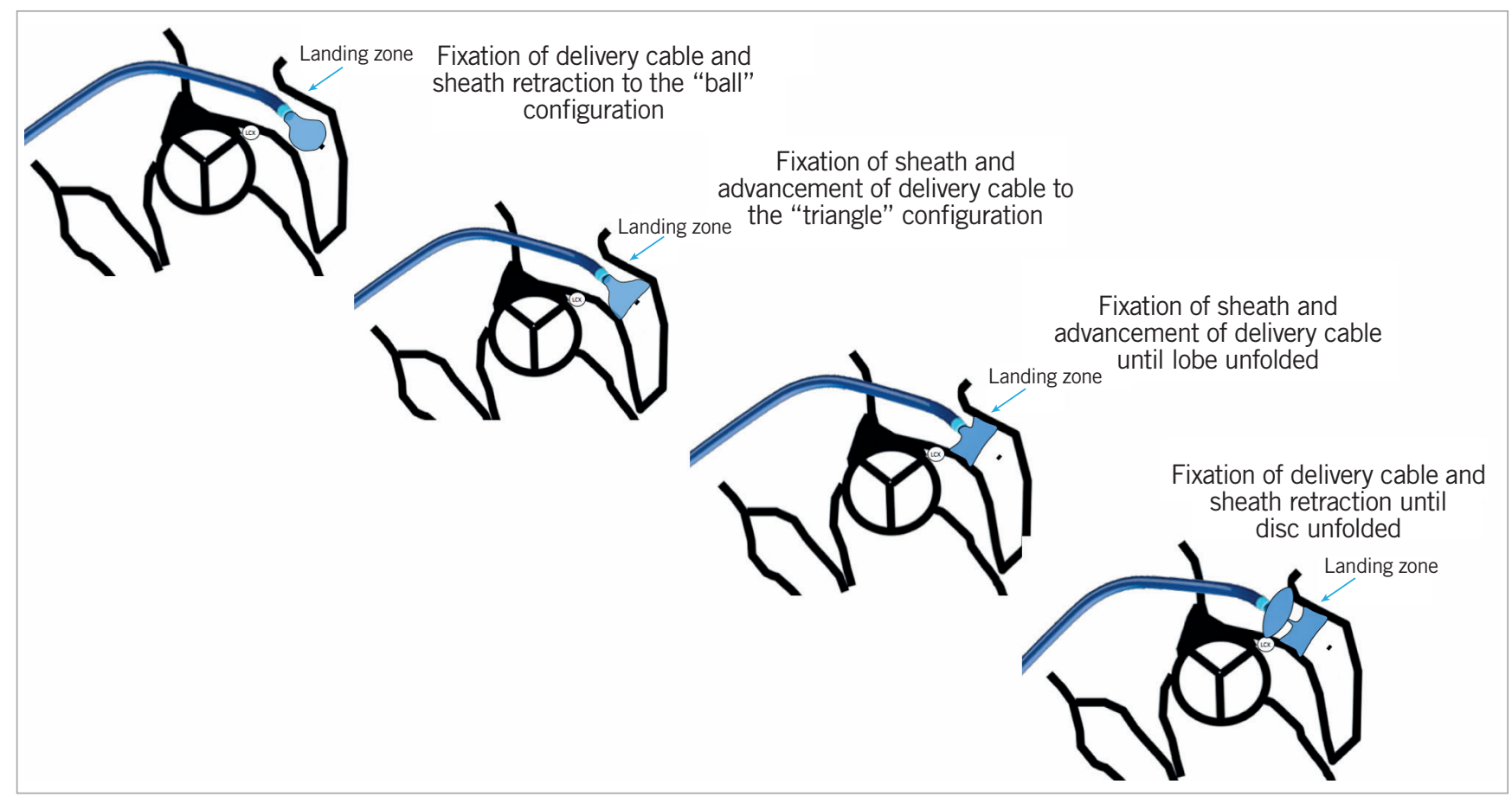

Figure 21. Step-by-step illustration of Amulet deployment.

positioned not above the ostium but is under tension at the ostium providing a more secure seal. Attention is paid to the presence of peri-device leaks and interrogation should be performed by TOE at $0,45,90$ and $135^{\circ}$. If the device size is appropriate but the position not satisfactory, partial recapture and repositioning is necessary. In this case, while stabilising the delivery cable, the sheath is re-advanced, thereby re-sheathing the disc and a portion of the lobe, to the radiopaque marker on the lobe or triangular shape allowing the anchors to disengage but avoiding entry of the anchors into the sheath (Supplementary Figure 21) as this may injure the anchors and may not provide the expected fixation after redeployment. Moreover, if the anchors enter the sheath, the soft portion of the sheath tip can invaginate (this can best be seen under magnification during a cine X-ray run). If the sheath tip is invaginated or otherwise injured, re-advancing the device may not be possible. Hence, if the device is removed such that the anchors have entered the sheath, it is best to remove the device entirely and reload it with the help of the provided reloader or use a new device. If sheath invagination is detected on cine X-ray imaging, it is best to re-insert a J-tipped soft wire through the sheath into the left atrium (i.e., with the wire tip in the left upper pulmonary vein or left atrium) and then re-insert the introducer over the wire to push back the invaginated tip into the original configuration before inserting and advancing a new device. If it becomes apparent that the device size is too small or too large, the device should be removed by reversing the previously outlined steps of deployment. Keep in mind that if a larger device size is chosen, the sheath may have to be larger for delivery. For example, if a 12 Fr sheath was used to deliver a $25 \mathrm{~mm}$ device and this device size proved to be too small, for the delivery of a larger size, the previous $12 \mathrm{Fr}$ sheath needs to be exchanged for a $14 \mathrm{Fr}$ sheath. For this reason, some operators decide to use a $14 \mathrm{Fr}$ sheath even when planning the implantation of a $22 \mathrm{~mm}$ or $25 \mathrm{~mm}$ Amulet device, or simply use the $14 \mathrm{Fr}$ sheath as a default sheath to avoid the necessity of sheath exchange if eventually a $>25 \mathrm{~mm}$ device needs to be used. Remember though that, if a $25 \mathrm{~mm}$ or smaller device is necessary but a $14 \mathrm{Fr}$ sheath is used for delivery, the adaptor provided with all Amulet devices $\leq 25 \mathrm{~mm}$ needs to be applied to the distal tip of the loading catheter to accommodate the discrepancy between the 14 Fr sheath and 12 Fr loading catheter. Before final release, waiting a few minutes to assess whether there has been any device movement or instability is recommended. When all the aforementioned morphological features are met and no device leak is present, the cable is detached by counter-clockwise rotation similar to the manoeuvre performed when releasing any other AMPLATZER occluder while applying slight backward tension to avoid inadvertent catching of the device fabric with the screw after detachment, and the delivery cable is pulled back into the sheath to avoid injury to the left atrial wall. Some operators perform the procedure without echocardiographic guidance and ascertain correct position with cineangiography through the sheath in one or two projections without any overlap of lobe and disc ${ }^{72}$. When adequate TOE imaging is available and the device position appears optimal, this is not required. The sheath is removed, and closure can be performed by manual pressure, with pre-set sutures, or a figure of 8 suture as previously described. Device deployment during cases with a long enough landing zone is simple and requires only shallow engagement of the LAA with the sheath tip at or near the landing zone. 
As long as this landing zone is adequate $(15-20 \mathrm{~mm})$, the configuration or number of lobes or any other LAA features distal to the landing zone are not important. However, when the landing zone is very short, as is sometimes encountered when the LAA has a chicken-wing configuration, the deployment manoeuvre differs in that the lobe is deployed deeper and in parallel with the wing segment of the chicken-wing, thereby "sandwiching" the too short landing zone and ostium between the lobe and the disc (Movie 24). Under these circumstances, it is important to recognise that a larger size than determined by the traditional landing zone is most often necessary (depending on the dimensions of the wing) and to ensure that the entire lobe is located in the wing because, if it is only partially in the wing (i.e., part of the lobe prolapses outside of the ostium), too many anchors may not reach the wall, increasing the embolisation risk. When the sandwich technique is used, initial engagement of the LAA by the TorqVue sheath needs to be deeper (in the wing) than necessary for all other LAA configurations. If the orientation of the wing is very superior/anterior, a very inferior/posterior TSP location may be favoured to facilitate deep and coaxial engagement and pronounced counter-clockwise sheath rotation may become necessary. It is worth mentioning that the sheath curves may not be sufficient to accomplish deep LAA wing engagement. In this case, as previously mentioned, while keeping the dilator in place the sheath can be shaped to increase the chance of deep engagement. Some operators, regardless of anatomy, elect to shape the sheath by overlying it with the fluoroscopic/cineangiographic anatomy ${ }^{105}$. If a chicken-wing configuration is encountered but the landing zone is adequate $(>15-20 \mathrm{~mm})$ or the diameter of the wing remains similar to the landing zone thereby extending the landing zone, deployment can be performed as usual (Supplementary Figure 22). When an LAA anatomy is encountered where the ostium is large but the landing zone narrow (i.e., a rapidly tapering LAA), oversizing by $2 \mathrm{~mm}$ larger than recommended in the instructions for use (IFU) may be considered to allow optimal sealing of the ostium by the disc. Likewise, if the landing zone measurements suggest a small (i.e., 16-22 mm) device, slight oversizing by $2 \mathrm{~mm}$ greater than the recommended size based on the chart provided by the manufacturer may be considered, as the smaller sizes have fewer anchors thereby potentially increasing the embolisation risk. The above-described technique of leading the sheath with the pigtail catheter (in the LAA) and sliding the sheath over the pigtail until the sheath tip is located at the landing zone can be modified. Some more experienced operators, for example, do not engage the LAA with the pigtail catheter but rather under TOE and fluoroscopic guidance advance the sheath close to the ostium or directly into the LAA and perform cineangiography through the sheath and subsequently advance the device to the sheath tip and allow partial deployment to the atraumatic "ball" configuration, engage the LAA more deeply and advance the system until the "ball" has passed the landing zone. Further deployment does not differ from the previously described technique. Similar to the technique mentioned during WATCHMAN implantation, some operators perform the exchange of the transseptal sheath for the delivery sheath over a soft J-tipped but otherwise stiff wire positioned in the LAA.

\section{Chapter 5. Studies and registries: results including efficacy and safety}

Published evidence on left atrial appendage closure consists of two randomised controlled trials (RCTs), a few large registries and a number of smaller single and multicentre registries and case series. The two RCTs to date have focused on patients eligible for oral anticoagulation (OAC) therapy receiving the WATCHMAN device. A summary of key efficacy and safety results for the WATCHMAN device are presented in Table 9 and for the AMPLATZER Cardiac Plug (ACP) and Amulet devices in Table 10.

\section{WATCHMAN EVIDENCE (Table 9) 106-113 $^{13}$}

PROTECT AF enrolled 707 patients with atrial fibrillation and a $\mathrm{CHADS}_{2}$ score of 1 or more between 2005 and 2008 and randomised them to treatment with warfarin or the WATCHMAN device $^{106}$. The device group was given warfarin for 45 days after the implant. It was a non-inferiority study and, after 1,065 patient years of follow-up, the primary efficacy endpoint of a combination of stroke, cardiovascular death, and systemic embolism was met. The device was successfully implanted in $91 \%$ of attempts. Adverse events were more common in the device group (7.4 per 100 patient years), driven by perioperative complications. By a mean of 3.8 years follow-up, the primary efficacy event rate was 2.3 per 100 patient years compared to 3.8 per 100 patient years in the warfarin group, with the device meeting superiority criteria with lower cardiovascular and all-cause mortality ${ }^{107}$.

The adverse event rate was the motivation for the only other randomised controlled trial to date. PREVAIL randomised 407 patients with a $\mathrm{CHADS}_{2}$ score of 2 or more to warfarin or the WATCHMAN device using the same anticoagulation and antiplatelet regimen ${ }^{108}$. The device was successfully implanted in $95.1 \%$ of attempts. At 18 months, the primary efficacy non-inferiority endpoint of stroke, systemic embolism and cardiovascular or unexplained death was not met. There was a much lower than expected event rate in the warfarin arm. The secondary efficacy non-inferiority endpoint of stroke or systemic embolism $>7$ days after implant was met. Early safety events in the WATCHMAN arm were lower than in PROTECT AF and met the pre-specified safety non-inferiority criteria.

PROTECT AF and PREVAIL five-year outcome data were combined in a meta-analysis ${ }^{6}$. The WATCHMAN device was non-inferior to warfarin for the composite of stroke, systemic embolism, and cardiovascular/unexplained death. Differences in mortality, haemorrhagic stroke and major bleeding favoured the WATCHMAN. There was a numerically higher rate of ischaemic stroke and systemic embolism in the WATCHMAN group, but this did not reach statistical significance.

The CAP registry followed the 502 patients enrolled in the device arm of PROTECT AF and an additional 460 non-randomised 
Table 9. WATCHMAN studies.

\begin{tabular}{|c|c|c|c|c|c|c|c|c|c|c|c|c|c|c|c|}
\hline \multicolumn{3}{|c|}{ Study details } & \multicolumn{4}{|c|}{ Patient details } & \multicolumn{4}{|c|}{ Efficacy } & \multicolumn{5}{|c|}{ Safety } \\
\hline $\begin{array}{l}\text { First } \\
\text { author and } \\
\text { dates of } \\
\text { publication }\end{array}$ & $\begin{array}{l}\text { RCT or } \\
\text { registry }\end{array}$ & \begin{tabular}{|c|} 
Number \\
of \\
patients \\
with \\
device
\end{tabular} & $\begin{array}{c}\text { Mean } \\
\text { age }\end{array}$ & \begin{tabular}{|l|} 
Mean \\
CHADS,/ \\
CHADS- \\
VASc \\
score
\end{tabular} & $\begin{array}{l}\% \\
\text { inelig- } \\
\text { ible for } \\
\text { OAC }\end{array}$ & $\begin{array}{c}\text { Mean } \\
\text { FU } \\
\text { (months) }\end{array}$ & $\begin{array}{l}\text { Implant } \\
\text { suc- } \\
\text { cess }\end{array}$ & $\begin{array}{l}\text { Major } \\
\text { leak }\end{array}$ & All stroke & $\begin{array}{l}\text { Ischaemic } \\
\text { stroke/SE }\end{array}$ & $\begin{array}{l}\text { SAE in } \\
\text { first } \\
7 \text { days }\end{array}$ & $\begin{array}{l}\text { Effu- } \\
\text { sion+ }\end{array}$ & $\begin{array}{l}\text { Emboli- } \\
\text { sation }\end{array}$ & $\begin{array}{l}\text { Proce- } \\
\text { dure- } \\
\text { related } \\
\text { stroke }\end{array}$ & $\begin{array}{l}\text { Proce- } \\
\text { dure- } \\
\text { related } \\
\text { death }\end{array}$ \\
\hline $\begin{array}{l}\text { Holmes } \\
2009^{106} \\
\text { Reddy } 2014^{107}\end{array}$ & MRCT & 463 & $71.7 \pm 8.8$ & $2.2 \pm 1.2 / 3.4$ & 0 & $\begin{array}{l}18 \pm 10 \\
45 \pm 20\end{array}$ & $88.0 \%$ & \begin{tabular}{|c|}
$8 \%$ at \\
$6-$ month \\
TOE
\end{tabular} & \begin{tabular}{|c|}
$2.3 / 100$ \\
patient years \\
$1.5 / 100$ \\
patient years
\end{tabular} & $\begin{array}{c}2.5 / 100 \\
\text { patient years } \\
1.6 / 100 \\
\text { patient years }\end{array}$ & $7.7 \%$ & $4.1 \%$ & $0.6 \%$ & $0.9 \%$ & 0 \\
\hline $\begin{array}{l}\text { Holmes } \\
2014^{108}\end{array}$ & MRCT & 269 & $74 \pm 4$ & $\begin{array}{l}2.6 \pm 1.0 / \\
3.8 \pm 1.2\end{array}$ & 0 & $11.8 \pm 5.8$ & $95.1 \%$ & & $\begin{array}{c}2.3 \% \\
\text { patients } \\
\text { during FU }\end{array}$ & $\begin{array}{c}2.3 \% \\
\text { patients } \\
\text { during FU }\end{array}$ & $4.2 \%$ & $1.9 \%$ & $0.7 \%$ & $0.4 \%$ & 0 \\
\hline Reddy $2017^{6}$ & $\begin{array}{c}\text { Meta- } \\
\text { analysis } \\
\text { of } 2 \text { RCTs }\end{array}$ & 732 & $72.6 \pm 8.4$ & $\begin{array}{l}2.3 \pm 1.1 / \\
3.6 \pm 1.4\end{array}$ & 0 & $\begin{array}{c}4,343 \\
\text { patient } \\
\text { years }\end{array}$ & $95.4 \%$ & & $\begin{array}{c}1.77 \\
\text { per } 100 \\
\text { patient years }\end{array}$ & $\begin{array}{c}1.6 \\
\text { per } 100 \\
\text { patient years }\end{array}$ & & & & & \\
\hline Reddy $2011^{98}$ & MReg & 460 & $74 \pm 8$ & $2.2 \pm 1.2$ & 0 & & $95.0 \%$ & & & & $3.7 \%$ & $2.2 \%$ & 0 & 0 & 0 \\
\hline Reddy $2013^{109}$ & MReg & 150 & $72.5 \pm 7.4$ & $\begin{array}{l}2.8 \pm 1.2 / \\
4.4 \pm 1.7\end{array}$ & $100 \%$ & $14.4 \pm 8.6$ & $95.0 \%$ & & \begin{tabular}{c|}
2.3 per 100 \\
patient years
\end{tabular} & $\begin{array}{c}1.7 \text { per } 100 \\
\text { patient years }\end{array}$ & & $1.3 \%$ & $1.3 \%$ & 0 & 0 \\
\hline $\begin{array}{l}\text { Boersma } \\
2016^{112} \text {, } \\
2017^{95}\end{array}$ & MReg & 1,021 & $73 \pm 9$ & $\begin{array}{l}2.8 \pm 1.3 / \\
4.5 \pm 1.6\end{array}$ & $62 \%$ & $\begin{array}{c}12 \\
\text { months }\end{array}$ & $98.5 \%$ & $0.7 \%$ & \begin{tabular}{|c|} 
Ischaemic \\
stroke \\
$1.1 \%$ per year
\end{tabular} & $\begin{array}{l}\text { Ischaemic } \\
\text { stroke/TIA/ } \\
\mathrm{SE}=1.5 \% \\
\text { per year }\end{array}$ & $2.8 \%$ & $0.4 \%$ & $0.2 \%$ & $0.1 \%$ & $0.1 \%$ \\
\hline Reddy $2017^{113}$ & MReg & 3,822 & & & & & $95.6 \%$ & & & & & $1 \%$ & 0.24 & $0.08 \%$ & $0.08 \%$ \\
\hline
\end{tabular}

Table 10. AMPLATZER studies.

\begin{tabular}{|c|c|c|c|c|c|c|c|c|c|c|c|c|c|c|c|c|}
\hline \multicolumn{4}{|c|}{ Study details } & \multicolumn{4}{|c|}{ Patient details } & \multicolumn{4}{|c|}{ Efficacy } & \multicolumn{5}{|c|}{ Safety } \\
\hline $\begin{array}{c}\text { First } \\
\text { author and } \\
\text { dates of } \\
\text { publication }\end{array}$ & $\begin{array}{l}\text { RCT or } \\
\text { registry }\end{array}$ & Device & $\begin{array}{l}\text { Number } \\
\text { of } \\
\text { patients } \\
\text { with } \\
\text { device }\end{array}$ & $\begin{array}{c}\text { Mean } \\
\text { age }\end{array}$ & $\begin{array}{c}\text { Mean } \\
\text { CHADS }_{2} \\
\text { CHADS- } \\
\text { VASc score }\end{array}$ & $\begin{array}{c}\% \\
\text { inelig- } \\
\text { ible for } \\
\text { OAC }\end{array}$ & $\begin{array}{l}\text { Mean FU } \\
\text { (months) }\end{array}$ & $\begin{array}{l}\text { Implant } \\
\text { success }\end{array}$ & $\begin{array}{l}\text { Major } \\
\text { leak }\end{array}$ & $\begin{array}{c}\text { All } \\
\text { stroke }\end{array}$ & $\begin{array}{l}\text { Ischae- } \\
\text { mic } \\
\text { stroke / } \\
\text { SE / TIA }\end{array}$ & $\begin{array}{l}\text { SAE in } \\
\text { first } \\
7 \text { days }\end{array}$ & $\begin{array}{l}\text { Effu- } \\
\text { sion+ }\end{array}$ & $\begin{array}{c}\text { Emboli- } \\
\text { sation }\end{array}$ & \begin{tabular}{|l|} 
Proce- \\
dure- \\
related \\
stroke
\end{tabular} & $\begin{array}{l}\text { Proce- } \\
\text { dure- } \\
\text { related } \\
\text { death }\end{array}$ \\
\hline $\begin{array}{l}\text { Nietlispach } \\
2013^{72}\end{array}$ & SReg & $\begin{array}{l}\text { ACP+ } \\
\text { Nded } \\
\text { Dev. }\end{array}$ & 152 & $72 \pm 10$ & $3.4 \pm 1.7$ & $76 \%$ & $\begin{array}{c}32 \text { (up to } \\
120 \text { ) }\end{array}$ & $\begin{array}{c}96.1 \% \\
99.2 \% \\
\text { in ACP } \\
\text { group } \\
\end{array}$ & $0.7 \%$ & \multicolumn{2}{|c|}{$0.5 \% /$ year } & $\begin{array}{c}7.2 \% \\
\text { overall, } \\
3.3 \% \text { in } \\
\text { ACP }\end{array}$ & $2.6 \%$ & $\begin{array}{c}3.9 \% \\
0.8 \% \\
\text { in ACP } \\
\text { group }\end{array}$ & $0.7 \%$ & $0.0 \%$ \\
\hline $\begin{array}{l}\text { Tzikas } \\
2016^{114}\end{array}$ & MReg & ACP & 1,047 & $7 \pm 8$ & $\begin{array}{l}2.8 \pm 1.3 / \\
4.5 \pm 1.6\end{array}$ & $73 \%$ & 13 & $97.3 \%$ & $1.9 \%$ & & $\begin{array}{c}\text { Stroke or } \\
\text { TIA } 2.3 \% \\
\text { per year }\end{array}$ & $5 \%$ & $0.5 \%$ & $0.8 \%$ & $0.9 \%$ & $0.8 \%$ \\
\hline $\begin{array}{l}\text { Lopez- } \\
\text { Minguez } \\
2015^{115} \\
\end{array}$ & MReg & ACP & 167 & $74.7 \pm 8.6$ & $3 / 4$ & $100 \%$ & $22 \pm 8.3$ & $94.6 \%$ & $8.2 \%$ & - & $\begin{array}{c}\text { Stroke or } \\
\text { TIA } 2.4 \% \\
\text { per year }\end{array}$ & $5.4 \%$ & $1.2 \%$ & $0.6 \%$ & 0 & 0 \\
\hline $\begin{array}{l}\text { Urena } \\
2013^{129}\end{array}$ & MReg & ACP & 52 & $74 \pm 8$ & $3 /-$ & $100 \%$ & $20 \pm 5$ & $98.1 \%$ & 0 & \multicolumn{2}{|c|}{$\begin{array}{l}1 \text { ischaemic stroke } \\
\text { and } 1 \text { TIA during FU }\end{array}$} & $5.8 \%$ & $1.9 \%$ & $1.9 \%$ & 0 & 0 \\
\hline Berti $2017^{118}$ & MReg & $A C P+A m$ & 613 & $75.1 \pm 8.0$ & $-/ 4.2 \pm 1.5$ & $84.5 \%$ & 20 & $95.4 \%$ & $0.5 \%$ & $\begin{array}{c}1.8 \text { per } \\
100 \\
\text { patient } \\
\text { years }\end{array}$ & $\begin{array}{c}\text { Stroke or } \\
\text { TIA } 2.45 \% \\
\text { per year }\end{array}$ & $6.2 \%$ & & $0.7 \%$ & & 0 \\
\hline $\begin{array}{l}\text { Landmesser } \\
2017^{97} \text { and } \\
2018^{116} \\
\end{array}$ & MReg & Am & 1,088 & $75 \pm 8.5$ & $-/ 4.2 \pm 1.6$ & $83 \%$ & 12 & $99.0 \%$ & $1.8 \%$ & \multicolumn{2}{|c|}{$2.9 \%$ per year } & $3.6 \%$ & $1.2 \%$ & $0.1 \%$ & $0.4 \%$ & $0.2 \%$ \\
\hline $\begin{array}{l}\text { Kleinecke } \\
2017^{117}\end{array}$ & SReg & Am & 50 & $76.1 \pm 8.3$ & $-/ 5.2 \pm 1.8$ & $24 \%$ & 12 & $98.0 \%$ & 0 & \multicolumn{2}{|c|}{$\begin{array}{c}6 \text { ischaemic strokes } \\
\text { per } 100 \text { patient } \\
\text { years }\end{array}$} & $8 \%$ & $4 \%$ & $2.0 \%$ & 0 & 0 \\
\hline $\begin{array}{l}\text { Nielsen- } \\
\text { Kudsk } \\
2017^{119}\end{array}$ & $\begin{array}{c}\text { MReg } \\
\text { (ICH } \\
\text { patients) }\end{array}$ & $A C P+A m$ & 151 & $72 \pm 8.7$ & $-/ 3.9$ & $100 \%$ & 6 & $97.7 \%$ & - & \multicolumn{2}{|c|}{\begin{tabular}{|c|}
17 (vs 81 ) \\
ischaemic strokes \\
per 1,000 patient \\
years \\
116 (vs 95 ) \\
recurrent ICH per \\
1,000 patient years
\end{tabular}} & $4 \%$ & $0.7 \%$ & $0.7 \%$ & $0.7 \%$ & 0 \\
\hline
\end{tabular}

ACP: AMPLATZER Cardiac Plug; AM: Amulet; FU: follow-up; ICH: intracranial haemorrhage; MRCT: multicentre randomised controlled trial; MReg: multicentre registry; Nded Dev.: non-dedicated devices for LAAO (AMPLATZER PFO, ASD, VSD Occluder); OAC: oral anticoagulation; SAE: serious adverse event; SReg: single-centre registry; TIA: transient ischaemic attack 
patients. There was a significant decline in procedure- or devicerelated adverse events, emphasising the role of operator experience in improving safety ${ }^{99}$.

The long-term incidence of severe bleeding was examined in the 1,114 patients enrolled in PROTECT AF and PREVAIL ${ }^{110}$. After a mean follow-up of 3.1 years, the overall bleeding rate between the device and the warfarin groups was similar; however, once the device group discontinued adjunctive $\mathrm{OAC}$ and antiplatelet therapy, there was a significant reduction in severe bleeding events. The overall similarity between groups was driven mainly by perioperative bleeding complications. Contemporary practice, particularly in patients with a bleeding history, often uses a less intensive anticoagulation or antiplatelet regimen perioperatively, with a lower incidence of procedure-related bleeding than that seen in PROTECT $\mathrm{AF}$, albeit in a different population and with different protocols ${ }^{111}$.

Evidence for the safety and efficacy of percutaneous left atrial appendage occlusion (LAAO) in patients unable to take oral anticoagulants is in the form of registries and case series. The ASAP registry enrolled 150 patients with a $\mathrm{CHADS}_{2}$ score of 1 or more ineligible for vitamin $\mathrm{K}$ antagonist (VKA) $\mathrm{OAC}^{92}$. The WATCHMAN device was inserted together with a dual antiplatelet regimen of acetylsalicylic acid (ASA) and clopidogrel for six months followed by acetylsalicylic acid alone. A history of haemorrhage or bleeding tendencies was present in $93 \%$; $8.7 \%$ had procedure- or device-related safety events. The incidence of stroke or systemic embolism was 2.6 per year, significantly lower than the $\mathrm{CHADS}_{2}$ estimated event rate of $7.3 \%$.

More recently, the international multicentre EWOLUTION prospective registry reported on 1,021 patients receiving a WATCHMAN device ${ }^{112}$. Oral anticoagulation was contraindicated in $62 \%$ and $45 \%$ had suffered a prior stroke. Implantation was successful in $98.5 \%$. Device- or procedure-related adverse events were seen in $2.8 \%$ up to seven days, a significant reduction compared to PROTECT AF, PREVAIL and the CAP registries. One-year follow-up revealed a mortality rate of $9.8 \%$, and an ischaemic stroke rate of $1.1 \%(84 \%$ RRR). Antiplatelet therapy was used in $83 \%$ and VKA in only $8 \%{ }^{97}$.

The US post-approval registry recorded outcomes on 3,822 consecutive WATCHMAN cases. There was a large proportion of new, inexperienced operators but the implant success rate remained high $(95.6 \%)$ with a low complication rate $(1.5 \%)^{113}$.

\section{ACP AND AMULET EVIDENCE (Table 10)}

Safety and efficacy data for the ACP device were examined in a 1,047-patient registry ${ }^{114}$. The procedure success rate was $97.3 \%$ with a procedure-related adverse event rate of 5\%. Although the majority of implants were performed on single or dual antiplatelet therapy, nearly $40 \%$ used OAC at some point. After a mean follow-up of 13 months, the annual stroke or transient ischaemic attack (TIA) rate was 2.3\%, against an estimated rate of $5.6 \%$ based on the $\mathrm{CHA}_{2} \mathrm{DS}_{2}$-VASc scores. The subgroup on long-term acetylsalicylic acid monotherapy or no therapy had an annual stroke or TIA rate of $1.3 \%$ against an estimated $5.6 \%$.
The longest follow-up with AMPLATZER devices was reported in a Swiss single-centre registry including 152 patients undergoing LAAO with non-dedicated AMPLATZER devices and the ACP using only fluoroscopic guidance intraprocedurally. The average annual stroke risk was $1.2 \%$ and major bleeding occurred in $1 \%$ /year. Notably, the population investigated had a predicted annual stroke risk of $3.5 \%$ without OAC and $1.5 \%$ with VKA, with a predicted annual major bleeding risk of $>3 \%{ }^{73}$.

The Iberian ACP registry of 167 patients also had a long followup $^{115}$. All patients were implanted using a DAPT regimen. In the first year the stroke incidence was 3.9\% (5.2\% when including periprocedural events) and in the second year $2.4 \%$, compared to an expected annual event rate of $9.6 \%$.

The Amulet registry enrolled 1,088 patients, 83\% with contraindications to $\mathrm{OAC}^{98}$. The device was successfully implanted in $99 \%$ with a $3.2 \%$ major adverse event rate; $77 \%$ of patients were discharged on a single antiplatelet agent or DAPT. At 12-month follow-up in this population with a mean $\mathrm{CHA}_{2} \mathrm{DS}_{2}$-VASc score of 4.2 there was a $2.9 \%$ ischaemic stroke rate ${ }^{116}$. In addition, a single-centre study has reported 12-month follow-up results on 49 patients with the Amulet device in which there was a $6.6 \%$ ischaemic stroke rate ${ }^{117}$.

An Italian multicentre registry collected outcome data on 613 ACP and Amulet procedures. The implant success rate was $95.4 \%$ and $6.2 \%$ had procedure-related adverse events ${ }^{118}$. The annual rate of stroke and thromboembolic events was $1.7 \%$, which represented a $66 \%$ reduction compared to that which was expected.

Patients with prior intracerebral haemorrhage may be particularly suitable for LAAO. In a Nordic registry, 151 patients with prior intracranial haemorrhage $(\mathrm{ICH})$ receiving the ACP or Amulet devices were compared to a propensity-matched group receiving standard care $(20 \%$ OAC, 50\% antiplatelets, and 30\% no therapy $)^{119}$. The LAAO group had a lower composite outcome of death, ischaemic stroke, and major bleeding (53.3 vs 366.7 events per 1,000 years, HR 0.16).

\section{THE LARIAT DEVICE}

Several early series demonstrated high acute success rates with LARIAT occlusion (mostly $>95 \%$ ) with considerable acute and long-term complication rates ${ }^{70,120-122}$. One should also take into account that many patients were screened out prior to implantation due to LAA morphology. High leakage rates were described in some studies ${ }^{120-122}$, although in another multicentre study leakage rates were lower than with the WATCHMAN device ${ }^{95}$. There was no uniform anticoagulation protocol following the procedure in the various studies; however, the majority of patients were on some antithrombotic therapy following the procedure. The largest LARIAT registry collected data retrospectively on 712 patients from 18 US hospitals. Procedure success rate was $95.5 \%$. Periprocedural complications occurred in 5.3\% and were influenced by the pericardial puncture technique. A further $4.5 \%$ had delayed complications, predominantly pericarditis. 


\section{OTHER DEVICES AND MIXED DEVICE REGISTRIES}

The LAmbre device was studied in a prospective multicentre registry enrolling 153 patients with a mean $\mathrm{CHA}_{2} \mathrm{DS}_{2}$-VASc score of $4^{123}$. There were 152 successful implants with $3.3 \%$ having serious complications. At discharge patients were initially prescribed DAPT. During 12 months of follow-up there were two ischaemic strokes and one haemorrhagic stroke.

A multicentre "real-world" experience in the United Kingdom included a variety of devices, predominantly the WATCHMAN, ACP, and Amulet ${ }^{94} ; 371$ patients undergoing LAAO had a $92.5 \%$ success rate and $3.5 \%$ procedure-related adverse event rate. Procedure success improved and adverse events reduced significantly over time. The ischaemic stroke rate was 0.57 per 100 years, a $90 \%$ relative risk reduction.

A meta-analysis of 49 LAAO publications involving 12,415 patients revealed a $96.3 \%$ success rate and procedure-related mortality of $0.2 \%$, stroke $0.3 \%$, pericardial effusion $2.3 \%$, device embolisation $0.4 \%$, and major bleeding $1.2 \%{ }^{124}$. A number of meta-analyses have compared LAAO with warfarin and indirectly with non-vitamin $\mathrm{K}$ dependent antagonist oral anticoagulants (NOACs) ${ }^{125-127}$. As the analysed RCTs have used only the WATCHMAN device and patients eligible for OAC, their results must be interpreted with caution. At best, they suggest that LAAO is comparable to NOACs in preventing death and ischaemic stroke or systemic embolism with similar bleeding risks.

\section{LEAKS AND DEVICE-RELATED THROMBUS}

In the PROTECT AF trial all patients with a WATCHMAN device were scheduled for 3-, 6-, and/or 12-month transoesophageal echocardiography (TOE) imaging. Device-related thrombus was noted in 15 patients $(3.4 \%)$, of whom only two had a subsequent ischaemic stroke, an event rate of 0.17 per 100 patient years ${ }^{103}$. Leaks were graded as minor $(<1 \mathrm{~mm})$, moderate $(1-3 \mathrm{~mm})$, or major $(>3 \mathrm{~mm})$ and were present in $32 \%$. There was no significant statistical relationship between the presence or severity of peri-device flow and the incidence of stroke or systemic embolism during follow-up. In the ACP registry, 339 had follow-up TOEs analysed, performed after a median of 134 days $^{92}$. Thrombus was observed in $3.2 \%$ and leaks in $12.5 \%$. Neither was associated with an increased risk of cardiovascular events.

CCTA of 117 patients three months after implant revealed device patency in approximately half of patients receiving WATCHMAN or ACP devices ${ }^{127}$. CCTA also suggested thrombus (mainly laminated) present on $16 \%$ of devices. None of the eight strokes seen during follow-up occurred in patients with thrombus or was related to device leaks.

In a recent publication including 1,739 patients implanted with a WATCHMAN device, the device-related thrombus (DRT) rate was influenced by the time of imaging and concurrent OAC or DAPT regimen ${ }^{98}$. DRT was detected in 65 patients $(3.75 \%)$ with $0.8 \%$ at 45 days (on warfarin and single antiplatelet therapy [SAPT]), $1.7 \%$ at 6 months (DAPT) and $1.8 \%$ at 12 months (high-dose ASA). Prior stroke/TIA, vascular disease or coronary artery disease (CAD), higher CHADS-VASc score, lower LVEF and non-paroxysmal atrial fibrillation (AF) and larger left atrial appendage (LAA) diameter were all predictors of DRT. DRT was associated with a fourfold increase in the risk of ischaemic stroke or serious events (SE) (6.3 events per 100 patient years).

In the WATCHMAN EWOLUTION registry $60 \%$ were discharged with DAPT and $26 \%$ on $\mathrm{OAC}^{96,112}$. The three-month TOE demonstrated a $2.6 \%$ DRT rate which was not influenced by medication regimen. In the Amulet registry $68.8 \%$ of patients were discharged on DAPT or OAC ${ }^{97,116}$. Of patients imaged during follow-up, $2.2 \%$ had DRT detected. In contrast, a French registry of 469 patients receiving the WATCHMAN or AMPLATZER devices demonstrated an incidence of DRT of $7.2 \%$. Older age and previous stroke were predictors of thrombus ${ }^{100}$. The Amulet device had a $25 \%$ incidence of DRT $(p<0.001)$, but this may have been related to the lower use of OAC or DAPT (which were protective factors) with this device. DRT was an independent predictor of ischaemic stroke or TIA during follow-up (adjusted HR 4.39, 95\% CI: $1.05-18.43)$.

\section{Chapter 6. Left atrial appendage occlusion (LAAO) vs oral anticoagulants: doubts and unresolved issues regarding existing data SECTION 1. LAAO vS SYSTEMIC ANTICOAGULATION GENERAL POINTS}

While the results of the studies and registries are summarised in Chapter 5, the current chapter aims to present a critical appraisal of the data forming the basis for current use and approvals for left atrial appendage (LAA) occluders.

The principle of left atrial appendage occlusion (LAAO) is generally accepted as a therapy for patients at high risk of atrial fibrillation (AF)-related thromboembolism who are unable to tolerate long-term treatment with oral anticoagulation. After considerable hesitation, regulators accepted this concept from data derived from prospective randomised trials comparing the WATCHMAN device against standard dose-adjusted warfarin therapy. The initial reluctance of regulators to accept this conclusion raises concerns and stimulates a critical appraisal of the relevant data in order to appreciate why the headline results of the trials should not be readily accepted.

Embolic and bleeding events in patients with $\mathrm{AF}$ remain relatively rare events. Whilst the non-vitamin $\mathrm{K}$ dependent oral anticoagulants (NOAC) vs warfarin trials ${ }^{130-133}$ recruited tens of thousands of patients, the pivotal trials underpinning LAAO, PROTECT AF ${ }^{115}$ and PREVAIL ${ }^{6}$, enrolled only 730 and 382 patients, respectively. The smaller sample sizes of the LAAO trials diminish confidence in detecting differences in rates of infrequently occurring events.

Besides sample size, other aspects that diminish confidence in the WATCHMAN trials relative to NOAC trials include laxer non-inferiority margins and the addition of cardiovascular (CV)/ unexplained death. Whilst the RELY ${ }^{130}$ and ARISTOTLE ${ }^{132}$ trials used a non-inferiority risk ratio of 1.46 and 1.44, respectively, the 
PROTECT AF and PREVAIL trials employed a laxer margin of 2.0 and 1.75 , respectively. The choice to include CV/unexplained death, an event unlikely to be affected by either treatment arm, biases towards non-inferiority.

\section{SPECIFIC LIMITATIONS OF PROTECT AF}

In PROTECT AF, lower rates of haemorrhagic stroke and $\mathrm{CV} /$ unexplained death drove the superiority of WATCHMAN over warfarin in the primary endpoint ${ }^{106}$. It is possible that these findings occurred by chance. PROTECT AF found an $85 \%$ reduction in the rate of haemorrhagic stroke with WATCHMAN vs warfarin $(0.2 \%$ vs $1.1 \%)$. However, the $1.1 \%$ rate of haemorrhagic stroke in the warfarin arm is unprecedented. The rate of haemorrhagic stroke in the warfarin arms of more than 38,000 patients enrolled in contemporary clinical trials ranges from $0.36 \%-0.5 \%{ }^{130-135}$.

In addition to the play of chance, Food and Drug Administration (FDA) reviewers noted uneven adjudication of haemorrhagic strokes in PROTECT $\mathrm{AF}^{136}$. Of the 10 events labelled haemorrhagic strokes in the warfarin group, five occurred after falls and four were associated with subdural haematoma. However, three WATCHMAN participants who fell and suffered subdural haematomas were not adjudicated as having a haemorrhagic stroke. Other reasons to doubt the haemorrhagic stroke signal of PROTECT AF include non-use of warfarin in one subject with intracranial haemorrhage ( $\mathrm{ICH})$, absence of imaging in one patient with adjudicated $\mathrm{ICH}$ and concomitant use of antiplatelet drugs in several patients. Finally, no haemorrhagic strokes were noted in the (higher-risk) warfarin arm of PREVAIL ${ }^{108}$.

The other driver of superiority of WATCHMAN in PROTECT $\mathrm{AF}$ was CV/unexplained death (1.0\% vs $2.4 \%)$. Two lines of evidence raise the possibility that this $60 \%$ reduction could be spurious: first, the $1.0 \%$ rate of CV death in the WATCHMAN arm is substantially lower than that reported in trials enrolling patients with similar $\mathrm{CHA}_{2} \mathrm{DS}_{2}$-VASC scores. The active treatment arms of RELY and ARISTOTLE had CV death rates of $2.7 \%$ and $1.8 \%$, respectively ${ }^{130,132}$. Second, and most persuasively, an FDAmandated inspection of all deaths in PREVAIL revealed that none could be attributed to either WATCHMAN or warfarin ${ }^{136}$.

\section{QUESTIONS AND DOUBTS IN PREVAIL}

FDA reviewers mandated PREVAIL because of the uncertainties and high rates of procedural complications in PROTECT AF. Instead of confirming non-inferiority, PREVAIL revealed concerning signals of higher rates of ischaemic stroke in the WATCHMAN arm.

This higher rate of ischaemic stroke in the WATCHMAN arm of PREVAIL resulted in an 18-month rate ratio of 1.33 (95\% credible interval: 0.78 to 2.13 ) in the first co-primary endpoint, a composite of stroke, systemic embolism, and CV/unexplained death. The upper bound of the credible interval (2.13) exceeded the non-inferiority margin of 1.75 , and WATCHMAN did not reach statistical non-inferiority.

PREVAIL also included a second co-primary efficacy endpoint of ischaemic stroke or systemic embolism more than seven days after the procedure. The absolute risk difference for WATCHMAN vs warfarin was 1.2 with a $95 \%$ credible interval of $0.36-2.75$. Since it was agreed that non-inferiority could be met if the $95 \%$ upper bound of the credible interval was at or below $2.75 \%$ for the absolute risk difference, WATCHMAN just made non-inferiority for this second co-primary endpoint.

It should be noted, however, that in the selection of non-inferiority based on risk differences the investigators expected an event rate of $4 \%$ for the active control arm. As it turned out, the observed event rate in the warfarin arm was $2 \%$ at the January 2013 follow-up and 1,35\% at the five-year follow-up. Fixing the non-inferiority margin as a risk difference rather than a risk ratio biases towards non-inferiority when the observed rate of events is less than expected (Table 11).

In the more stringent category of rate ratio - a measure of relative risk- the rate of late ischaemic events was more than twofold higher in the WATCHMAN arm. The rate ratio of 2.2 included $95 \%$ credible intervals of 0.8 to 4.9 . Thus, inferring non-inferiority based on absolute risk differences requires acceptance that WATCHMAN may be nearly fivefold worse than warfarin.

\section{INCONCLUSIVE WATCHMAN META-ANALYSES}

Two meta-analyses of PROTECT AF and PREVAIL ${ }^{6,137}$ reveal a similar pattern of results from the original trial: higher rates of ischaemic stroke, and lower rates of haemorrhagic stroke and CV/unexplained death. Neither meta-analysis reported absolute numbers of events or heterogeneity. An independent patient-level meta-analysis found an $\mathrm{I}^{2}$ value of $66 \%$ for the primary composite efficacy endpoint ${ }^{138}$. Small numbers of endpoints and high heterogeneity limit conclusions from the published WATCHMAN meta-analysis.

Table 11. PREVAIL: co-primary late ischaemic efficacy endpoint. Ischaemic stroke/systemic embolism excluding the first 7 days after randomisation.

\begin{tabular}{|c|c|c|c|c|c|c|}
\hline Data points & $\begin{array}{l}\text { Device } \\
\text { 18-month rate }\end{array}$ & $\begin{array}{l}\text { Warfarin } \\
\text { 18-month rate }\end{array}$ & $\begin{array}{l}\text { 18-month rate } \\
\text { diff } 95 \% \mathrm{Cl}\end{array}$ & $\begin{array}{c}\text { NI criteria met upper } \\
<1.75 \text { risk ratio }\end{array}$ & $\begin{array}{l}\text { 18-month rate } \\
\text { diff } 95 \% \mathrm{Cl}\end{array}$ & $\begin{array}{c}\text { NI criteria met upper } \\
<2.75 \text { rate diff }\end{array}$ \\
\hline Jan 2013 & $2.5 \%$ & $2.0 \%$ & $1.6(0.5-4.2)$ & No & $53 \%(0.19-2.73)$ & No \\
\hline June 2014 & $2.9 \%$ & $1.3 \%$ & $2.8(0.9-7.3)$ & No & $1.6 \%(0.23-3.42)$ & No \\
\hline 5-year & $2.5 \%$ & $1.3 \%$ & $2.2(0.8-4.9)$ & No & $1.2 \%(0.36-2.75)$ & Yes \\
\hline
\end{tabular}




\section{SECTION 2. DOES LAAO REDUCE MAJOR BLEEDING?}

One of the major arguments offered for LAAO is avoidance of systemic anticoagulation. However, in the most recent WATCHMAN meta-analysis, including five-year data, rates of major bleeding in the WATCHMAN and warfarin arms were not statistically differ$e^{2} t^{6}$. FDA reviewers confirmed this finding in their review of the CAP registry. In this registry of patients (mean age -74 ; $\mathrm{CHADS}_{2}$ -2.4) who received the WATCHMAN device, major bleeding occurred in $13.3 \%$ of patients (rate of $4.0 \%$ per patient years), which was higher than the rates of major bleeding in the warfarin arms of PROTECT AF (11.9\%) and PREVAIL (10.1\%) ${ }^{136}$.

Major bleeding after LAAO (Table 12) probably stems from efforts to counter device-related thrombus (DRT) with antiplatelet agents. The Apixaban Versus Acetylsalicylic Acid [ASA] to Prevent Stroke in Atrial Fibrillation Patients Who Have Failed or Are Unsuitable for Vitamin K Antagonist Treatment (AVERROES) trial enrolled more than 5,500 patients with AF who were at increased risk of stroke and for whom oral anticoagulation (OAC) was unsuitable (similar to those currently referred for LAAO) and reported major bleeding rates of $1.4 \%$ per year on apixaban and $1.2 \%$ per year on acetylsalicylic acid (ASA) $(p=0.57)^{139}$. Similarly, in the Birmingham Atrial Fibrillation Treatment of the Aged Study (BAFTA), elderly patients with AF treated with ASA had similar rates of extracranial and intracranial haemorrhage compared with patients treated with well-managed warfarin (with good time in target range [TTR] $)^{134}$. Long-term treatment with ASA following LAAO is still an open issue and needs to be established. Given that some operators leave patients on ASA long term post LAAO implantation, the question arises if patients can tolerate long-term ASA, why not warfarin with good anticoagulation control (high TTR) or a NOAC?

Recent reports on DRT necessitating intensification of antithrombotic treatment raise some concerns. An analysis from WATCHMAN trials reported a $3.7 \%$ rate of DRT, which was associated with a greater than threefold risk of all-cause stroke/systemic embolism $^{98}$. A retrospective review of consecutive patients receiving LAAO from eight centres in France reported a 7.2\% per year incidence of DRT ${ }^{100}$. Protective factors for DRT included remaining on DAPT (HR $0.10,95 \% \mathrm{CI}: 0.01$ to $0.76 ; \mathrm{p}=0.03$ ) and OAC at discharge (HR $0.26,95 \% \mathrm{CI}: 0.09$ to $0.77 ; \mathrm{p}=0.02$ ).

\section{SECTION 3. UNCERTAINTY IN ANTICOAGULATION INELIGIBLE PATIENTS}

There is an unmet need for stroke prevention in anticoagulation-ineligible patients; however, these patients were excluded from the randomised controlled trials. One hypothesis is that anticoagulation-ineligible patients would benefit from some degree of protection from LAAO.

An alternative hypothesis is that LAAO would be inferior to no therapy in higher-risk patients. Evidence for this hypothesis stems from the systemic nature of stroke (e.g., atherosclerosis, coagulation disorders, and increased platelet aggregation), the limitations of PROTECT AF, the increased signal of ischaemic stroke in PREVAIL, and the bleeding-risk trade-offs of antiplatelet therapy. What is more, even if LAAO reached equipoise with no antithrombotic therapy, one must also factor in the procedural risks of LAAO. Excluding voluntary industry-sponsored registries, the summary of procedural risks from PROTECT AF, PREVAIL, $\mathrm{ASAP}^{91}$, and $\mathrm{CAP} 2^{98}$ was $6 \%$. A major complication rate so high creates a strong counterforce against future benefit in stroke prevention and the need to await ongoing randomised trials of LAAO in ineligible patients.

\section{UNCERTAINTIES WITH LAAO REGISTRY STUDIES}

A recent systematic review of observational studies of LAAO in 1,107 patients (mean CHADS, score 2.7) reported high adverse event rates of $23.5 \%$ for AMPLATZER, $13.6 \%$ for WATCHMAN, and $18.8 \%$ for studies including multiple technologies ${ }^{125}$. A more recent registry, EWOLUTION, enrolled higher-risk patients (average $\mathrm{CHA}_{2} \mathrm{DS}_{2}$-VASc $4.5 \pm 1.6$ ), more than half of whom were deemed not eligible for OAC. Successful device implantation occurred in $98.5 \%$ of subjects and procedure- and/or devicerelated severe adverse events within the first seven days occurred at a rate of $2.8 \%{ }^{112}$. A retrospective registry of LAAO using multiple technologies from eight centres in the UK reported a $92.5 \%$ procedural success rate and a complication rate of $3.5 \%{ }^{123}$.

Most of these studies report stroke and bleeding events over varying follow-up periods. A previously published Nordic propensity-matched study suggested the benefit of LAAO compared to standard medical therapy in AF patients with a prior $\mathrm{ICH}^{119}$. The use of historical control groups is problematic because of wide variation in the reported rates of stroke across cohorts of patients with $\mathrm{AF}^{140}$. What is more, many of the observational studies, including EWOLUTION, do not mandate consecutive enrolment of patients, raising the likelihood of selection bias.

\section{NO COMPARISONS WITH NOACS}

In the randomised controlled trials of LAAO vs warfarin, noninferiority of the device was driven by a reduction in haemorrhagic stroke and cardiovascular death. Evidence from numerous randomised controlled trials of more than 50,000 patients shows that direct-acting oral anticoagulants are superior to warfarin in efficacy and safety, especially in the reduction of haemorrhagic stroke ${ }^{141}$. There are currently no comparisons of LAAO with NOACs.

Table 12. Major bleeding in different trials.

\begin{tabular}{|l|c|c|c|c|c|c|c|}
\hline & $\begin{array}{c}\text { Device group } \\
\text { PROTECT and } \\
\text { PREVAIL }\end{array}$ & $\begin{array}{c}\text { Control group } \\
\text { PROTECT and } \\
\text { PREVAIL }\end{array}$ & $\begin{array}{c}\text { CAP registry } \\
\text { First major } \\
\text { bleeding }\end{array}$ & $\begin{array}{c}\text { AVERROES } \\
\text { Apixaban }\end{array}$ & $\begin{array}{c}\text { AVERROES } \\
\text { Acetylsalicylic } \\
\text { acid }\end{array}$ & $\begin{array}{c}\text { BAFTA } \\
\text { Warfarin }\end{array}$ & $\begin{array}{c}\text { BAFTA } \\
\text { ASA }\end{array}$ \\
\hline Major bleeding, all & $3.1 \%$ & $3.5 \%$ & $4.0 \%$ & $1.4 \%$ & $1.2 \%$ & $1.4 \%$ & $1.6 \%$ \\
\hline
\end{tabular}


The concerns outlined above must be fully addressed to justify the ultimate acceptance of this therapy. Although the analysis is harsh and highly critical, it forms the basis for doubt about the value of the therapy. This section on the need for more convincing evidence is included in this manuscript to allow readers to appreciate that much needs to be accomplished before guidelines can strongly recommend LAAO as an appropriate therapy, even in patients for whom traditional OAC is contraindicated.

The procedure of LAA occlusion was approved by the FDA in 2015 for "patients with AF and increased risk for stroke who are deemed by their physicians to be suitable for warfarin and have an appropriate rationale to seek a nonpharmacologic alternative to warfarin". Notably, the British approach was much more conservative. In 2010 the National Health Service (NHS) in England, guided by the perceived weakness of evidence and high rate of complications, approved LAA occlusion only for commissioning thorough evaluation. This process enabled a limited number of carefully selected patients to undergo the procedure through a limited formal evaluation programme in specific institutions. This evaluation process was recently concluded in 525 patients who were followed for up to two years ${ }^{142}$. This evaluation resulted in an NHS recommendation to use LAA occluders only in patients in whom anticoagulation is not possible, notwithstanding that firm evidence from randomised controlled trials is still lacking.

\section{Chapter 7. Consensus update, LAA - indication}

In patients with non-valvular atrial fibrillation (AF) and a $\mathrm{CHA}_{2} \mathrm{DS}_{2}$-VASc score $\geq 2$ (3 in females), prevention against stroke and embolism is indicated. Currently, the standard therapy is oral anticoagulation (OAC).

Indication for LAAO device implantation will be discussed for the following five clinical situations:

- Patients with non-valvular AF who are eligible for chronic longterm OAC

- Patients with a contraindication for OAC

- Patients with an elevated bleeding risk under chronic OAC

- Non-compliant patients (unwilling or unable to take OAC)

- Specific subgroups:

a. OAC not efficient ("stroke on OAC")

b. Electrically isolated left atrial appendage post catheter ablation

c. Combination of AF ablation and LAA occluder implantation

d. LAA closure for "primary primary" prevention

\section{PATIENTS WITH NON-VALVULAR ATRIAL FIBRILLATION WHO} ARE ELIGIBLE FOR LONG-TERM ORAL ANTICOAGULATION

Patients with AF who are eligible for long-term OAC are the only patient group prospectively studied in two randomised controlled trials: the PROTECT AF and PREVAIL studies. These studies are described in detail in Chapter 5.

The PROTECT trial long-term data revealed a non-inferiority of the LAAO therapy compared to warfarin for preventing the combined outcome of stroke, systemic embolism, and cardiovascular death, as well as superiority for cardiovascular and all-cause mortality ${ }^{107}$.

The final results of the PREVAIL study as well as a meta-analysis which included the data from the PROTECT AF study at a follow-up time of five years were recently published ${ }^{6}$. Notably, the PREVAIL trial failed to show non-inferiority of LAAO regarding the first composite co-primary endpoint of stroke, systemic embolism (SE), or cardiovascular/unexplained death. The second co-primary endpoint of post-procedure ischaemic stroke/SE did achieve non-inferiority in the meta-analysis. The composite endpoints were similar between groups. The ischaemic stroke/SE rate was numerically higher with LAAO, but this difference did not reach statistical significance (HR 1.71, 95\% CI: 0.78-2.13; $\mathrm{p}=0.080$ ); however, differences in haemorrhagic stroke, disabling/ fatal stroke, cardiovascular/unexplained death, all-cause death, and post-procedure bleeding favoured LAAO.

The results of the two studies were scrutinised by various authorities and raised debates and queries that are summarised in Chapter 6. They were also expressed in the UK NICE position paper regarding funding of the procedure. Nevertheless, LAAO for this population was approved by the FDA based on these two studies and their respective continued access registries. All available randomised data demonstrating non-inferiority used the WATCHMAN device for LAA occlusion; however, due to the results of large registries using the WATCHMAN and the AMPLATZER family, there was no suggestion of a relevant difference between the devices. We therefore do not feel obliged to make recommendations to use one device or another. The study comparing both devices, the Amulet IDE trial (NCT02879448) is currently recruiting.

It is important to mention that the studies compared LAAO to warfarin but NOACs are currently being used, with better efficacy and safety than warfarin. Therefore, one cannot assume non-inferiority of LAAO against NOACs.

These data of patients eligible for LAAO as well as the questions raised regarding the data, and the contemporary widespread use of NOACs are leading to the current consensus statement regarding clinical decision making. In general, the authors agree that patients who have no significantly increased risk for bleeding should primarily receive oral anticoagulation due to the compelling data and clinical experience with these drugs to prevent stroke and embolism. LAAO should not be offered in those patients as a simple and equal alternative (Table 13). However, there are patients - even at a low bleeding risk- who, despite thorough explanation of the favourable results and the much stronger evidence base on NOACs in AF, indicate that they are not willing or able to take medication regularly. Implantation of an LAA occluding device might possibly be an alternative treatment given the PROTECT AF and PREVAIL data (Figure 22, Table 13).

The authors agree that AF patients with an indication for stroke prevention due to their risk profile for stroke should not be left untreated (Table 13). When both OAC and any antithrombotic 


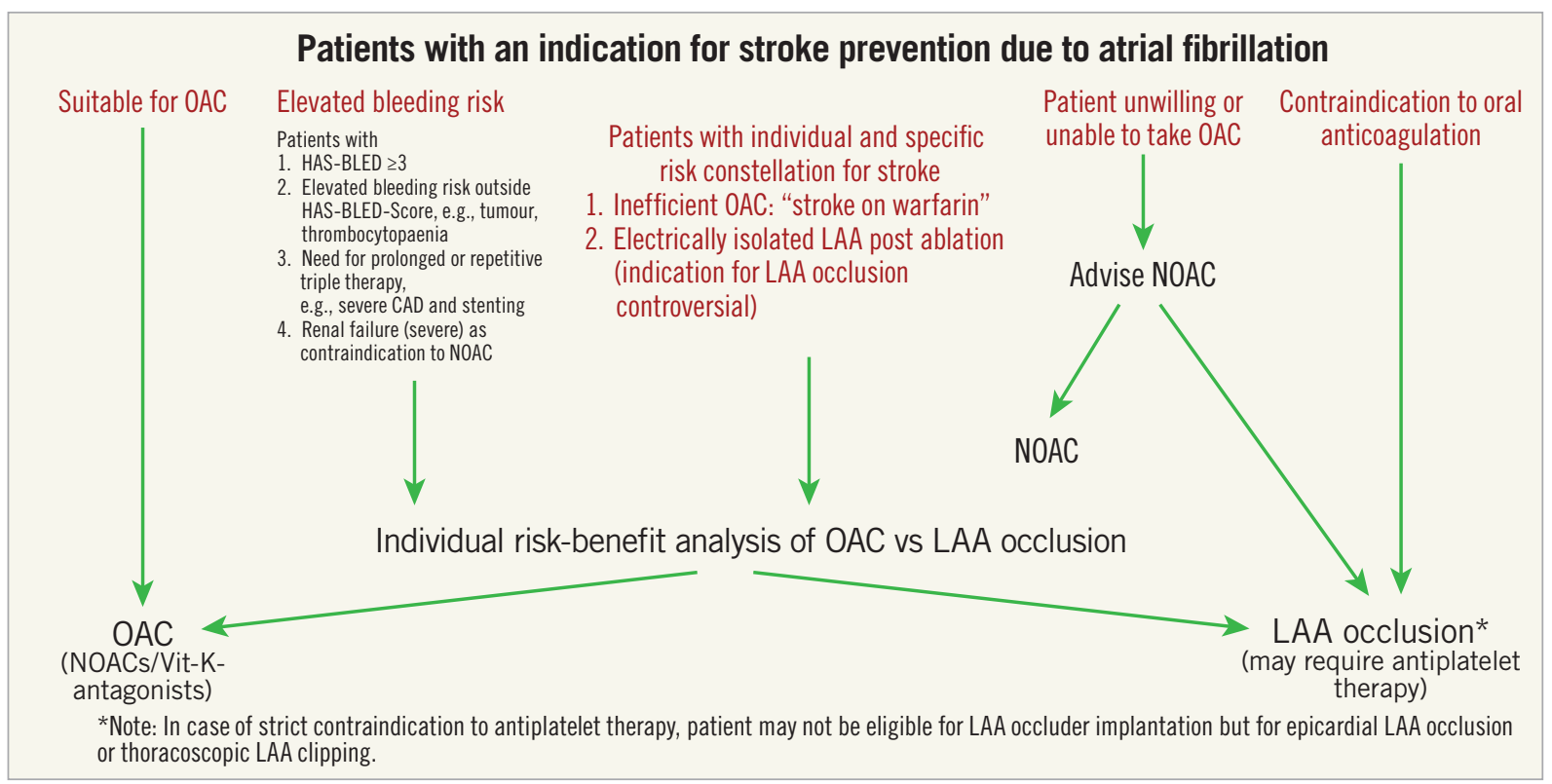

Figure 22. Decision tree for LAA closure.

Table 13. Patients who are eligible for long-term oral anticoagulation and who require prevention of stroke and embolism.

\begin{tabular}{|c|c|c|}
\hline $\begin{array}{l}\text { Clinical situation and therapeutic } \\
\text { concept }\end{array}$ & $\begin{array}{l}\text { Consensus } \\
\text { statement }\end{array}$ & Icon \\
\hline $\begin{array}{l}\text { According to current guidelines, } \\
\text { patients who are eligible for long-term } \\
\text { OAC and who also require prevention } \\
\text { of stroke and embolism should receive } \\
\text { OAC, preferably NOAC therapy }\end{array}$ & $\begin{array}{l}\text { "Should do } \\
\text { this" }\end{array}$ & \\
\hline $\begin{array}{l}\text { Patients who are eligible for long-term } \\
\text { OAC and who also require prevention } \\
\text { of stroke and embolism may receive } \\
\text { an LAAO instead of long-term OAC } \\
\text { only if they refuse OAC despite } \\
\text { explanation }\end{array}$ & "May do this" & \\
\hline \multicolumn{3}{|c|}{$\begin{array}{l}\text { LAAO: left atrial appendage occlusion; NOAC: non-VKA oral antagonists; } \\
\text { OAC: oral anticoagulation }\end{array}$} \\
\hline
\end{tabular}

are totally contraindicated, rather than leave the patient untreated, one may consider epicardial closure, although thrombus formation has previously been described also on epicardial closure. If 2-4 weeks of antithrombotic treatment (even single antiplatelet treatment, preferably Plavix) are deemed possible, then an endocardial device implantation is possible, albeit at a somewhat higher risk of thromboembolic complication (see Chapter 8 for further discussion).

\section{PATIENTS WITH A CONTRAINDICATION TO ORAL ANTICOAGULATION}

There is currently no clear-cut definition of an "absolute" contraindication to $\mathrm{OAC}$ in the field of stroke prevention in $\mathrm{AF}$ patients. However, there are clinical conditions where the majority of clinicians agree that the administration of chronic $\mathrm{OAC}$ is contraindicated, mainly due to an excessively high risk of major, especially life-threatening or disabling bleeding (Table 14).

Those patients are currently prospectively studied in the ASAP-TOO trial (NCT02928497) ${ }^{143}$ and, in part, in the ongoing CLOSURE-AF trial (NCT03463317) (personal communication). However, we know from various registries such as the $\mathrm{ACP}$ and EWOLUTION registries, reviewed in Chapter 5, that safety and efficacy of occluder devices in those patients generated a favourable outcome. Thus, in patients with a contraindication to long-term oral anticoagulation, LAAO may be a recommended therapeutic alternative and should be performed instead of no treatment (Figure 22, Table 15).

The majority of centres keep their post-occluder implantation patients on dual or single antiplatelet therapy for variable time, and some centres terminate all antiplatelets after 3 or 6 months post implant. It is currently not clear if there is a need for longterm antiplatelet therapy, mainly due to the limited number of patients with a bleeding risk. (Chapter $\mathbf{8}$ for the discussion of postimplantation antithrombotic management).

The bleeding risk of ASA alone was significantly lower as compared to rivaroxaban, given at even lower doses than in atrial $\mathrm{AF}^{144}$.

Table 14. Medical conditions which represent contraindications to long-term oral anticoagulation.

- Risk for major bleeding, especially life-threatening or disabling bleeding due to an "untreatable" source of

- Intracranial/intraspinal bleeding (e.g., diffuse amyloid angiopathy, untreatable vascular malformation)

- Severe gastrointestinal (e.g., diffuse angiodysplasia) pulmonary or urogenital source of bleeding that cannot be corrected

- Severe side effects under vitamin $\mathrm{K}$ antagonists and/or contraindication for NOAC 
Table 15. Atrial fibrillation patients who are not eligible ("contraindicated") for long-term oral anticoagulation and require prevention of stroke and embolism.

\begin{tabular}{|c|c|c|}
\hline $\begin{array}{l}\text { Clinical situation and therapeutic } \\
\text { concept }\end{array}$ & $\begin{array}{l}\text { Consensus } \\
\text { statement }\end{array}$ & Icon \\
\hline $\begin{array}{l}\text { AF patients with } \mathrm{CHA}_{2} \mathrm{DS}_{2} \text {-VASc } \\
\text { score } \geq 2 \text { ( } 3 \text { in females) who have } \\
\text { absolute contraindications for } \\
\text { long-term OAC may be considered for } \\
\text { LAAO if a minimum period } \\
\text { ( } 2-4 \text { weeks) of a single antiaggregant } \\
\text { can be given }\end{array}$ & $\begin{array}{l}\text { "Should do } \\
\text { this" }\end{array}$ & \\
\hline
\end{tabular}

The AVERROES trial demonstrated a similar major bleeding risk for ASA as compared to apixaban; however, this was only true for the intention-to-treat analysis; on-treatment, ASA showed a significantly lower overall bleeding rate ${ }^{139}$. In the BAFTA trial, ASA $75 \mathrm{mg}$ and well-managed warfarin had similar risks of major bleeding and intracranial haemorrhage ${ }^{145}$.

Secondly, for the few patients who may not tolerate any antiplatelet therapy, either an epicardial catheter approach (e.g., the LARIAT system) or thoracoscopic clipping of the LAA might be options ${ }^{12}$. If a single antiaggregant cannot be given to the patient, even for two weeks at least, then it is the consensus among the authors of this document that an endocardial device should not be implanted.

\section{PATIENTS WITH AN ELEVATED BLEEDING RISK UNDER CHRONIC ORAL ANTICOAGULATION}

Patients with an elevated bleeding risk during long-term oral anticoagulation are listed in Table 5. This patient group has so far never been studied in a prospective randomised trial; the currently recruiting CLOSURE-AF trial (NCT03463317) is randomising those patients.

Notably, in patients with a history of severe bleeding on oral anticoagulation, the circumstances around the bleeding event (e.g., inappropriate high INR levels under warfarin; transient factors for increased bleeding risk) should be carefully evaluated and considered before defining the patient as high bleeding risk. In such cases continuation of appropriate OAC/NOAC therapy or LAAO should be carefully balanced.

High bleeding risk patients were included in major registries such as the ACP, the Amulet and the EWOLUTION registries and therefore a positive effect of occluding device implantation may be evident - with all the limitations that are inherent to registry data.

Among 787 survivors of an intracranial bleed and AF, two cohorts (one with LAA occluder, the other with conservative treatment) were identified using propensity matching to balance for stroke and bleeding risk ${ }^{119}$. The primary outcome was a composite of all-cause mortality, acute ischaemic stroke and major bleeding. The results were clearly in favour of LAA occluder treatment in terms of ischaemic stroke, recurrent haemorrhagic stroke, major bleeding, and survival. These results triggered the STROKECLOSE trial (NCT02830152) which is randomising those patients.

A similar clinical challenge is given in patients with previous major gastrointestinal (GI) bleeding. In particular, patients where a potential future bleeding source cannot be fully eliminated (e.g., diffuse angiodysplasia) may benefit from LAAO. The clinical applicability and positive effect on stroke and bleeding rate were demonstrated in a recent registry analysis ${ }^{146}$.

Patients with end-stage renal disease or on haemodialysis treatment represent a cohort with several "therapy dilemmas": on the one hand, it is known that those patients with AF have a high event rate including embolic stroke; on the other hand, most NOACs are contraindicated (although observational data with apixaban in haemodialysis patients are promising) ${ }^{147}$ and warfarin may generate more harm than benefit if anticoagulation control is poor. In studies with good warfarin control (high TTR), there is a reduction in ischaemic stroke and acceptable bleeding risks even in dialysis patients ${ }^{148}$. This makes it understandable why those patients might benefit significantly from $\mathrm{LAAO}^{149}$ : it avoids long-term warfarin (or the possibly unsafe use of unproven low-dose NOACs) therapy, whereas many end-stage renal disease patients need antiplatelet therapy anyway (which is part of the routine post-LAAO drug regimen in many countries).

The authors therefore agree that in the patient group with an elevated bleeding risk an individual risk-benefit assessment needs to be carried out on an individual patient basis (Table 16). A decision has to be made between LAAO and medication. There are specific subgroups within those patients who have an elevated bleeding risk, where specific registry data indicate a favourable outcome with LAAO, such as in patients post intracranial bleeding and in patients post severe GI bleeding due to an uncorrectable source.

\section{NON-COMPLIANT PATIENTS (UNWILLING OR UNABLE TO TAKE ORAL ANTICOAGULATION)}

Non-compliance with chronic drug treatment is a major problem and affects all areas of chronic cardiovascular treatments such as statins, antihypertensive, and anticoagulation therapy.

Table 16. Patients with an elevated bleeding risk during long-term oral anticoagulation.

\begin{tabular}{|l|l|l|}
\hline \multicolumn{1}{|c|}{$\begin{array}{c}\text { Clinical situation and therapeutic } \\
\text { concept }\end{array}$} & $\begin{array}{c}\text { Consensus } \\
\text { statement }\end{array}$ & Icon \\
\hline $\begin{array}{l}\text { In patients with an elevated bleeding } \\
\text { risk during long-term oral } \\
\text { anticoagulation (e.g., post intracranial } \\
\text { bleeding) an individual risk-benefit } \\
\text { assessment needs to be carried out } \\
\text { between oral anticoagulation and LAA } \\
\text { occlusion }\end{array}$ & $\begin{array}{c}\text { "Should do } \\
\text { this" }\end{array}$ & \\
\hline $\begin{array}{l}\text { In patients with an elevated bleeding } \\
\text { risk during long-term OAC, LAA } \\
\text { occlusion may be considered }\end{array}$ & "May do this" & \\
\hline OAC: oral anticoagulation & \\
\hline
\end{tabular}


For example, in a registry of 2,932 patients, the two-year probability of dabigatran persistence was $69 \%{ }^{150}$.

We can distinguish four main variations of non-compliance: one due to the non-ability of a patient or their relatives to ensure daily drug treatment, mainly due to initial or advanced forms of dementia; second, the patient might be non-compliant due to an active lifestyle or stressful profession which finally leads to no or irregular drug intake; third, patients are not willing to take medications; and fourth, patients stop taking their medication triggered by a clinical event like minor bleeding or planned surgery. In the German LAARGE registry, patient choice was a major reason for LAAO in $20 \%$ of cases ${ }^{151}$.

Non-compliance is a relevant and important aspect in the area of drug treatment in AF treatment. There are no conclusive or randomised data sets as to whether those non-compliant patients due to the various reasons mentioned above - benefit from LAAO. However, a patient with a significant stroke risk due to AF should benefit from excluding the LAA from the blood circulation as compared to no treatment. Therefore, in patients with non-compliance, attempts should be made to overcome the reason resulting in non-compliance; if this is not successful, LAAO may be considered in such patients (Figure 22, Table 17).

However, in patients who are opposed to chronic drug intake but can be convinced to take the medication after appropriate information, LAAO is currently not offered as a simple and equally effective alternative.

While such a decision may be evidence-based, the question of whether financial coverage of LAAO for intentionally non-compliant patients is justified is a societal decision that is beyond the scope of this document.

Table 17. Non-compliant patients (unwilling or unable to take oral anticoagulation).

\begin{tabular}{|c|c|c|}
\hline $\begin{array}{l}\text { Clinical situation and therapeutic } \\
\text { concept }\end{array}$ & $\begin{array}{l}\text { Consensus } \\
\text { statement }\end{array}$ & Icon \\
\hline $\begin{array}{l}\text { Any AF patients with an increased risk } \\
\text { for stroke and embolism and no } \\
\text { contraindication for OAC should } \\
\text { receive personal and detailed advice } \\
\text { that according to current evidence } \\
\text { long-term OAC treatment is the } \\
\text { preferred prophylactic strategy. }\end{array}$ & "Should do this" & \\
\hline $\begin{array}{l}\text { In AF patients with a high risk score } \\
\text { for stroke and embolism who refuse } \\
\text { OAC even after personal and detailed } \\
\text { advice, LAA occlusion may be } \\
\text { considered }\end{array}$ & "May do this" & \\
\hline $\begin{array}{l}\text { In patients with documented } \\
\text { non-compliance, LAA occlusion can be } \\
\text { discussed as a therapeutic alternative } \\
\text { after attempts to resolve the reasons } \\
\text { for non-compliance }\end{array}$ & "May do this" & \\
\hline $\begin{array}{l}\text { In patients who are opposed to chronic } \\
\text { drug intake, LAA occlusion is currently } \\
\text { not offered as a simple and equally } \\
\text { effective treatment alternative }\end{array}$ & $\begin{array}{l}\text { "Should not do } \\
\text { this" }\end{array}$ & \\
\hline $\begin{array}{l}\text { AF: atrial fibrillation; LAA: left atrial app } \\
\text { anticoagulation }\end{array}$ & age; OAC: oral & \\
\hline
\end{tabular}

\section{SPECIFIC SUBGROUPS: SEVERAL SMALL-SCALE STUDIES AND CASE SERIES DESCRIBED THE USE OF LAAO IN THE FOLLOWING SPECIFIC SUBGROUPS. DATA ARE NOT ROBUST ENOUGH TO MAKE SPECIFIC RECOMMENDATIONS}

\section{a. Oral anticoagulation not efficient ("stroke on OAC")}

Patients who - by clinical judgement - have embolic strokes with a high likelihood that the embolism originates from the LAA (e.g., mobile thrombus in the LAA) despite adequate oral anticoagulation ("malignant LAA") are normally treated with a more intensified anticoagulation strategy. To avoid the necessity of chronic dual or triple therapy, LAAO is a potential alternative and clinically used in such patients; however, data are insufficient to make specific recommendations (Figure 22).

\section{b. Electrically isolated left atrial appendage post catheter ablation}

Patients who underwent electrical isolation of the LAA as part of a left-sided AF ablation procedure exhibit an increased risk of stroke despite oral anticoagulation ${ }^{15}$. Other series were less decisive about this issue ${ }^{152-154}$. This may be related to different methods used to isolate the LAA in the studies (circular LAA isolation around the LAA base versus a wide area of LAA isolation). Two recently published studies reported an increased incidence of LAA thrombus formation/thromboembolism event after LAA isolation $^{120,155}$. Currently, data are scarce, and there are no randomised studies available comparing oral anticoagulation against LAA occluder implantation; however, due to clinical experience LAAO implantation may be a reasonable way to prevent patients with an electrically isolated LAA from stroke, especially if their anticoagulation is imperfect. Data are insufficient to make specific recommendations among this group of patients.

\section{c. Combination of atrial fibrillation ablation and LAA occluder implantation}

In patients with an elevated bleeding and stroke risk who undergo left AF ablation, combining ablation and LAA occluder implantation in one procedure may be a "reasonable opportunity": AF ablation requires a transseptal approach, which allows additional occluder implantation using the same left atrial access and therefore avoids an additional procedure with TSP. Feasibility has been demonstrated in small cohorts, but outcome trials comparing one combined procedure to consecutive procedures are missing ${ }^{120,155-157}$. It needs to be emphasised that the indication for LAAO in high-risk patients should follow the same risk-benefit analysis as in patients without $\mathrm{AF}$ ablation. The fact that the operator is in the left atrium anyway should not lower the threshold for LAAO at the current stage of experience and data with the combined procedure. Therefore, the individual indication process is not substantially different, and so the combined procedure is not a separate indication per se. d. Left atrial appendage closure for "primary primary" prevention In selected cases, experienced operators perform LAA closure immediately before atrial septal defect closure in patients without a history of AF because of their high risk for developing AF and potential technical problems for later closure due to the septal device ${ }^{158}$. There are no data available supporting this approach, 
but "primary (no prior AF) primary (no prior stroke or bleeding)" LAA closure is common with cardiac surgery ${ }^{159,160}$.

\section{Chapter 8. Antithrombotic therapy after left atrial appendage closure}

The optimal post-interventional antithrombotic drug regimen as well as treatment duration after LAAO remain a controversial issue ${ }^{161}$. Since the majority of patients subjected to LAAO are at high risk for bleeding, the anticoagulation regimen should be tailored individually.

\section{BEFORE IMPLANTATION}

Mobile thrombus visualised by TOE screening or CCTA scan is considered a contraindication to catheter-based LAAO. In such cases, PTT-guided unfractionated heparin or weight-adjusted fractionated therapy is an option as well as $\geq 4$ weeks of OAC with VKA or NOAC. Both strategies may allow thrombus resolution to be documented on repeat TOE or CCTA before LAAO is performed. There is very limited experience on LAA closure in the presence of an immobile thrombus that sits deeply in the LAA which can be jailed within the LAA by a superficially implanted device. Information is insufficient to make recommendations at this point, but it can be assumed that LAAO in such a situation is quite common.

\section{DURING IMPLANTATION}

Femoral venous puncture by itself does not necessitate anticoagulant therapy withdrawal. Most operators use intravenous anticoagulation agents (mostly unfractionated heparin) during the procedure (Table 18). The antithrombotic protocol of the PROTECT AF study $^{106,162}$ instructed an INR $<2.0$ at the time of procedure. ASA 81-325 mg was begun at least one day before the procedure and weight-adjusted heparin (70-100 IU/kg) was administered after TSP to maintain an ACT $>200 \mathrm{~s}$ for the duration of the procedure ${ }^{106,162}$. However, some operators perform the procedure while patients are on VKA with a therapeutic INR or on NOAC, an approach that can neither be supported nor condemned by currently available data. Intravenous heparin is generally administered at the latest immediately after crossing the interatrial septum. A weight-adjusted bolus of unfractionated heparin (70-100 IU/ kg) is most commonly used, which should maintain an ACT $\geq 250 \mathrm{~s}$.

\section{PATIENTS WITHOUT CONTRAINDICATIONS TO ORAL ANTICOAGULATION}

In both the PROTECT AF and PREVAIL studies ${ }^{12,162}$, patients received a combination of oral anticoagulation using warfarin plus ASA $75 \mathrm{mg}$ for 45 days, followed by six months of dual platelet inhibition with clopidogrel $75 \mathrm{mg}$ and lifelong continuation of ASA $325 \mathrm{mg}$ /day alone. During evaluation at 45 days post implant, bleeding complications occurred in $1.2 \%$ of the patients treated with oral anticoagulation and ASA therapy, translating into an estimated annual bleeding rate of $10.5 \%$. In the following study period, when patients received dual platelet inhibition, $0.6 \%$ of patients had a bleeding event $(1.6 \% \text { per year })^{103}$. In the long term at five years, the overall annual risk of major bleeding was $3.1 \%{ }^{6}$. NOAC seems a possible alternative to warfarin for the initial period ${ }^{100,111,163,164}$. Overall, the above-mentioned drug regimen is feasible in patients eligible for OAC but is associated with a relatively high risk of bleeding events.

Table 18 (part 1). Antithrombotic therapy before and after LAAO.

\begin{tabular}{|c|c|c|c|}
\hline Clinical situation and therapeutic concept & $\begin{array}{l}\text { Consensus } \\
\text { statement }\end{array}$ & Symbol & References \\
\hline $\begin{array}{l}\text { Acetylsalicylic acid } 75-325 \mathrm{mg} / \text { day for the procedure and then continued long term (load } \\
300-500 \mathrm{mg} \text { prior to procedure if not previously on acetylsalicylic acid) }\end{array}$ & "Should do this" & & $\begin{array}{l}108,114 \\
100,170\end{array}$ \\
\hline $\begin{array}{l}\text { Anticoagulation, using unfractionated heparin, is recommended during the implantation } \\
\text { procedure prior to or immediately after TSP, aiming for an activated clotting time of }>250 \mathrm{~s}\end{array}$ & "Should do this" & & 106,111 \\
\hline $\begin{array}{l}\text { After WATCHMAN implantation, warfarin (INR 2-3) should be given for } 45 \text { days, followed by } \\
\text { clopidogrel for } 6 \text { months after the procedure in low bleeding risk group of patients, while in } \\
\text { high bleeding risk group OAC should not be applied }\end{array}$ & "Should do this" & & 106,108 \\
\hline NOAC is a possible alternative to warfarin after WATCHMAN implantation & "May do this" & & $155,163-165$ \\
\hline $\begin{array}{l}\text { After WATCHMAN implantation in patients not suitable for oral anticoagulation, DAPT } \\
\text { including clopidogrel } 75 \mathrm{mg} / \text { day for } 1 \text { to } 6 \text { months after the procedure (load } 300-600 \mathrm{mg} \\
\text { prior to procedure if not previously on clopidogrel) }\end{array}$ & "May do this" & & $106,108,171$ \\
\hline $\begin{array}{l}\text { After AMPLATZER Cardiac Plug or Amulet implantation, DAPT including clopidogrel } 75 \mathrm{mg} / \\
\text { day for } 1 \text { to } 6 \text { months after the procedure (load } 300-600 \mathrm{mg} \text { prior to procedure if not } \\
\text { previously on clopidogrel) }\end{array}$ & "May do this" & & 115,170 \\
\hline $\begin{array}{l}\text { Other options that may be considered on a case-by-case basis include a single antiplatelet } \\
\text { therapy (acetylsalicylic acid or clopidogrel) for short periods of time, as long as approved by } \\
\text { a team consensus }\end{array}$ & "May do this" & & 172 \\
\hline
\end{tabular}


Table 18 (part 2). Antithrombotic therapy during and after LAAO.

\begin{tabular}{|c|c|c|c|c|c|c|}
\hline Device/patient & $\begin{array}{c}\text { Heparin } \\
(\text { ACT } \geq 250)\end{array}$ & $\begin{array}{l}\text { Low-molecular- } \\
\text { weight heparin }\end{array}$ & $\begin{array}{c}\text { Acetylsalicylic } \\
\text { acid }\end{array}$ & OAC & Clopidogrel & Comments \\
\hline $\begin{array}{l}\text { WATCHMAN/low } \\
\text { bleeding risk }\end{array}$ & $\begin{array}{l}\text { Prior to or } \\
\text { immediately } \\
\text { after TSP }\end{array}$ & $\begin{array}{l}\text { Post-procedure } \\
\text { till INR } \geq 2 \text { for } \\
\text { warfarin }\end{array}$ & $\begin{array}{l}\text { Load } 300-500 \mathrm{mg} \\
\text { prior to procedure if } \\
\text { not on } \\
\text { acetylsalicylic acid, } \\
\text { continue } 75-325 \\
\mathrm{mg} / \text { day indefinitely }\end{array}$ & \begin{tabular}{|l|} 
Start warfarin after \\
procedure INR $2-3$ \\
till 45 days or \\
continue till \\
adequate occlusion \\
by TOE. NOAC are \\
possible alternatives
\end{tabular} & $\begin{array}{l}\text { Start } 75 \mathrm{mg} / \text { day } \\
\text { when }(\mathrm{N}) \mathrm{OAC} \\
\text { stopped, continue } \\
\text { till } 6 \text { months after } \\
\text { the procedure }\end{array}$ & $\begin{array}{l}\text { Some centres do } \\
\text { not withhold } \\
\text { (N)OAC at the time } \\
\text { of procedure (no } \\
\text { data to support or } \\
\text { deny this approach) }\end{array}$ \\
\hline $\begin{array}{l}\text { WATCHMAN/high } \\
\text { bleeding risk }\end{array}$ & $\begin{array}{l}\text { Prior to or } \\
\text { immediately } \\
\text { after TSP }\end{array}$ & None & $\begin{array}{l}\text { Load } 300-500 \mathrm{mg} \\
\text { prior to procedure if } \\
\text { not on } \\
\text { acetylsalicylic acid, } \\
\text { continue } 75-325 \\
\mathrm{mg} / \text { day indefinitely }\end{array}$ & None & $\begin{array}{l}\text { Load } 300-600 \mathrm{mg} \\
\text { prior to procedure if } \\
\text { not on clopidogrel, } \\
\text { continue } 75 \mathrm{mg} / \\
\text { day } 1-6 \text { months } \\
\text { while ensuring } \\
\text { adequate occlusion } \\
\text { and no device- } \\
\text { related thrombus }\end{array}$ & $\begin{array}{l}\text { Clopidogrel often } \\
\text { given for shorter } \\
\text { time in very } \\
\text { high-risk situations, } \\
\text { clopidogrel may } \\
\text { replace long-term } \\
\text { acetylsalicylic acid } \\
\text { if better tolerated }\end{array}$ \\
\hline ACP/Amulet & $\begin{array}{l}\text { Prior to or } \\
\text { immediately } \\
\text { after TSP }\end{array}$ & None & $\begin{array}{l}\text { Load } 300-500 \mathrm{mg} \\
\text { prior to procedure if } \\
\text { not on } \\
\text { acetylsalicylic acid, } \\
\text { continue } 75-325 \\
\mathrm{mg} / \text { day indefinitely }\end{array}$ & None & $\begin{array}{l}\text { Load } 300-600 \mathrm{mg} \\
\text { prior to procedure if } \\
\text { not on clopidogrel, } \\
\text { continue } 75 \mathrm{mg} / \\
\text { day } 1-6 \text { months } \\
\text { while ensuring } \\
\text { adequate occlusion } \\
\text { and no device- } \\
\text { related thrombus }\end{array}$ & $\begin{array}{l}\text { Clopidogrel often } \\
\text { given for shorter } \\
\text { time in very } \\
\text { high-risk situations, } \\
\text { clopidogrel may } \\
\text { replace long-term } \\
\text { acetylsalicylic acid } \\
\text { if better tolerated }\end{array}$ \\
\hline
\end{tabular}

aLess than $5 \mathrm{~mm}$ leak. ACP: AMPLATZER Cardiac Plug; ACT: activated clotting time; DAPT: dual antiplatelet therapy; INR: international normalised ratio; OAC: oral anticoagulation; (N)OACs: (non-vitamin K dependent) oral anticogulants; TOE: transoesophageal echocardiography; TSP: transseptal puncture

\section{PATIENTS WITH CONTRAINDICATIONS TO ORAL ANTICOAGULATION}

Based on current guidelines, most of the LAAO interventions are performed in patients who had a bleeding complication or have a contraindication to chronic oral anticoagulation with VKA or NOACs ${ }^{11,165-167}$. Stroke prophylaxis is particularly challenging and, to date, no randomised clinical trials have been published in this patient population. In this setting, operators refrain from implementing a drug regimen including an oral anticoagulant and commonly prescribe DAPT for at least one month or until a sixmonth TOE follow-up, modifying the therapy upon its result. A satisfactory result on TOE (complete LAAO or small residual shunt $<5 \mathrm{~mm}$ jet width in the absence of device surface thrombi) allows withdrawing one antiplatelet agent, unless otherwise indicated. The other antiplatelet agent is usually continued indefinitely, although the bleeding risk of ASA by itself must be considered. This treatment rationale of DAPT was mainly derived from previous experience with the PLAATO device ${ }^{168}$ as well as atrial septal defect and patent foramen ovale device occlusions. A low thrombogenicity was found with the AMPLATZER device family ${ }^{169}$ and resulted in DAPT only with no oral anticoagulation in its instructions for use. The safety and feasibility of this drug regimen was shown in the registry data for the $\mathrm{ACP}^{116}$. Recently, a large registry of patients treated with the Amulet device indicated that those discharged without OAC ( $>80 \%)$, in particular those on single ASA therapy, did not appear to have a higher risk of devicerelated thrombus ${ }^{16}$, whilst another analysis not restricted by the use of a single device indicated that the risk of device-related thrombus was lower with DAPT or $\mathrm{OAC}^{100}$. Patients who underwent WATCHMAN implantation in the Aspirin Plavix (ASAP) registry received DAPT including clopidogrel for six months and ASA indefinitely without $\mathrm{OAC}^{17}$. The rate of ischaemic stroke was only $1.7 \%$ compared with $2.2 \%$ in the PROTECT AF device group. The usual practice is to load ASA or clopidogrel naïve patients accordingly (Table 18).

During follow-up, patients treated with DAPT may still experience a significant bleeding complication with an estimated annualised bleeding rate of $6.6 \%$ to $14.4 \%$ for the initial phase $\mathrm{e}^{91,98,111,116,170}$. Thus, a post-implant drug regimen with DAPT appears to be effective in preventing thrombus formation on the device but is still associated with a substantial rate of bleeding events. Moreover, the optimal duration of DAPT remains poorly defined. Several operators are stopping all antithrombotic therapies within the first year in patients with no other indication for them.

The prospective randomised open-label ADRIFT trial (Assessment of Dual Antiplatelet Therapy Versus Rivaroxaban In Atrial Fibrillation Patients Treated With Left Atrial Appendage Closure) is ongoing and compares two doses of rivaroxaban (10 and $15 \mathrm{mg}$ /day) to DAPT with ASA $75 \mathrm{mg}$ and clopidogrel $75 \mathrm{mg} /$ day in these patients (NCT03273322).

\section{EXTREMELY HIGH-RISK SITUATIONS}

Although not studied systematically, several registries include patients at extremely high risk for bleeding who were treated with no or only a single antiplatelet (ASA or clopidogrel) for limited periods of time which was then stopped at variable times following 
the implantation. Although information is scarce about this mode of therapy, it is the consensus of the authors of this document that this approach may be used in individual patients if agreed upon by an expert team. We believe that a period of two to four weeks of antiplatelet therapy should be strived for even in high bleeding risk situations. Patients who are not eligible even for such a short period of antiplatelet treatment may be considered better candidates for epicardial closure (either surgical or using the LARIAT device) in experienced hands.

\section{THROMBUS ON THE DEVICE}

Thrombus formation on the device is difficult to define ${ }^{102}$ but is not uncommon in patients with AF who are treated by LAA closure (3.7\% to $7.2 \%$ in recent large series) and, when present, is associated with a higher rate of stroke and systemic embolism ${ }^{100,171}$. The more recent generation of the AMPLATZER devices (Amulet) does not seem to be associated with a lower risk of thrombus than the older generation in the few comparisons that are available ${ }^{163}$. Both OAC and antiplatelet therapy may be independently associated with a lower risk of device-related thrombus ${ }^{100}$, indicating that a strategy with no antithrombotic at all is not appropriate in patients treated with LAAO. Subcutaneous heparin or OAC with warfarin or a NOAC for a period of weeks to months may lead to thrombus resolution in many cases. Therefore, anticoagulant therapy is recommended in all patients with device-associated thrombus regardless of symptoms until thrombus resolution is confirmed by follow-up TOE or CCTA.

\section{INCOMPLETE OCCLUSION OF THE LEFT ATRIAL APPENDAGE}

Incomplete LAAO may create a pocket containing thrombus allowing emboli to enter the systemic circulation. Small residual shunts with a jet diameter $<5 \mathrm{~mm}$ are usually deemed irrelevant and may close spontaneously with time. They do not warrant further drug or device interventions. For patients with persistent large shunts, a study found that the stroke risk is not different compared with patients in whom the LAA is completely occluded regardless of whether or not anticoagulant therapy is continued ${ }^{103}$. However, these findings should be considered with caution because of the relatively small number of patients and the low event rate. Whether persistent large ( $\geq 5 \mathrm{~mm}$ ) shunts deserve long-term OAC with VKA or NOAC or a second occlusion attempt remains at the operator's discretion.

\section{Chapter 9. Requirements for operator and centres}

\section{TRAINING AND KNOWLEDGE OF PHYSICIANS PERFORMING} THE PROCEDURE

LAAO is a preventive procedure and therefore patient safety is of paramount importance. The LAA is a thin-walled cardiac free wall structure that exhibits a highly variable and complex anatomy unique to each patient. In addition, percutaneous LAAO requires TSP, which increases the complexity of the procedure. Currently, there are several LAAO devices available that are implanted in a similar but not identical way ${ }^{65,172}$. Moreover, patient characteristics may vary substantially with respect to previous cardiac interventions, comorbidities, and indications for LAAO. Therefore, training of physicians performing the procedure should aim to: "Master the technique, know the device, know the patient".

\section{OPERATORS WHO EMBARK ON LAAO SHOULD HAVE THE FOLLOWING SKILL SETS:}

1. Extensive knowledge of cardiac anatomy, particularly of the LA, the LAA, and the surrounding structures.

2. Understanding and familiarisation with respective cardiac imaging, including fluoroscopy, TOE, ICE, and cardiac CCTA.

3. Proficiency in performing TSP is a key factor for a successful LAAO programme; adequate experience in safe and accurate TSP technique and performance of at least 10 TSPs in other procedures or guided by an expert in the initial LAAO procedures prior to embarking on the unproctored performance of LAAO.

4. Comprehensive knowledge and adequate skills to prevent and treat LAAO-related complications such as cardiac tamponade and device embolisation (pericardiocentesis, percutaneous device snaring, etc. $)^{173}$.

5. Acquaintance with particular LAAO device characteristics and special features.

6. Understanding of patient-specific characteristics that may have implications for the LAAO procedure such as previous AF ablations, previous open heart surgery, vascular access issues, etc.

Depending on their background, during training operators should focus on different aspects of the procedure. For example, interventional cardiologists who are not familiar with TSP should acquire adequate experience before starting to perform LAAO or be proctored by an expert for at least the first 10 LAAOs. Experience in manipulating and deploying devices for other structural heart disease operations can be valuable for improving LAAO techniques, so operators should be encouraged to participate in several such interventions if feasible. Knowledge of more than one device type for LAAO is also welcomed as it may increase the spectrum of anatomies to be treated. In case of minimal experience in cardiac imaging and depending on which modality is used in a particular centre, operators should attend relevant cardiac imaging courses before embarking on LAAO procedures and consult respective experts for individual cases.

A key factor for procedural success is a structured training process before becoming an independent operator. Currently, the training is offered by the device manufacturer. We believe that a training process for the implantation of a specific device should include the following ${ }^{174,175}$ :

1. A theoretical course on LAAO-related anatomy, clinical data, and device implantation techniques. The course may be taken online and should include didactic case examples of straightforward and complex anatomies. Critical issues such as patient planning, device selection, and prevention and management of complications should be thoroughly discussed.

2. A practical training, including handling of the equipment and simulator training during interactive workshops. Attendance in 
discussion of real cases is of paramount importance. In case of no or minimal TSP experience, a practical training should also be provided, including pitfalls in TSP and bail-out techniques.

3. During their first procedures with each kind of device, operators should be properly proctored by experienced operators. The number of proctored cases before becoming an independent operator varies and depends on previous experience in LAAO, structural heart disease, AF ablation, or other relevant interventions. In principle, proctoring should be provided until both operator and proctor agree that the operator can perform LAAO alone with adequate safety and confidence. In case the operator has not performed an LAAO procedure for an extended period of time, proctoring should be re-offered, if prior experience was small.

\section{CENTRE AND LABORATORY REQUIREMENTS}

Like other interventions, LAAO is a team effort. Therefore, all members of the team should be familiar with procedural steps, and patient and device characteristics. Ideally, the TOE operator, if one is involved, should participate in workshops dedicated to LAAOrelated imaging and the anaesthetist (if applicable) should also be accustomed to LAAO. The procedures should be performed in an adequately equipped cardiac catheterisation laboratory, electrophysiology laboratory, or hybrid room. The room should be properly sized to accommodate anaesthesia and TOE equipment and have a fixed $\mathrm{C}$-arm system for fluoroscopic imaging and continuous haemodynamic monitoring. The room should have the equipment to manage cardiac perforation and tamponade, device or air embolisation, etc. Large sheaths and catheters, TSP kits, different wires, snares, and pericardiocentesis equipment should be readily available. Site readiness for the procedure necessitates not only a knowledgeable operator but also a thorough team understanding of the procedure and of the individual role of each member of the team. According to current practice, in-house cardiovascular surgery in centres performing LAAO procedures is not deemed mandatory but arrangements for rapid transfer to a centre with cardiac surgery should be active, with a maximum delay of 60 minutes to the operation. Finally, sites that perform LAAO procedures should monitor their outcomes and complications and search for corrective measures in case of cumulative adverse events.

\section{Chapter 10. Surgical left atrial appendage closure}

Surgical closure of the left LAA is secondary to the main surgical procedure in most cases. Recent guidelines (2017) from the Society of Thoracic Surgeons stated that, at the time of concomitant cardiac operations in patients with $\mathrm{AF}$, it is reasonable to manage the LAA surgically for longitudinal thromboembolic morbidity prevention (Class IIA, Level C expert opinion), and complete LAA obliteration is recommended in all surgical ablation procedures ${ }^{176}$.

This secondary nature of surgical LAAO and an ensuing lack of scrutiny are probably responsible for the reported rates of incomplete closure that exceed $50 \%$ for various surgical techniques ${ }^{177-179}$. Surgical closure techniques include internal over-sewing with a double-layer running suture, purse-string suture, ligation, surgical excision of the LAA and external stapler closure ${ }^{180}$. Failure of closure can be defined as a residual pouch of $>1 \mathrm{~cm}$ within the appendage stump or persistent flow (gap) between the left atrium and appendage. Incomplete occlusion can increase stroke rate ${ }^{179}$. It is not clear if certain techniques of appendage closure provide superior results. A recent randomised study demonstrated early failure of $60 \%$ in stapler LAAO, compared with $13 \%$ failure with internal ligation and $20 \%$ with surgical excision $(\mathrm{p}=0.06)^{180}$. Another study reported that a residual gap was found early after surgery in $37 \%$ of patients, with a higher failure rate in internal over-sewing than amputation or stapler ${ }^{181}$. Reviewing a number of studies, Healey et al found that the failure rate was lower in stapler occlusion of the LAA than suture closure alone $(28 \% \text { vs } 55 \%)^{182}$. Badhwar et al stated that stapling has had particularly poor outcomes, with the majority of patients having a residual stump, which can be thrombogenic $^{176}$. A surgeon should also remember that the circumflex coronary artery is situated close to the LAA orifice and deep stitches can injure, kink, or ligate the artery. There is also a potential of bleeding from suture lines due to frailty of the appendage tissue. Most recent systematic reviews and meta-analysis have demonstrated that LAA surgical closure reduces the short-term mortality and stroke rate in valvular surgery in patients with AF. On the other hand, the clinical effect of concomitant closure of appendage in non-AF and non-valvular cases in the sense of "primary primary" prevention (Chapter 7) is not clear although it is conceivable that it may even reduce complications associated with perioperative and postoperative AF which is frequent in these cases ${ }^{183}$. It is important to realise that no randomised studies are available showing a positive effect of surgical LAAO on stroke outcome. Therefore, the results of the ongoing LAAO III trial are awaited. However, several cohort studies point to the potential benefit of LAAO in patients with AF. Yao et al found that, among patients undergoing cardiac surgery, concurrent surgical LAAO, compared with no surgical LAAO, was associated with reduced risk of subsequent stroke and all-cause mortality ${ }^{184}$. Friedman DJ et al reported that, in older patients with AF undergoing concomitant cardiac surgery, surgical LAAO, compared with no LAAO, was associated with a lower risk of readmission for thromboembolism over three years ${ }^{185}$.

Surgical LAAO can be performed as an isolated or concomitant procedure by several minimally invasive techniques and devices through either epicardial or hybrid (epicardial and endocardial) approaches. Epicardial approaches include the Sierra Ligation System (Aegis Medical Innovations Inc., Vancouver, BC, Canada) and the AtriClip (AtriCure, Inc., Mason, OH, USA). The Aegis device is introduced via percutaneous subxiphoid pericardial access, with ECG navigation onto the appendage and a suture looped around the appendage base. A small series has demonstrated the feasibility of the technique in humans ${ }^{186,187}$. The AtriClip Occlusion System is a clip placed epicardially at the base of the LAA. There are several published series of its use in humans with an intraoperative success rate of $95 \%{ }^{188-191}$. The AtriClip is the only FDA-approved device for surgical LAAO. 
Anticoagulation policy after surgical LAAO remains undefined. It depends largely on concomitant valvular procedures ${ }^{183}$ and also on CHADS or $\mathrm{CHA}_{2} \mathrm{DS}_{2}$-VASc risk factors. Since prior series have demonstrated a high rate of leaks after surgical LAAO, it is reasonable to follow up the patients with at least one TOE 30 days after the operation. The 2016 ESC guidelines on AF gave a class I indication to continued anticoagulation following surgical LAAO in patients at risk according to the traditional risk scores ${ }^{165}$. The 2017 STS guidelines are less strict about this point ${ }^{176}$. Most importantly, while surgical LAA closure probably decreases stroke rates in certain populations, it has never been systematically studied as an alternative to oral anticoagulation, for instance, in patients at high bleeding risk or with contraindication to anticoagulation. Moreover, while patients who cannot receive any form of antithrombotic therapy even for limited periods of time may not be candidates for percutaneous LAA closure, data are also lacking about the role of surgical LAAO in this population.

In summary, observational, non-randomised data may suggest that concomitant surgical LAAO resulted in reduced stroke rates and short-term mortality among patients with AF undergoing valvular surgery. Its role as a stand-alone procedure as a substitute for anticoagulation remains to be established. The role of preventive surgical LAAO in patients without prior AF ("primary primary" prevention [Chapter 7]) as suggested by several authors remains to be established (Table 19).

\section{Chapter 11. Future and ongoing studies for LAAO}

Currently, there are some ongoing trials that aim to explore and eventually confirm LAAO efficacy on large samples of patients with absolute contraindications to OAC, while others aim to

Table 19. LAA closure by cardiac surgery.

\begin{tabular}{|c|c|c|}
\hline $\begin{array}{l}\text { Clinical situation and therapeutic } \\
\text { concept }\end{array}$ & $\begin{array}{l}\text { Consensus } \\
\text { statement }\end{array}$ & Icon \\
\hline $\begin{array}{l}\text { Surgical LAA excision or occlusion in } \\
\text { conjunction with any type of cardiac } \\
\text { surgery in patient with AF }\end{array}$ & "May do this" & \\
\hline $\begin{array}{l}\text { Surgical LAA excision or occlusion can } \\
\text { be performed as an isolated or } \\
\text { concomitant procedure by several } \\
\text { minimally invasive techniques and } \\
\text { devices with epicardial or hybrid } \\
\text { (epicardial and endocardial) approaches } \\
\text { in cases when endocardial closure cannot } \\
\text { be done or when no antithrombotic } \\
\text { therapy can be administered even for } \\
2-4 \text { weeks following the procedure }\end{array}$ & "May do this" & \\
\hline $\begin{array}{l}\text { Surgical LAA excision or exclusion in } \\
\text { conjunction with any type of cardiac } \\
\text { surgery in patient with AF and significant } \\
\text { comorbidities, when prolongation of the } \\
\text { procedure may be dangerous, in re-do } \\
\text { cases because of pericardial adhesions, } \\
\text { in very thin, friable or calcified atrial walls }\end{array}$ & $\begin{array}{l}\text { "Should not do } \\
\text { this" }\end{array}$ & \\
\hline AF: atrial fibrillation; LAA: left atrial appen & & \\
\hline
\end{tabular}

assess the potential benefit of LAAO in comparison to NOAC. All the ongoing trials on LAAO are summarised in Table 20.

The ANDES (Short-Term Anticoagulation Versus Antiplatelet Therapy for Preventing Device Thrombosis Following Left Atrial Appendage Closure $)^{192}$ trial that should be recruiting shortly has planned 350 patients in a comparison of short-term (eight weeks) anticoagulation therapy (NOAC) versus antiplatelet therapy for the prevention of device thrombosis following transcatheter LAAO. Considering the lack of data on NOAC therapy post LAAO, a blinded interim analysis will be performed after the inclusion of the first 150 patients. The final sample size will be adjusted following the results of the blinded interim analysis. Follow-up after treatment will be of 24 months' duration.

The ASAP-TOO trial ${ }^{193}$ is presently ongoing, with 888 planned patients who are ineligible for anticoagulation therapy and randomised 2:1 to LAAO with WATCHMAN versus single or dual antiplatelet therapy. The trial's primary effectiveness endpoint is the evaluation of time to the first occurrence of ischaemic stroke or systemic embolism during the five-year follow-up. The trial's primary safety endpoint is one of the following occurrences: death, ischaemic stroke, systemic embolism, device- or procedure-related events requiring open cardiac surgery or major cardiovascular intervention (pseudoaneurysm repair, arteriovenous fistula repair, or other major endovascular repair) within seven days of follow-up.

The STROKECLOSE trial ${ }^{194}$ is currently recruiting patients with previous intracerebral haemorrhage, randomised to LAAO with AMPLATZER Amulet or medical therapy. With 750 planned recruited patients, this trial will evaluate a composite endpoint of stroke (ischaemic or haemorrhagic), systemic embolism, lifethreatening or major bleeding and all-cause mortality.

The PRAGUE-17 trial ${ }^{195}$ is presently recruiting patients (400 planned) randomised to NOAC or LAAO with AMPLATZER Amulet or WATCHMAN. The combined endpoint is the occurrence of stroke or systemic cardioembolic events, or clinically significant bleeding or cardiovascular death or procedure- or device-related complications at one-year follow-up.

The SAFE-LAAC ${ }^{196}$ trial is currently recruiting patients (target 160) randomised to LAAO followed by 30 days of DAPT versus LAAO followed by six months of DAPT, with evaluation of a composite of stroke, TIA, peripheral embolism, non-fatal myocardial infarction, cardiovascular mortality, all-cause mortality, moderate and severe bleeding (BARC type 2, 3, and 5), left atrial appendage thrombus evidence.

The CLOSURE-AF (Left Atrial Appendage CLOSURE in Patients With Atrial Fibrillation Compared to Medical Therapy) ${ }^{197}$ is another trial which aims to determine the clinical benefit of percutaneous catheter-based LAAO in patients with non-valvular $\mathrm{AF}$ at high risk of stroke $\left(\mathrm{CHA}_{2} \mathrm{DS}_{2}\right.$-VASc score $\left.\geq 2\right)$ as well as high risk of bleeding as compared to best medical care (including NOAC when eligible), in a 24-month follow-up.

OCCLUSION-AF (Left Atrial Appendage Occlusion Versus Novel Oral Anticoagulation for Stroke Prevention in Atrial 


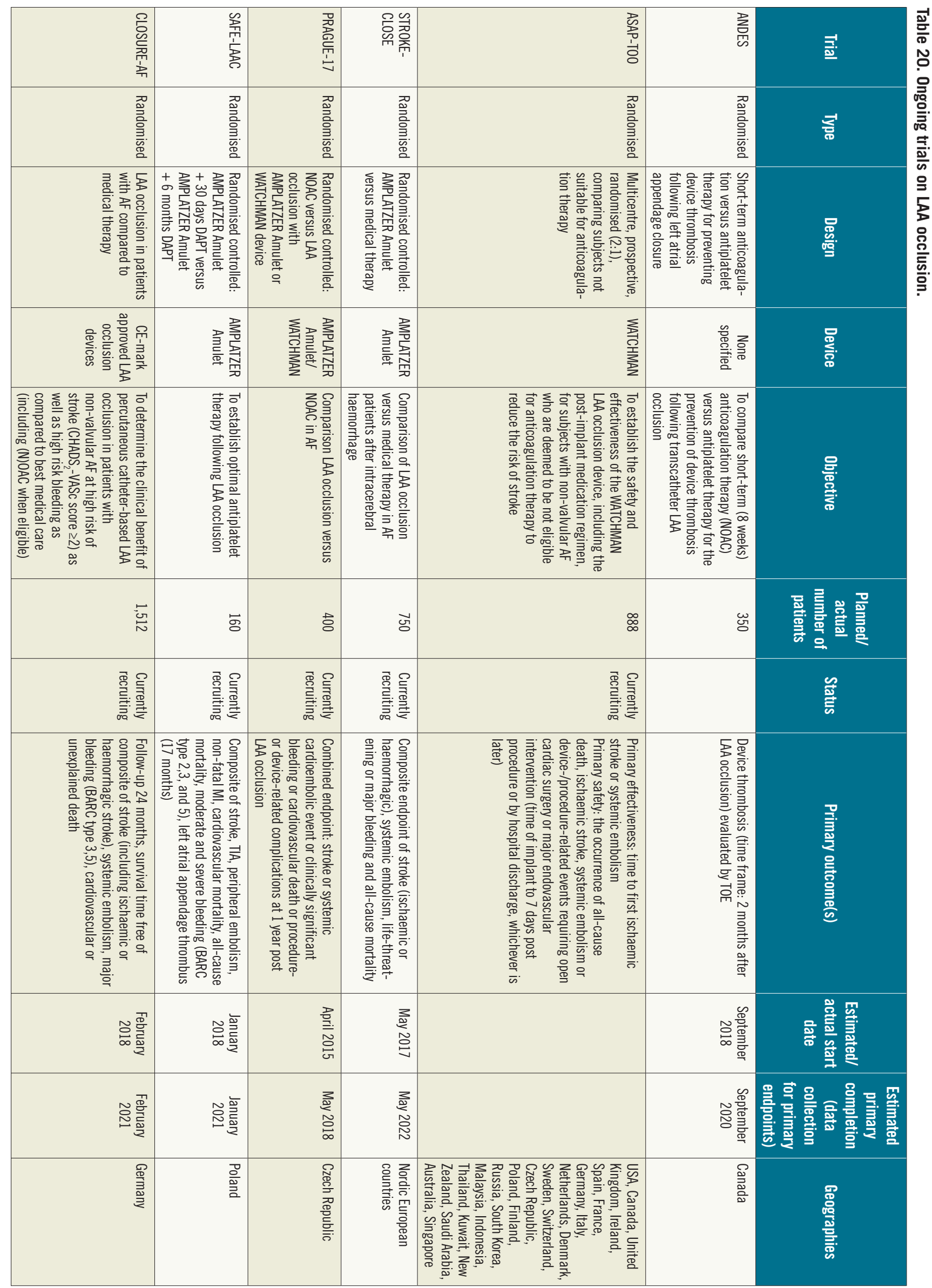




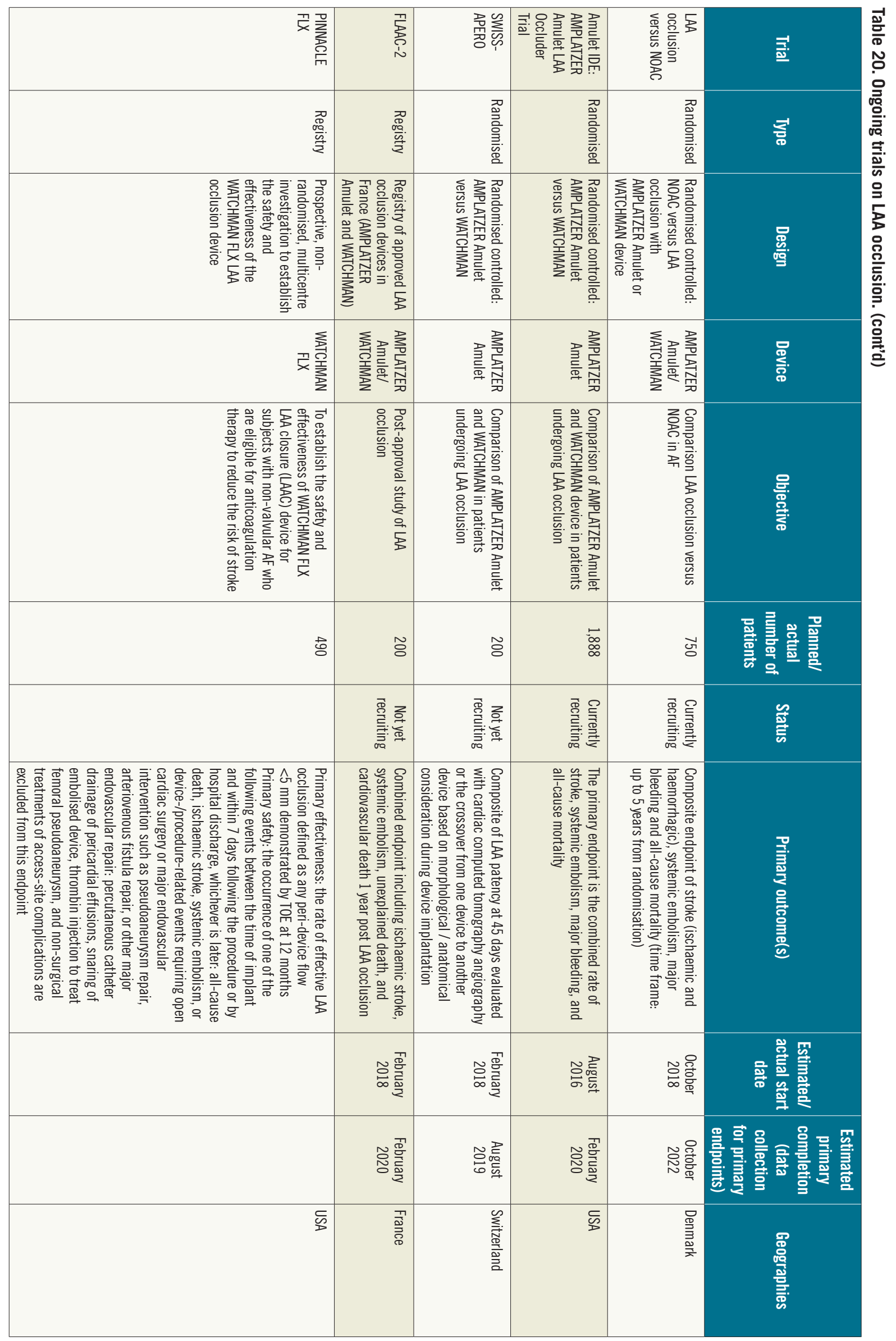




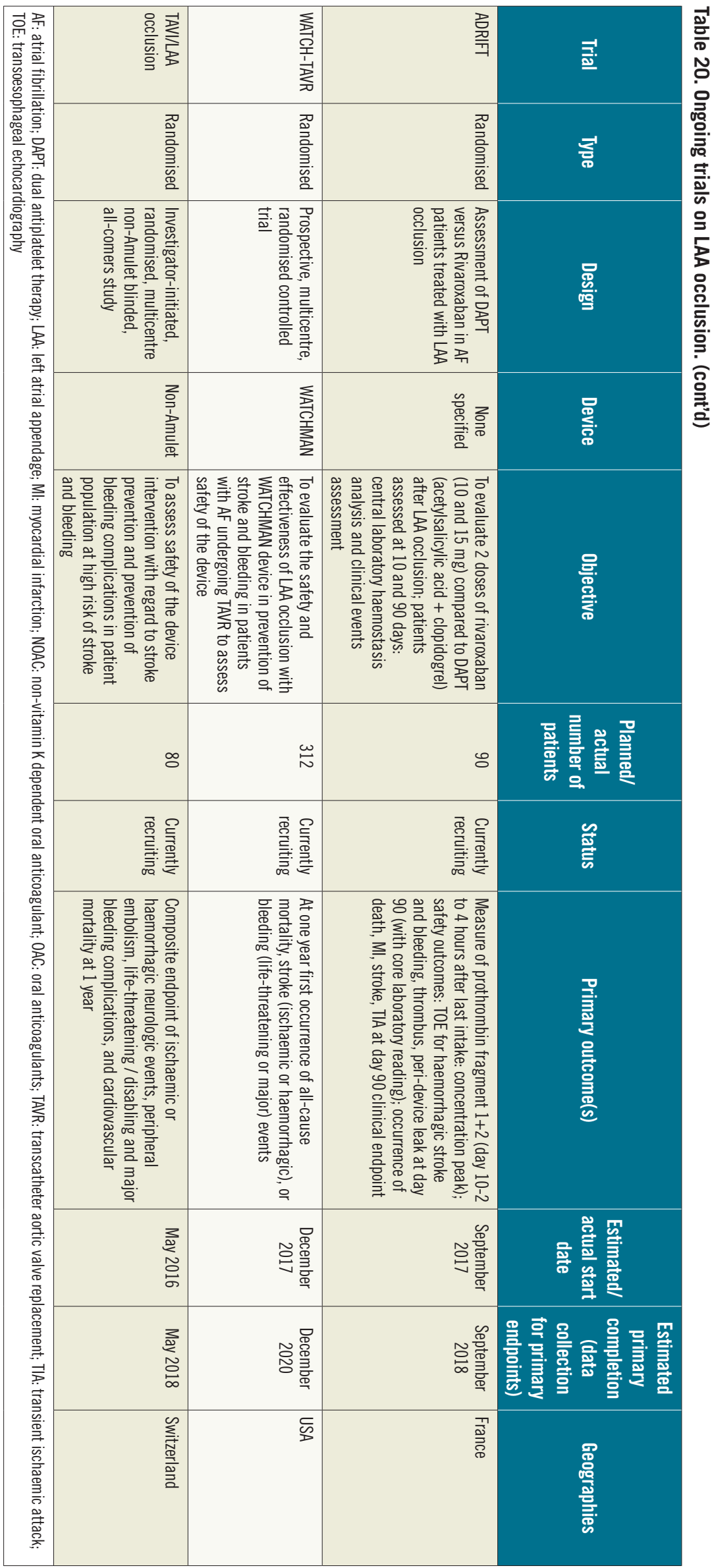


Fibrillation) is also a large (750 patients) ongoing trial recruiting $\mathrm{AF}$ patients to LAA closure versus NOAC ${ }^{198}$.

Other trials have been planned for direct comparison of LAAO with the AMPLATZER Amulet versus WATCHMAN.

The AMPLATZER Amulet LAA Occluder trial (Amulet IDE ) ${ }^{199}$ is currently recruiting patients (target 800) randomised to LAAO with AMPLATZER Amulet versus WATCHMAN to compare device safety (a composite of procedure-related complications or all-cause death or major bleeding up to 12 months), efficacy (ischaemic stroke and/or systemic embolism up to 18 months) and the effectiveness of closure at 45 days of follow-up.

The SWISS-APERO ${ }^{200}$ trial, with 200 patients planned, will compare the AMPLATZER Amulet and WATCHMAN for the composite of LAA patency at 45 days evaluated with CCTA or the crossover from one device to the other due to morphological/ anatomical assessments.

The FLAAC $2^{201}$ is a planned registry (target 200 patients) of approved LAAO devices in France (AMPLATZER Amulet and WATCHMAN), with evaluation of a combined endpoint including ischaemic strokes, systemic embolisms, unexplained deaths, and cardiovascular death during the first year post LAAO.

The PINNACLE FLX ${ }^{202}$ is a planned registry (up to 490 enrolled patients) to establish the safety and effectiveness of the new WATCHMAN FLX device. The primary effectiveness is defined as the rate of effective LAA closure (defined as any peri-device flow $<5 \mathrm{~mm}$ demonstrated by TOE) at 12 -month follow-up. The primary safety endpoint is the occurrence of one of the following events within seven days after the procedure or hospital discharge (whichever is later): all-cause death, ischaemic stroke, systemic embolism, or device- or procedure-related events requiring open cardiac surgery or major endovascular intervention such as pseudoaneurysm repair, arteriovenous fistula repair, or other major endovascular repair.

Despite the depth of results that have already been documented and that should emerge from the ongoing trials, there are still issues related to LAAO to be faced.

It is desirable that future studies find a definite or partial answer to the following open questions:

1. Confirm the benefit of LAAO in comparison to antiplatelet or no therapy in patients with absolute/relative contraindications to OAC.

2. Evaluate LAAO efficacy in comparison to NOAC.

3. Compare different LAAO devices in order to define the most detailed indications for use; the two most used devices are WATCHMAN and AMPLATZER Amulet.

4. Define optimal post-LAAO therapy. The currently recruiting trial "Assessment of Dual Antiplatelet Therapy Versus Rivaroxaban in Atrial Fibrillation Patients Treated With Left Atrial Appendage Closure (ADRIFT)" ${ }^{203}$ is to evaluate two different rivaroxaban regimens (10 or $15 \mathrm{mg}$ a day) in comparison to DAPT (ASA plus clopidogrel: control arm representing standard of care) after successful LAAO. The aim is to investigate whether rivaroxaban could provide correct anticoagulation levels and adequately suppress coagulation activation after LAAO.
5. Define the best preprocedural imaging (CCTA and/or TOE), optimise intraprocedural imaging (intracardiac echocardiography [ICE] versus TOE), and the most suitable clinical and imaging follow-up. Particular attention needs to be paid to the meaning of procedural results (residual leaks, device thrombosis, and so on).

6. Identify sub-populations who would benefit the most from LAAO (e.g., patients in haemodialysis and/or with renal failure ineligible for NOAC, patients affected by acute coronary syndrome and AF, etc.).

7. Exploring the field of combined procedures (LAAO plus ablation, valve repair/replacement, etc.). There are two ongoing trials that are exploring transcatheter aortic valve replacement (TAVR) and LAAO. One is the Boston Scientific trial, "WATCHMAN for Patients With Atrial Fibrillation Undergoing Transcatheter Aortic Valve Replacement (WATCH-TAVR)"204, to evaluate the safety and effectiveness of left atrial appendage occlusion with the WATCHMAN device in prevention of stroke and bleeding in patients with AF undergoing TAVR. The other trial is Abbott's "Comparison of LAAO versus standard medical therapy in patients in AF undergoing TAVR (TAVR/LAAO)"205 which aims to compare the safety (and efficacy) of LAAO using the Abbott LAAO device with standard medical therapy in a prospective, multicentre, randomised trial in patients undergoing TAVR in routine clinical practice.

8. Defining the role of LAAO combined with (reduced dose) OAC in patients with recurrent stroke after LAAO or during OAC.

\section{Chapter 12. Summary}

This document replaces the 2014 scientific document ${ }^{206,207}$ and aimed systematically to review changes in knowledge base, assess their significance and make recommendations regarding their application to contemporary clinical practice regarding atrial fibrillation (AF) and left atrial appendage (LAA) occlusion.

The main takeaway messages and changes from the previous consensus document are the following:

1. Chapter 1 of this document reviews the mechanisms behind LAA thrombus formation and its association with thromboembolic events in atrial fibrillation. Apparently, a combination of the structure of LAA, stasis within it, abnormal haemostasis and inner surface of the atrium especially in the LAA area all contribute to the pivotal role of LAA in embolic complications of LAA thrombosis. These set the rationale for its prevention by either anticoagulants or LAA occlusion (LAAO).

2. Chapter 2 reflects that the WATCHMAN device and the AMPLATZER Amulet have the largest track record. Various other endocardial techniques are emerging that need to be studied further. Most of the recommendations in this document are not widely applicable to devices other than the WATCHMAN and AMPLATZER Amulet. Considerable experience has been gained with the epi-endocardial LARIAT device, mainly in the USA where it has been used for some time as the only approved occluder system. The LARIAT device may be useful among patients with an absolute contraindication for antithrombotic 
therapy; however, this is uncertain as there are reports about thrombus formation within the pouch.

3. Chapter 3 discusses the role of imaging which has undergone a significant change over the last few years. Preprocedural imaging is mandatory to rule out left atrial or LAA thrombus and to check the suitability for closure. Different groups are using different combinations of imaging techniques of the LAA, the most common of which are fluoroscopy, transoesophageal echocardiography, and computed tomography, but which also include intracardiac echocardiography and rotational atriography during the procedure. Post-procedural imaging is mandatory 6-24 weeks after the procedure and is optional after that, in an attempt to detect device-related thrombi and to exclude significant leak.

4. Chapter 4 provides a very detailed illustrative guide to the procedures of implantation of the WATCHMAN and AMPLATZER Amulet, covering all technical details.

5. Chapter $\mathbf{5}$ presents evidence accumulated regarding LAA occlusion over recent years. While the completed randomised controlled trials are still limited to the two landmark WATCHMAN trials (PROTECT and PREVAIL), longer-term follow-up and meta-analyses are now available from these trials. They further support the evidence presented in the previous version of this document, i.e., that LAAO using the WATCHMAN device is non-inferior and in several aspects even superior to treatment with warfarin in warfarin-eligible patients. A large body of evidence has accumulated over these years from registries looking at the use of LAAO devices of the two main types in patients with contraindications to or at high risk for bleeding with oral anticoagulants. These registries provide the knowledge base underlying the current recommendations for the use of LAAO in these patients. They also provide information on the risk for device-related thrombus and peri-device leaks, their association to antithrombotic therapies and their consequences.

6. Chapter $\mathbf{6}$ presents a critical appraisal of the results presented in Chapter 5, as well as limitations of the studies which form the basis for our recommendations.

7. Chapter 7 provides our recommendations regarding indications for LAAO following the same line as in the previous document, with slight changes due to accumulating evidence. We believe that NOACs are the mainstay therapy for stroke prevention in $\mathrm{AF}$, and that LAAO should be offered mainly to patients in whom there are absolute contraindications or who carry a high risk for bleeding with the use of NOACs that outweighs their proven advantage in stroke prevention. A list is presented of these high-risk situations that should prompt individual consideration of the use of LAA occlusion. We considered that information is insufficient to make specific recommendation in specific situations such as stroke on anticoagulants, deep thrombus within the LAA, LAA electrical isolation, and LAAO concomitant with AF ablation.

8. Chapter 8 discusses recommendations regarding antithrombotic therapy following LAAO. They are not based on randomised controlled trials but on the results of large registries. The duration of treatment with the various components has not been uniform across the different studies and registries. We believe that DAPT is now established as the preferred method of treatment in patients ineligible for warfarin or in patients receiving non-WATCHMAN devices, with acetylsalicylic acid prescribed indefinitely and clopidogrel for 1-6 months depending on the bleeding risk. Other options such as a single antiplatelet therapy may be considered in individual cases with high risk of bleeding, albeit at a potential cost of slightly increased thrombus on the device and thromboembolic events. We believe that endocardial LAAO should not be offered to a patient who cannot receive at least several weeks of any antiplatelet therapy. Both the risk of device-related thrombus and the treatment options as well as peri-device leaks are further discussed in Chapter $\mathbf{8}$.

9. Chapter 9 deals with standards for training of operators and centre readiness. We believe that embarking on LAAO requires extensive understanding of the LAAO anatomy, proficiency in procedures involving TSP techniques, thorough understanding of the device operation and procedure acquired through online courses and workshops. We also encourage operators to have training in experienced centres or to be proctored at their own centres with their organic team. Special attention should be given to the training of echocardiography experts in order to support these procedures. Immediate access to pericardial tap and the availability of cardiac surgery with open chest within one hour of the complication are prerequisites.

10. Chapter 10 discusses that, although most LAAO procedures are performed by interventional cardiology teams, there is an increasing interest in surgical LAAO or removals in cases undergoing cardiac surgery or in those who cannot undergo endocardial closure. Incidental surgical closure of LAA resulted in reduced stroke rate and short-term mortality among patients with AF undergoing valvular surgery. Its role as a stand-alone procedure or as a substitute to anticoagulation remains to be established. The role of preventive percutaneous LAAO in patients without prior atrial fibrillation, as suggested by several authors, remains to be established.

11. Chapter 11 reviews the ongoing studies and unanswered questions in the field such as the use of non-vitamin $\mathrm{K}$ dependent oral anticoagulants (NOACs), different antithrombotic protocols, head-to-head comparisons between devices, and more.

\section{Appendix. Affiliations}

1. Integrated Heart Center, Shaare Zedek Medical Center, Jerusalem, Israel; 2. Heartcenter Leipzig at Leipzig University and Leipzig Heart Institute, Department of Electrophysiology, Leipzig, Germany; 3. Baptist Health Louisville, Louisville, KY, USA; 4. Cardiology Clinical Academic Group Molecular \& Clinical Sciences Research Institute, St. George's University of London, London, United Kingdom; 5. Liverpool Centre for Cardiovascular Science, University of Liverpool and Liverpool Heart \& Chest Hospital, Liverpool, United Kingdom; 
6. Aalborg Thrombosis Research Unit, Department of Clinical Medicine, Aalborg University, Aalborg, Denmark; 7. Centre Hospitalier Universitaire Trousseau et Université François Rabelais, Tours, France; 8. Oxford University Hospitals NHS Foundation Trust, Oxford Biomedical Research Centre, Department of Cardiology, Oxford, United Kingdom; 9. Dept. of Cardiology and Intensive Care, Hospital for Internal Medicine Munich South, Munich, Germany; 10. Dept. of Cardiology, University of Bonn, Bonn, Germany; 11. Vancouver General Hospital, University of British Columbia, Vancouver, Canada; 12. Structural \& Congenital Heart Disease, AHEPA University Hospital \& Interbalkan European Medical Center, Thessaloniki, Greece; 13. Cardiac Surgery, Sheba Medical Center, Tel-Hashomer, Israel; 14. Cardiovascular Center Zurich, Hirslanden Klinik im Park, Zurich, Switzerland; 15. Heart Hospital-Fondazione C.N.R. Reg. Toscana G. Monasterio, Cardiology Department, Massa, Italy; 16. CardioVascular Center CVC, Cardiology and Angiology, Frankfurt, Germany; 17. Anglia Ruskin University, Chelmsford, United Kingdom; 18. University of California San Francisco, San Francisco, CA, USA; 19. Yunnan Hospital Fuwai, Kunming, China; 20. Cardiology, Cardiovascular Department, University Hospital Bern, Bern, Switzerland.

\section{References}

1. Wolf PA, Abbott RD, Kannel WB. Atrial fibrillation as an independent risk factor for stroke: the Framingham Study. Stroke. 1991;22:983-8.

2. Blackshear JL, Odell JA. Appendage obliteration to reduce stroke in cardiac surgical patients with atrial fibrillation. Ann Thorac Surg. 1996;61:755-9.

3. Mahajan R, Brooks AG, Sullivan T, Lim HS, Alasady M, Abed HS, Ganesan AN, Nayyar S, Lau DH, Roberts-Thomson KC, Kalman JM, Sanders P. Importance of the underlying substrate in determining thrombus location in atrial fibrillation: implications for left atrial appendage closure. Heart. 2012;98:1120-6.

4. Parashar A, Sud K, Devgun J, Agarwal S, Bassi M, Tuzcu EM, Griffin B, Krishnaswamy A, Kapadia S. Feasibility of LAA Closure for Left Atrial Thrombus in Patients With Aortic Stenosis and AF. J Am Coll Cardiol. 2016; 68:770-1.

5. Pollick C, Taylor D. Assessment of left atrial appendage function by transesophageal echocardiography. Implications for the development of thrombus. Circulation. 1991;84:223-31.

6. Reddy VY, Doshi SK, Kar S, Gibson DN, Price MJ, Huber K, Horton RP, Buchbinder M, Neuzil P, Gordon NT, Holmes DR Jr; PREVAIL and PROTECT AF Investigators. 5-Year Outcomes After Left Atrial Appendage Closure. From the PREVAIL and PROTECT AF Trials. J Am Coll Cardiol. 2017;70:2964-75. 7. Parekh A, Jaladi R, Sharma S, Van Decker WA, Ezekowitz MD. Images in cardiovascular medicine. The case of a disappearing left atrial appendage thrombus: direct visualization of left atrial thrombus migration, captured by echocardiography, in a patient with atrial fibrillation, resulting in a stroke. Circulation. 2006;114:e513-4.

8. Lip GY. Does atrial fibrillation confer a hypercoagulable state? Lancet. 1995;346:1313-4.

9. Khan AA, Lip GYH. The prothrombotic state in atrial fibrillation: pathophysiological and management implications. Cardiovasc Res. 2019;115:31-45.

10. Watson T, Shantsila E, Lip GY. Mechanisms of thrombogenesis in atrial fibrillation: Virchow's triad revisited. Lancet. 2009;373:155-66.

11. Goette A, Kalman JM, Aguinaga L, Akar J, Cabrera JA, Chen SA, Chugh SS, Corradi D, D'Avila A, Dobrev D, Fenelon G, Gonzalez M, Hatem SN, Helm R, Hindricks G, Ho SY, Hoit B, Jalife J, Kim YH, Lip GY,
Ma CS, Marcus GM, Murray K, Nogami A, Sanders P, Uribe W, Van Wagoner DR, Nattel S; Document Reviewers. EHRA/HRS/APHRS/SOLAECE expert consensus on atrial cardiomyopathies: definition, characterization, and clinical implication. Europace. 2016;18:1455-90.

12. Sanfilippo AJ, Abascal VM, Sheehan M, Oertel LB, Harrigan P, Hughes RA, Weyman AE. Atrial enlargement as a consequence of atrial fibrillation. A prospective echocardiographic study. Circulation. 1990;82:792-7.

13. Predictors of thromboembolism in atrial fibrillation: II. Echocardiographic features of patients at risk. The Stroke Prevention in Atrial Fibrillation Investigators. Ann Intern Med. 1992;116:6-12.

14. Salem DN, Stein PD, Al-Ahmad A, Bussey HI, Horstkotte D, Miller N, Pauker SG. Antithrombotic therapy in valvular heart disease--native and prosthetic: the Seventh ACCP Conference on Antithrombotic and Thrombolytic Therapy. Chest. 2004;126:457S-482S.

15. Nakagami H, Yamamoto K, Ikeda U, Mitsuhashi T, Goto T, Shimada K. Mitral regurgitation reduces the risk of stroke in patients with nonrheumatic atrial fibrillation. Am Heart J. 1998;136:528-32.

16. Lip GY, Rumley A, Dunn FG, Lowe GD. Thrombogenesis in mitral regurgitation and aortic stenosis. Angiology. 1996;47:1117-25.

17. Transesophageal echocardiographic correlates of thromboembolism in high-risk patients with nonvalvular atrial fibrillation. The Stroke Prevention in Atrial Fibrillation Investigators Committee on Echocardiography. Ann Intern Med. 1998;128:639-47.

18. Takada T, Yasaka M, Nagatsuka K, Minematsu K, Yamaguchi T. Blood flow in the left atrial appendage and embolic stroke in nonvalvular atrial fibrillation. Eur Neurol. 2001;46:148-52.

19. Santiago D, Warshofsky M, Li Mandri G, Di Tullio M, Coromilas J, Reiffel J, Homma S. Left atrial appendage function and thrombus formation in atrial fibrillation-flutter: a transesophageal echocardiographic study. J Am Coll Cardiol. 1994;24:159-64.

20. Doukky R, Garcia-Sayan E, Patel M, Pant R, Wassouf M, Shah S, D'Silva O, Kehoe RF. Impact of Diastolic Function Parameters on the Risk for Left Atrial Appendage Thrombus in Patients with Nonvalvular Atrial Fibrillation: A Prospective Study. J Am Soc Echocardiogr. 2016;29:545-53.

21. Shimamoto K, Kawagoe T, Dai K, Inoue I. Thrombus in the left atrial septal pouch mimicking myxoma. J Clin Ultrasound. 2014;42:185-8.

22. Holda MK, Krawczyk-Ozog A, Koziej M, Sorysz D, Holda J, Dudek D, Klimek-Piotrowska W. Left-Sided Atrial Septal Pouch is a Risk Factor for Cryptogenic Stroke. J Am Soc Echocardiogr. 2018;31:771-776.

23. Goldsmith IR, Blann AD, Patel RL, Lip GY. von Willebrand factor, fibrinogen, and soluble P-selectin levels after mitral valve replacement versus mitral valve repair. Am J Cardiol. 2000;85:1218-22.

24. Breithardt OA, Papavassiliu T, Borggrefe M. A coronary embolus originating from the interatrial septum. Eur Heart J. 2006;27:2745.

25. Masawa N, Yoshida Y, Yamada T, Joshita T, Ooneda G. Diagnosis of cardiac thrombosis in patients with atrial fibrillation in the absence of macroscopically visible thrombi. Virchows Arch A Pathol Anat Histopathol. 1993;422:67-71.

26. Shirani J, Alaeddini J. Structural remodeling of the left atrial appendage in patients with chronic non-valvular atrial fibrillation: Implications for thrombus formation, systemic embolism, and assessment by transesophageal echocardiography. Cardiovasc Pathol. 2000;9:95-101

27. Tziakas DN, Chalikias GK, Papanas N, Stakos DA, Chatzikyriakou SV, Maltezos E. Circulating levels of collagen type I degradation marker depend on the type of atrial fibrillation. Europace. 2007;9:589-96.

28. Frustaci A, Chimenti C, Bellocci F, Morgante E, Russo MA, Maseri A. Histological substrate of atrial biopsies in patients with lone atrial fibrillation. Circulation. 1997;96:1180-4.

29. Li X, Ma C, Dong J, Liu X, Long D, Tian Y, Yu R. The fibrosis and atrial fibrillation: is the transforming growth factor-beta 1 a candidate etiology of atrial fibrillation. Med Hypotheses. 2008;70:317-9. 
30. Lip GY, Lowe GD, Rumley A, Dunn FG. Increased markers of thrombogenesis in chronic atrial fibrillation: effects of warfarin treatment. Br Heart $J$. 1995;73:527-33.

31. Marin F, Roldan V, Climent V, Garcia A, Marco P, Lip GY. Is thrombogenesis in atrial fibrillation related to matrix metalloproteinase- 1 and its inhibitor, TIMP-1? Stroke. 2003;34:1181-6.

32. Akoum N, Fernandez G, Wilson B, McGann C, Kholmovski E, Marrouche N. Association of atrial fibrosis quantified using LGE-MRI with atrial appendage thrombus and spontaneous contrast on transesophageal echocardiography in patients with atrial fibrillation. J Cardiovasc Electrophysiol. 2013;24:1104-9.

33. Mondillo S, Sabatini L, Agricola E, Ammaturo T, Guerrini F, Barbati R, Pastore M, Fineschi D, Nami R. Correlation between left atrial size, prothrombotic state and markers of endothelial dysfunction in patients with lone chronic nonrheumatic atrial fibrillation. Int J Cardiol. 2000;75:227-32.

34. Turgut N, Akdemir O, Turgut B, Demir M, Ekuklu G, Vural O, Ozbay G, Utku U. Hypercoagulopathy in stroke patients with nonvalvular atrial fibrillation: hematologic and cardiologic investigations. Clin Appl Thromb Hemost. 2006;12:15-20.

35. Choudhury A, Chung I, Blann AD, Lip GYH. Elevated platelet microparticle levels in nonvalvular atrial fibrillation: relationship to p-selectin and antithrombotic therapy. Chest. 2007;131:809-15.

36. Conway DS, Heeringa J, Van Der Kuip DA, Chin BS, Hofman A, Witteman JC, Lip GY. Atrial fibrillation and the prothrombotic state in the elderly: the Rotterdam Study. Stroke. 2003;34:413-7.

37. Habara S, Dote K, Kato M, Sasaki S, Goto K, Takemoto H, Hasegawa D, Matsuda O. Prediction of left atrial appendage thrombi in non-valvular atrial fibrillation. Eur Heart J. 2007;28:2217-22.

38. Nozawa T, Inoue H, Hirai T, Iwasa A, Okumura K, Lee JD, Shimizu A, Hayano M, Yano K. D-dimer level influences thromboembolic events in patients with atrial fibrillation. Int J Cardiol. 2006;109:59-65.

39. Vene N, Mavri A, Kosmelj K, Stegnar M. High D-dimer levels predict cardiovascular events in patients with chronic atrial fibrillation during oral anticoagulant therapy. Thromb Haemost. 2003;90:1163-72.

40. Heppell RM, Berkin KE, McLenachan JM, Davies JA. Haemostatic and haemodynamic abnormalities associated with left atrial thrombosis in nonrheumatic atrial fibrillation. Heart. 1997;77:407-11.

41. Ancedy Y, Berthelot E, Lang S, Ederhy S, Boyer-Chatenet L, Di Angelantonio E, Soulat-Dufour L, Etienney A, Adavane-Scheuble S, Boccara F, Cohen A. Is von Willebrand factor associated with stroke and death at mid-term in patients with non-valvular atrial fibrillation? Arch Cardiovasc Dis. 2018; 111:357-69.

42. Carter AM, Catto AJ, Grant PJ. Association of the alpha-fibrinogen Thr312Ala polymorphism with poststroke mortality in subjects with atrial fibrillation. Circulation. 1999;99:2423-6.

43. Bozdemir V, Kirimli O, Akdeniz B, Ulgenalp A, Aslan A, Kala V, Ozel E, Senarslan O, Badak O, Baris N, Guneri S. The association of beta-fibrinogen $455 \mathrm{G} / \mathrm{A}$ gene polymorphism with left atrial thrombus and severe spontaneous echo contrast in atrial fibrillation. Anadolu Kardiyol Derg. 2010;10:209-15.

44. Marin F, Corral J, Roldan V, Gonzalez-Conejero R, del Rey ML, Sogorb F, Lip GY, Vicente V. Factor XIII Val34Leu polymorphism modulates the prothrombotic and inflammatory state associated with atrial fibrillation. J Mol Cell Cardiol. 2004;37:699-704.

45. Roldan V, Marin F, Gonzalez-Conejero R, Garcia-Honrubia A, Marti S, Alfaro A, Valdes M, Corral J, Lip GY, Vicente V. Factor VII -323 decanucleotide $\mathrm{D} / \mathrm{I}$ polymorphism in atrial fibrillation: implications for the prothrombotic state and stroke risk. Ann Med. 2008;40:553-9.

46. Conen D, Ridker PM, Everett BM, Tedrow UB, Rose L, Cook NR, Buring JE, Albert CM. A multimarker approach to assess the influence of inflammation on the incidence of atrial fibrillation in women. Eur Heart $J$. 2010;31:1730-6.
47. Marcus GM, Smith LM, Glidden DV, Wilson E, McCabe JM, Whiteman D, Tseng ZH, Badhwar N, Lee BK, Lee RJ, Scheinman MM, Olgin JE. Markers of inflammation before and after curative ablation of atrial flutter. Heart Rhythm. 2008;5:215-21.

48. Conway DS, Buggins P, Hughes E, Lip GY. Prognostic significance of raised plasma levels of interleukin- 6 and C-reactive protein in atrial fibrillation. Am Heart J. 2004;148:462-6.

49. Chung MK, Martin DO, Sprecher D, Wazni O, Kanderian A, Carnes CA, Bauer JA, Tchou PJ, Niebauer MJ, Natale A, Van Wagoner DR. C-reactive protein elevation in patients with atrial arrhythmias: inflammatory mechanisms and persistence of atrial fibrillation. Circulation. 2001;104:2886-91.

50. Cermak J, Key NS, Bach RR, Balla J, Jacob HS, Vercellotti GM. C-reactive protein induces human peripheral blood monocytes to synthesize tissue factor. Blood. 1993;82:513-20.

51. Neumann FJ, Ott I, Marx N, Luther T, Kenngott S, Gawaz M, Kotzsch M, Schomig A. Effect of human recombinant interleukin-6 and interleukin-8 on monocyte procoagulant activity. Arterioscler Thromb Vasc Biol. 1997;17: 3399-405.

52. Burstein SA. Cytokines, platelet production and hemostasis. Platelets. 1997;8:93-104.

53. Ederhy S, Di Angelantonio E, Dufaitre G, Meuleman C, Masliah J, BoyerChatenet L, Boccara F, Cohen A. C-reactive protein and transesophageal echocardiographic markers of thromboembolism in patients with atrial fibrillation. Int J Cardiol. 2012;159:40-6,

54. Qu YC, Du YM, Wu SL, Chen QX, Wu HL, Zhou SF. Activated nuclear factor-kappaB and increased tumor necrosis factor-alpha in atrial tissue of atrial fibrillation. Scand Cardiovasc J. 2009;43:292-7.

55. Pinto A, Tuttolomondo A, Casuccio A, Di Raimondo D, Di Sciacca R, Arnao V, Licata G. Immuno-inflammatory predictors of stroke at follow-up in patients with chronic non-valvular atrial fibrillation (NVAF). Clin Sci (Lond). 2009;116:781-9.

56. Pamukcu B, Lip GY, Snezhitskiy V, Shantsila E. The CD40-CD40L system in cardiovascular disease. Ann Med. 2011;43:331-40.

57. Armesilla AL, Lorenzo E, Gomez del Arco P, Martinez-Martinez S, Alfranca A, Redondo JM. Vascular endothelial growth factor activates nuclear factor of activated $\mathrm{T}$ cells in human endothelial cells: a role for tissue factor gene expression. Mol Cell Biol. 1999;19:2032-43.

58. Chung NA, Belgore F, Li-Saw-Hee FL, Conway DS, Blann AD, Lip GY. Is the hypercoagulable state in atrial fibrillation mediated by vascular endothelial growth factor? Stroke. 2002;33:2187-91.

59. Freedman JE, Loscalzo J, Barnard MR, Alpert C, Keaney JF, Michelson AD. Nitric oxide released from activated platelets inhibits platelet recruitment. J Clin Invest. 1997;100:350-6.

60. Swiatkowska M, Cierniewska-Cieslak A, Pawlowska Z, Cierniewski CS. Dual regulatory effects of nitric oxide on plasminogen activator inhibitor type 1 expression in endothelial cells. Eur J Biochem. 2000;267:1001-7.

61. Davis ME, Cai H, Drummond GR, Harrison DG. Shear stress regulates endothelial nitric oxide synthase expression through c-Src by divergent signaling pathways. Circ Res. 2001;89:1073-80.

62. Cai H, Li Z, Goette A, Mera F, Honeycutt C, Feterik K, Wilcox JN, Dudley SC Jr., Harrison DG, Langberg JJ. Downregulation of endocardial nitric oxide synthase expression and nitric oxide production in atrial fibrillation: potential mechanisms for atrial thrombosis and stroke. Circulation. 2002;106:2854-8.

63. Borgognone A, Shantsila E, Worrall SM, Prompunt E, Loka T, Loudon BL, Chimen M, Ed Rainger G, Lord JM, Turner A, Nightingale P, Feelisch M, Kirchhof P, Lip GYH, Watson SP, Frenneaux MP, Madhani M. Nitrite circumvents platelet resistance to nitric oxide in patients with heart failure preserved ejection fraction and chronic atrial fibrillation. Cardiovasc Res. 2018;114: 1313-23. 
64. Goette A, Staack T, Rocken C, Arndt M, Geller JC, Huth C, Ansorge S, Klein HU, Lendeckel U. Increased expression of extracellular signal-regulated kinase and angiotensin-converting enzyme in human atria during atrial fibrillation. J Am Coll Cardiol. 2000;35:1669-77.

65. Price MJ. The WATCHMAN Left Atrial Appendage Closure Device: Technical Considerations and Procedural Approach. Interv Cardiol Clin. 2018;7:201-12.

66. Whisenant B, Weiss P. Left Atrial Appendage Closure with TranscatheterDelivered Devices. Interv Cardiol Clin. 2014;3:209-18.

67. Gloekler S, Shakir S, Doblies J, Khattab AA, Praz F, Guerios Ê, Koermendy D, Stortecky S, Pilgrim T, Buellesfeld L, Wenaweser P, Windecker S, Moschovitis A, Jaguszewski M, Landmesser U, Nietlispach F, Meier B. Early results of first versus second generation Amplatzer occluders for left atrial appendage closure in patients with atrial fibrillation. Clin Res Cardiol. 2015;104:656-65

68. Huang H, Liu Y, Xu Y, Wang Z, Li Y, Cao K, Zhang S, Yang Y, Yang X, Huang D, Yu B, Su X, Wu L, Huang C. Percutaneous Left Atrial Appendage Closure With the LAmbre Device for Stroke Prevention in Atrial Fibrillation: A Prospective, Multicenter Clinical Study. JACC Cardiovasc Interv. 2017; 10:2188-94

69. Sabiniewicz R, Hiczkiewicz J, Wanczura P, Stecko W, Curzytek A. First-inhuman experience with the Cardia Ultraseal left atrial appendage closure device: The feasibility study. Cardiol J. 2016;23:652-4.

70. Bartus K, Han FT, Bednarek J, Myc J, Kapelak B, Sadowski J, Lelakowski J, Bartus S, Yakubov SJ, Lee RJ. Percutaneous left atrial appendage suture ligation using the LARIAT device in patients with atrial fibrillation: initial clinical experience. J Am Coll Cardiol. 2013;62:108-18.

71. Berti S, Paradossi U, Meucci F, Trianni G, Tzikas A, Rezzaghi M, Stolkova M, Palmieri C, Mori F, Santoro G. Periprocedural intracardiac echocardiography for left atrial appendage closure: a dual-center experience. JACC Cardiovasc Interv. 2014;7:1036-44.

72. Nietlispach F, Gloekler S, Krause R, Shakir S, Schmid M, Khattab A, Wenaweser P, Windecker S, Meier B. Amplatzer left atrial appendage occlusion: single center 10-year experience. Catheter Cardiovasc Interv. 2013;82: 283-9.

73. Veinot JP, Harrity PJ, Gentile F, Khandheria BK, Bailey KR, Eickholt JT, Seward JB, Tajik AJ, Edwards WD. Anatomy of the normal left atrial appendage: a quantitative study of age-related changes in 500 autopsy hearts: implications for echocardiographic examination. Circulation. 1997;96:3112-5.

74. Wang Y, Di Biase L, Horton RP, Nguyen T, Morhanty P, Natale A. Left atrial appendage studied by computed tomography to help planning for appendage closure device placement. J Cardiovasc Electrophysiol. 2010;21:973-82.

75. Troupis J, Crossett M, Scneider-Kolsky M, Nandurkar D. Presence of accessory left atrial appendage/diverticula in a population with atrial fibrillation compared with those in sinus rhythm: a retrospective review. Int $J$ Cardiovasc Imaging. 2012;28:375-80.

76. Di Biase L, Santangeli P, Anselmino M, Mohanty P, Salvetti I, Gili S, Horton R, Sanchez JE, Bai R, Mohanty S, Pump A, Cereceda Barantes M, Gallinghouse GJ, Burkhardt JD, Cesarani F, Scaglione M, Natale A, Gaita F. Does the left atrial appendage morphology correlate with the risk of stroke in patients with atrial fibrillation? Results from a multicenter study. $J \mathrm{Am}$ Coll Cardiol. 2012;60:531-8.

77. Khurram IM, Dewire J, Mager M, Maqbool F, Zimmerman SL, Zipunnikov V, Beinart R, Marine JE, Spragg DD, Berger RD, Ashikaga H, Nazarian S, Calkins H. Relationship between left atrial appendage morphology and stroke in patients with atrial fibrillation. Heart Rhythm. 2013;10:1843-9.

78. Romero J, Husain SA, Kelesidis I, Sanz J, Medina HM, Garcia MJ. Detection of left atrial appendage thrombus by cardiac computed tomography in patients with atrial fibrillation: a meta-analysis. Circ Cardiovasc Imaging. 2013;6:185-94.
79. Patel AR, Fatemi O, Norton PT, West JJ, Helms AS, Kramer CM, Ferguson JD. Cardiac cycle-dependent left atrial dynamics: implications for catheter ablation of atrial fibrillation. Heart Rhythm. 2008;5:787-93.

80. Budge LP, Shaffer KM, Moorman JR, Lake DE, Ferguson JD, Mangrum JM. Analysis of in vivo left atrial appendage morphology in patients with atrial fibrillation: a direct comparison of transesophageal echocardiography, planar cardiac CT, and segmented three-dimensional cardiac CT. J Interv Card Electrophysiol. 2008;23:87-93.

81. Lopez-Minguez JR, Gonzalez-Fernandez R, Fernandez-Vegas C, MillanNunez V, Fuentes-Canamero ME, Nogales-Asensio JM, Doncel-Vecino J, Yuste Dominguez M, Garcia Serrano L, Sanchez Quintana D. Comparison of imaging techniques to assess appendage anatomy and measurements for left atrial appendage closure device selection. J Invasive Cardiol. 2014;26:462-7. 82. Saw J, Fahmy P, Spencer R, Prakash R, McLaughlin P, Nicolaou S,Tsang M. Comparing Measurements of CT Angiography, TOE, and Fluoroscopy of the Left Atrial Appendage for Percutaneous Closure. J Cardiovasc Electrophysiol. 2016;27:414-22.

83. Wang DD, Eng M, Kupsky D, Myers E, Forbes M, Rahman M, Zaidan M, Parikh S, Wyman J, Pantelic M, Song T, Nadig J, Karabon P, Greenbaum A, O'Neill W. Application of 3-Dimensional Computed Tomographic Image Guidance to WATCHMAN Implantation and Impact on Early Operator Learning Curve: Single-Center Experience. JACC Cardiovasc Interv. 2016; 9:2329-40.

84. Rajwani A, Nelson AJ, Shirazi MG, Disney PJS, Teo KSL, Wong DTL, Young GD, Worthley SG. CT sizing for left atrial appendage closure is associated with favourable outcomes for procedural safety. Eur Heart J Cardiovasc Imaging. 2017;18:1361-8.

85. Goitein O, Fink N, Hay I, Di Segni E, Guetta V, Goitein D, Brodov Y, Konen E, Glikson M. Cardiac CT Angiography (CCTA) predicts left atrial appendage occluder device size and procedure outcome. Int $J$ Cardiovasc Imaging. 2017;33:739-47.

86. Al-Kassou B, Tzikas A, Stock F, Neikes F, Volz A, Omran H. A comparison of two-dimensional and real-time 3D transoesophageal echocardiography and angiography for assessing the left atrial appendage anatomy for sizing a left atrial appendage occlusion system: impact of volume loading. EuroIntervention. 2017;12:2083-91.

87. Goitein O, Fink N, Guetta V, Beinart R, Brodov Y, Konen E, Goitein D, Di Segni E, Grupper A, Glikson M. Printed MDCT 3D models for prediction of left atrial appendage (LAA) occluder device size: a feasibility study. EuroIntervention. 2017;13:e1076-9.

88. Eng MH, Wang DD, Greenbaum AB, Gheewala N, Kupsky D, Aka T, Song T, Kendall BJ, Wyman J, Myers E, Forbes M, O’Neill WW. Prospective, randomized comparison of 3-dimensional computed tomography guidance versus TEE data for left atrial appendage occlusion (PRO3DLAAO). Catheter Cardiovasc Interv. 2018;92:401-7.

89. Saw J. Intracardiac Echocardiography for Endovascular Left Atrial Appendage Closure: Is it Ready for Primetime? JACC Cardiovasc Interv. 2017;10:2207-10.

90. Reddy VY, Holmes D, Doshi SK, Neuzil P, Kar S. Safety of percutaneous left atrial appendage closure: results from the Watchman Left Atrial Appendage System for Embolic Protection in Patients with AF (PROTECT AF) clinical trial and the Continued Access Registry. Circulation. 2011;123:417-24.

91. Reddy VY, Möbius-Winkler S, Miller MA, Neuzil P, Schuler G, Wiebe J, Sick P, Sievert H. Left Atrial Appendage Closure With the Watchman Device in Patients With a Contraindication for Oral Anticoagulation: The ASAP Study (ASA Plavix Feasibility Study With Watchman Left Atrial Appendage Closure Technology). J Am Coll Cardiol. 2013;61:2551-6.

92. Saw J, Tzikas A, Shakir S, Gafoor S, Omran H, Nielsen-Kudsk JE, Kefer J, Aminian A, Berti S, Santoro G, Nietlispach F, Moschovitis A, Cruz-Gonzalez I, Stammen F, Tichelbäcker T, Freixa X, Ibrahim R, Schillinger W, Meier B, Sievert H, Gloekler S. Incidence and Clinical Impact of Device-Associated 
Thrombus and Peri-Device Leak Following Left Atrial Appendage Closure With the Amplatzer Cardiac Plug. JACC Cardiovasc Interv. 2017;10:391-9.

93. Lempereur M, Aminian A, Freixa X, Gafoor S, Kefer J, Tzikas A, Legrand Z, Saw J. Device-associated thrombus formation after left atrial appendage occlusion: A systematic review of events reported with the Watchman, the Amplatzer Cardiac Plug and the Amulet. Catheter Cardiovasc Interv. 2018;92:E216-7.

94. Lakkireddy D, Afzal MR, Lee RJ, Nagaraj H, Tschopp D, Gidney B, Ellis C, Altman E, Lee B, Kar S, Bhadwar N, Sanchez M, Gadiyaram V, Evonich R, Rasekh A, Cheng J, Cuoco F, Chandhok S, Gunda S, Reddy M, Atkins D, Bommana S, Cuculich P, Gibson D, Nath J, Ferrell R, Matthew E, Wilber D. Short and long-term outcomes of percutaneous left atrial appendage suture ligation: Results from a US multicenter evaluation. Heart Rhythm. 2016;13:1030-6.

95. Pillarisetti J, Reddy YM, Gunda S, Swarup V, Lee R, Rasekh A, Horton R, Massumi A, Cheng J, Bartus K, Badhwar N, Han F, Atkins D, Bommana S, Earnest M, Nath J, Ferrel R, Bormann S, Dawn B, Di Biase L, Mansour M, Natale A, Lakkireddy D. Endocardial (Watchman) vs epicardial (Lariat) left atrial appendage exclusion devices: Understanding the differences in the location and type of leaks and their clinical implications. Heart Rhythm. 2015;12:1501-7.

96. Boersma LV, Ince H, Kische S, Pokushalov E, Schmitz T, Schmidt B, Gori T, Meincke F, Protopopov AV, Betts T, Foley D, Sievert H, Mazzone P, De Potter T, Vireca E, Stein K, Bergmann MW; EWOLUTION Investigators. Efficacy and safety of left atrial appendage closure with WATCHMAN in patients with or without contraindication to oral anticoagulation: 1-Year follow-up outcome data of the EWOLUTION trial. Heart Rhythm. 2017;14:1302-8.

97. Landmesser U, Schmidt B, Nielsen-Kudsk JE, Lam SCC, Park JW, Tarantini G, Cruz-Gonzalez I, Geist V, Della Bella P, Colombo A, Zeus T, Omran H, Piorkowski C, Lund J, Tondo C, Hildick-Smith D. Left atrial appendage occlusion with the AMPLATZER Amulet device: periprocedural and early clinical/echocardiographic data from a global prospective observational study. EuroIntervention. 2017;13:867-76.

98. Dukkipati SR, Kar S, Holmes DR, Doshi SK, Swarup V, Gibson DN, Maini B, Gordon NT, Main ML, Reddy VY. Device-Related Thrombus After Left Atrial Appendage Closure: Incidence, Predictors, and Outcomes. Circulation. 2018;138:874-85.

99. Saw J, Fahmy P, DeJong P, Lempereur M, Spencer R, Tsang M, Gin K, Jue J, Mayo J, McLaughlin P, Nicolaou S. Cardiac CT angiography for device surveillance after endovascular left atrial appendage closure. Eur Heart $J$ Cardiovasc Imaging. 2015;16:1198-206.

100. Fauchier L, Cinaud A, Brigadeau F, Lepillier A, Pierre B, Abbey S, Fatemi M, Franceschi F, Guedeney P, Jacon P, Paziaud O, Venier S, Deharo JC, Gras D, Klug D, Mansourati J, Montalescot G, Piot O, Defaye P. Devicerelated thrombosis after percutaneous left atrial appendage occlusion for atrial fibrillation. J Am Coll Cardiol. 2018;71:1528-36.

101. Pracon R, Bangalore S, Dzielinska Z, Konka M, Kepka C, Kruk M, Kaczmarska-Dyrda E, Petryka-Mazurkiewicz L, Bujak S, Solecki M, Pskit A, Dabrowska A, Sieradzki B, Plonski A, Ruzyllo W, Witkowski A, Demkow M. Device Thrombosis After Percutaneous Left Atrial Appendage Occlusion Is Related to Patient and Procedural Characteristics but Not to Duration of Postimplantation Dual Antiplatelet Therapy. Circ Cardiovasc Interv. 2018;11: e005997.

102. Meier B. What Lies Beneath Left Atrial Appendage Occlusion: Know Your Enemy. Circ Cardiovasc Interv. 2018;11:e006360.

103. Viles-Gonzalez JF, Kar S, Douglas P, Dukkipati S, Feldman T, Horton R, Holmes D, Reddy VY. The clinical impact of incomplete left atrial appendage closure with the Watchman Device in patients with atrial fibrillation: a PROTECT AF (Percutaneous Closure of the Left Atrial Appendage Versus Warfarin Therapy for Prevention of Stroke in Patients With Atrial Fibrillation) substudy. J Am Coll Cardiol. 2012;59:923-9.
104. Spencer RJ, DeJong P, Fahmy P, Lempereur M, Tsang MYC, Gin KG, Lee PK, Nair P, Tsang TSM, Jue J, Saw J. Changes in Left Atrial Appendage Dimensions Following Volume Loading During Percutaneous Left Atrial Appendage Closure. JACC Cardiovasc Interv. 2015;8:1935-41.

105. Gafoor S, Heuer L, Schulz P, Matic P, Franke J, Bertog S, Reinartz M, Vaskelyte L, Hofmann I, Sievert H. "A bend in time": Shaping the sheath facilitates left atrial appendage closure. Catheter Cardiovasc Interv. 2015;86: E224-8.

106. Holmes DR, Reddy VY, Turi ZG, Doshi SK, Sievert H, Buchbinder M, Mullin CM, Sick P; PROTECT AF Investigators. Percutaneous closure of the left atrial appendage versus warfarin therapy for prevention of stroke in patients with atrial fibrillation: a randomised non-inferiority trial. Lancet. 2009;374: 534-42.

107. Reddy VY, Sievert H, Halperin J, Doshi SK, Buchbinder M, Neuzil P, Huber K, Whisenant B, Kar S, Swarup V, Gordon N, Holmes D; PROTECT AF Steering Committee and Investigators. Percutaneous left atrial appendage closure vs warfarin for atrial fibrillation: a randomized clinical trial. JAMA. 2014;312:1988-98.

108. Holmes DR Jr, Kar S, Price MJ, Whisenant B, Sievert H, Doshi SK, Huber K, Reddy VY. Prospective randomized evaluation of the Watchman Left Atrial Appendage Closure device in patients with atrial fibrillation versus longterm warfarin therapy: the PREVAIL trial. J Am Coll Cardiol. 2014;64:1-12.

109. Reddy VY, Doshi SK, Sievert H, Buchbinder M, Neuzil P, Huber K, Halperin JL, Holmes D; PROTECT AF Investigators. Percutaneous left atrial appendage closure for stroke prophylaxis in patients with atrial fibrillation: 2.3-Year Follow-up of the PROTECT AF (Watchman Left Atrial Appendage System for Embolic Protection in Patients with Atrial Fibrillation) Trial. Circulation. 2013;127:720-9.

110. Price MJ, Reddy VY, Valderrabano M, Halperin JL, Gibson DN, Gordon N, Huber KC, Holmes DR Jr. Bleeding Outcomes After Left Atrial Appendage Closure Compared With Long-Term Warfarin: A Pooled, Patient-Level Analysis of the WATCHMAN Randomized Trial Experience. JACC Cardiovasc Interv. 2015;8:1925-32.

111. Bergmann MW, Betts TR, Sievert H, Schmidt B, Pokushalov E, Kische S, Schmitz T, Meincke F, Stein KM, Boersma LVA, Ince H. Safety and efficacy of early anticoagulation drug regimens after WATCHMAN left atrial appendage closure: three-month data from the EWOLUTION prospective, multicentre, monitored international WATCHMAN LAA closure registry. EuroIntervention. 2017;13:877-84.

112. Boersma LV, Schmidt B, Betts TR, Sievert H, Tamburino C, Teiger E, Pokushalov E, Kische S, Schmitz T, Stein KM, Bergmann MW; EWOLUTION investigators. Implant success and safety of left atrial appendage closure with the WATCHMAN device: peri-procedural outcomes from the EWOLUTION registry. Eur Heart J. 2016;37:2465-74.

113. Reddy VY, Gibson DN, Kar S, O'Neill W, Doshi SK, Horton RP, Buchbinder M, Gordon NT, Holmes DR. Post-Approval U.S. Experience With Left Atrial Appendage Closure for Stroke Prevention in Atrial Fibrillation. J Am Coll Cardiol. 2017;69:253-61.

114. Tzikas A, Shakir S, Gafoor S, Omran H, Berti S, Santoro G, Kefer J, Landmesser U, Nielsen-Kudsk JE, Cruz-Gonzalez I, Sievert H, Tichelbacker T, Kanagaratnam P, Nietlispach F, Aminian A, Kasch F, Freixa X, Danna P, Rezzaghi M, Vermeersch P, Stock F, Stolcova M, Costa M, Ibrahim R, Schillinger W, Meier B, Park JW. Left atrial appendage occlusion for stroke prevention in atrial fibrillation: multicentre experience with the AMPLATZER Cardiac Plug. EuroIntervention. 2016;11:1170-9.

115. Lopez Minguez JR, Asensio JM, Gragera JE, Costa M, Gonzalez IC, de Carlos FG, Diaz JA, Martin Yuste V, Gonzalez RM, Dominguez-Franco A, Buendia AB, Garibi JH, Hernandez FH, Ribeiro VH. Two-year clinical outcome from the Iberian registry patients after left atrial appendage closure. Heart. 2015;101:877-83 
116. Landmesser U, Tondo C, Camm J, Diener HC, Paul V, Schmidt B, Settergren M, Teiger E, Nielsen-Kudsk JE, Hildick-Smith D. Left atrial appendage occlusion with the AMPLATZER Amulet device: one-year followup from the prospective global Amulet observational registry. EuroIntervention. 2018;14:e590-7

117. Kleinecke C, Park JW, Godde M, Zintl K, Schnupp S, Brachmann J. Twelve-month follow-up of left atrial appendage occlusion with Amplatzer Amulet. Cardiol J. 2017;24:131-8.

118. Berti S, Santoro G, Brscic E, Montorfano M, Vignali L, Danna P, Tondo C, D'Amico G, Stabile A, Saccà S, Patti G, Rapacciuolo A, Poli A, Golino P, Magnavacchi P, De Caterina A, Meucci F, Pezzulich B, Rezzaghi M, Stolcova M, Tarantini G. Left atrial appendage closure using AMPLATZER ${ }^{\mathrm{TM}}$ devices: A large, multicenter, Italian registry. Int J Cardiol. 2017;248:103-7.

119. Nielsen-Kudsk J, Johnsen SP, Wester P, Damgaard D, Airaksinen J, Lund J, De Backer O, Pakarinen S, Odenstedt J, Vikman S, Settergren M, Kongstad O, Rosenqvist M, Krieger D. Left atrial appendage occlusion versus standard medical care in patients with atrial fibrillation and intracerebral haemorrhage: a propensity score-matched follow-up study. EuroIntervention. 2017;13:371-8.

120. Fink T, Schlüter M, Heeger CH, Lemeš C, Maurer T, Reissmann B, Rottner L, Santoro F, Tilz RR, Alessandrini H, Rillig A, Mathew S, Wohlmuth P, Fang Q, Lee R, Ouyang F, Kuck KH, Metzner A. Combination of Left Atrial Appendage Isolation and Ligation to Treat Nonresponders of Pulmonary Vein Isolation. JACC Clin Electrophysiol. 2018;4:1569-79.

121. Miller MA, Gangireddy SR, Doshi SK, Aryana A, Koruth JS, Sennhauser S, d'Avila A, Dukkipati SR, Neuzil P, Reddy VY. Multicenter study on acute and long-term safety and efficacy of percutaneous left atrial appendage closure using an epicardial suture snaring device. Heart Rhythm. 2014;11:1853-9.

122. Sievert H, Rasekh A, Bartus K, Morelli RL, Fang Q, Kuropka J, Le D, Gafoor S, Heuer L, Safavi-Naeini P, Hue TF, Marcus GM, Badhwar N, Massumi A, Lee RJ. Left Atrial Appendage Ligation in Nonvalvular Atrial Fibrillation Patients at High Risk for Embolic Events With Ineligibility for Oral Anticoagulation: Initial Report of Clinical Outcomes. JACC Clin Electrophysiol. 2015;1:465-74.

123. Betts TR, Leo M, Panikker S, Kanagaratnam P, Koa-Wing M, Davies DW, Hildick-Smith D, Wynne DG, Ormerod O, Segal OR, Chow AW, Todd D, Cabrera Gomez S, Kirkwood GJ, Fox D, Pepper C, Foran J, Wong T. Percutaneous left atrial appendage occlusion using different technologies in the United Kingdom: A multicenter registry. Catheter Cardiovasc Interv. 2017; 89:484-92.

124. Yerasi C, Lazkani M, Kolluru P, Miryala V, Kim J, Moole H, Sawant AC, Morris M, Pershad A. An updated systematic review and meta-analysis of early outcomes after left atrial appendage occlusion. J Interv Cardiol. 2018;31: 197-206.

125. Bajaj NS, Parashar A, Agarwal S, Sodhi N, Poddar KL, Garg A, Tuzcu EM, Kapadia SR. Percutaneous left atrial appendage occlusion for stroke prophylaxis in nonvalvular atrial fibrillation: a systematic review and analysis of observational studies. JACC Cardiovasc Interv. 2014;7:296-304.

126. Li X, Wen SN, Li SN, Bai R, Liu N, Feng L, Ruan YF, Du X, Dong JZ, Ma CS. Over 1-year efficacy and safety of left atrial appendage occlusion versus novel oral anticoagulants for stroke prevention in atrial fibrillation: A systematic review and meta-analysis of randomized controlled trials and observational studies. Heart Rhythm. 2016;13:1203-14.

127. Sahay S, Nombela-Franco L, Rodes-Cabau J, Jimenez-Quevedo P, Salinas P, Biagioni C, Nunez-Gil I, Gonzalo N, de Agustin JA, Del Trigo M, Perez de Isla L, Fernandez-Ortiz A, Escaned J, Macaya C. Efficacy and safety of left atrial appendage closure versus medical treatment in atrial fibrillation: a network meta-analysis from randomised trials. Heart. 2017;103:139-47.

128. Cochet H, Iriart X, Sridi S, Camaioni C, Corneloup O, Montaudon M, Laurent F, Selmi W, Renou P, Jalal Z, Thambo JB. Left atrial appendage patency and device-related thrombus after percutaneous left atrial appendage occlusion: a computed tomography study. Eur Heart J Cardiovasc Imaging. 2018;19:1351-61.

129. Urena M, Rodés-Cabau J, Freixa X, Saw J, Webb JG, Freeman M, Horlick E, Osten M, Chan A, Marquis JF, Champagne J, Ibrahim R. Percutaneous left atrial appendage closure with the AMPLATZER cardiac plug device in patients with nonvalvular atrial fibrillation and contraindications to anticoagulation therapy. J Am Coll Cardiol. 2013;62:96-102.

130. Connolly SJ, Ezekowitz MD, Yusuf S, Eikelboom J, Oldgren J, Parekh A, Pogue J, Reilly PA, Themeles E, Varrone J, Wang S, Alings M, Xavier D, Zhu J, Diaz R, Lewis BS, Darius H, Diener HC, Joyner CD, Wallentin L; RE-LY Steering Committee and Investigators. Dabigatran versus Warfarin in Patients with Atrial Fibrillation. $N$ Engl J Med. 2009;361:1139-51.

131. Patel MR, Mahaffey KW, Garg J, Pan G, Singer DE, Hacke W, Breithardt G, Halperin JL, Hankey GJ, Piccini JP, Becker RC, Nessel CC, Paolini JF, Berkowitz SD, Fox KA, Califf RM; ROCKET AF Investigators. Rivaroxaban versus Warfarin in Nonvalvular Atrial Fibrillation. $N$ Engl J Med. 2011;365:883-91.

132. Granger CB, Alexander JH, McMurray JJ, Lopes RD, Hylek EM, Hanna M, Al-Khalidi HR, Ansell J, Atar D, Avezum A, Bahit MC, Diaz R, Easton JD, Ezekowitz JA, Flaker G, Garcia D, Geraldes M, Gersh BJ, Golitsyn S, Goto S, Hermosillo AG, Hohnloser SH, Horowitz J, Mohan P, Jansky P, Lewis BS, Lopez-Sendon JL, Pais P, Parkhomenko A, Verheugt FW, Zhu J, Wallentin L; ARISTOTLE Committees and Investigators. Apixaban versus Warfarin in Patients with Atrial Fibrillation. N Engl J Med. 2011;365: 981-92.

133. Giugliano RP, Ruff CT, Braunwald E, Murphy SA, Wiviott SD, Halperin JL, Waldo AL, Ezekowitz MD, Weitz JI, Špinar J, Ruzyllo W, Ruda M, Koretsune Y, Betcher J, Shi M, Grip LT, Patel SP, Patel I, Hanyok JJ, Mercuri M, Antman EM; ENGAGE AF-TIMI 48 Investigators. Edoxaban versus Warfarin in Patients with Atrial Fibrillation. N Engl J Med. 2013;369:2093-104.

134. Mant J, Hobbs FD, Fletcher K, Roalfe A, Fitzmaurice D, Lip GY, Murray E; BAFTA investigators; Midland Research Practices Network (MidReC). Warfarin versus aspirin for stroke prevention in an elderly community population with atrial fibrillation (the Birmingham Atrial Fibrillation Treatment of the Aged Study, BAFTA): a randomised controlled trial. Lancet. 2007;370:493-503.

135. ACTIVE Writing Group of the ACTIVE Investigators, Connolly S, Pogue J, Hart R, Pfeffer M, Hohnloser S, Chrolavicius S, Pfeffer M, Hohnloser S, Yusuf S. Clopidogrel plus aspirin versus oral anticoagulation for atrial fibrillation in the Atrial fibrillation Clopidogrel Trial with Irbesartan for prevention of Vascular Events (ACTIVE W): a randomised controlled trial. Lancet. 2006;367:1903-12.

136. FDA. Executive Summary P130013 Prepared for the October 8, 2014 meeting of the Circulatory System Devices Panel.

137. Holmes DR Jr, Doshi SK, Kar S, Price MJ, Sanchez JM, Sievert H, Valderrabano M, Reddy VY. Left Atrial Appendage Closure as an Alternative to Warfarin for Stroke Prevention in Atrial Fibrillation: A Patient-Level MetaAnalysis. J Am Col Cardiol. 2015;65:2614-23.

138. Mandrola J, Foy A, Naccarelli G. Percutaneous Left Atrial Appendage Closure is not Ready for Routine Clinical Use. Heart Rhythm. 2018;15: 298-301.

139. Connolly SJ, Eikelboom J, Joyner C, Diener HC, Hart R, Golitsyn S, Flaker G, Avezum A, Hohnloser SH, Diaz R, Talajic M, Zhu J, Pais P, Budaj A, Parkhomenko A, Jansky P, Commerford P, Tan RS, Sim KH, Lewis BS, Van Mieghem W, Lip GY, Kim JH, Lanas-Zanetti F, Gonzalez-Hermosillo A, Dans AL, Munawar M, O’Donnell M, Lawrence J, Lewis G, Afzal R, Yusuf S; AVERROES Steering Committee and Investigators. Apixaban in Patients with Atrial Fibrillation. N Engl J Med. 2011;364:806-17.

140. Quinn GR, Severdija ON, Chang Y, Singer DE. Wide Variation in Reported Rates of Stroke Across Cohorts of Patients with Atrial Fibrillation. Circulation. 2017;135:208-19. 
141. Ruff CT, Giugliano RP, Braunwald E, Hoffman EB, Deenadayalu N, Ezekowitz MD, Camm AJ, Weitz JI, Lewis BS, Parkhomenko A, Yamashita T, Antman EM. Comparison of the efficacy and safety of new oral anticoagulants with warfarin in patients with atrial fibrillation: a meta-analysis of randomised trials. Lancet. 2014;383:955-62.

142. Newcastle and York External Assessment Centre. Nice Observational Data Unit. Commissioning Through Evaluation (CTE) Percutaneous Occlusion of the Left Atrial Appendage in Non-Valvular Atrial Fibrillation for the Prevention of Thromboembolism (LAAO). Final report 15.02.2018. http://allcatsrgrey.org.uk/wp/wpfb-file/left-atrial-appendage-occlusion-evaluationreport-pdf/

143. Holmes DR, Reddy VY, Buchbinder M, Stein K, Elletson M, Bergmann MW, Schmidt B, Saw J. The Assessment of the Watchman Device in Patients Unsuitable for Oral Anticoagulation (ASAP-TOO) trial. Am Heart $J$. 2017;189:68-74.

144. Eikelboom JW, Connolly SJ, Bosch J, Dagenais GR, Hart RG, Shestakovska O, Diaz R, Alings M, Lonn EM, Anand SS, Widimsky P, Hori M, Avezum A, Piegas LS, Branch KRH, Probstfield J, Bhatt DL, Zhu J, Liang Y, Maggioni AP, Lopez-Jaramillo P, O’Donnell M, Kakkar AK, Fox, KAA, Parkhomenko AN, Ertl G, Stork S, Keltai M, Ryden L, Pogosova N, Dans AL, Lanas F, Commerford PJ, Torp-Pedersen C, Guzik TJ, Verhamme PB, Vinereanu D, Kim J, Tonkin AM, Lewis BS, Felix C, Yusoff S; COMPASS Investigators. Rivaroxaban with or without Aspirin in Stable Cardiovascular Disease. N Engl J Med. 2017;377:1319-30.

145. Mihas C, Alevizos A, Arapaki A, Mariolis A. Warfarin versus aspirin for stroke prevention (BAFTA). Lancet. 2007;370:1606; author reply 1606-7.

146. Lempereur M, Aminian A, Freixa X, Gafoor S, Shakir S, Omran H, Berti S, Santoro G, Kefer J, Landmesser U, Nielsen-Kudsk JE, Cruz-Gonzalez I, Kanagaratnam P, Nietlispach F, Ibrahim R, Sievert H, Schillinger W, Park JW, Gloekler S, Tzikas A. Left Atrial Appendage Occlusion in Patients With Atrial Fibrillation and Previous Major Gastrointestinal Bleeding (from the Amplatzer Cardiac Plug Multicenter Registry). Am J Cardiol. 2017;120:414-20.

147. Potpara TS, Ferro CJ, Lip GYH. Use of oral anticoagulants in patients with atrial fibrillation and renal dysfunction. Nat Rev Nephrol. 2018;14: $337-51$.

148. Lau YC, Proietti M, Guiducci E, Blann AD, Lip GYH. Atrial Fibrillation and Thromboembolism in Patients With Chronic Kidney Disease. $J$ Am Coll Cardiol. 2016;68:1452-64.

149. Kefer J, Tzikas A, Freixa X, Shakir S, Gafoor S, Nielsen-Kudsk JE, Berti S, Santoro G, Aminian A, Landmesser U, Nietlispach F, Ibrahim R, Danna PL, Benit E, Budts W, Stammen F, De Potter T, Tichelbacker T, Gloekler S, Kanagaratnam P, Costa M, Cruz-Gonzalez I, Sievert H, Schillinger W, Park JW, Meier B, Omran H. Impact of chronic kidney disease on left atrial appendage occlusion for stroke prevention in patients with atrial fibrillation. Int J Cardiol. 2016;207:335-40.

150. Paquette M, Riou França L, Teutsch C, Diener HC, Lu S, Dubner SJ, Ma CS, Rothman KJ, Zint K, Halperin JL, Huisman MV, Lip GYH, Nieuwlaat R. Persistence With Dabigatran Therapy at 2 Years in Patients With Atrial Fibrillation. J Am Coll Cardiol. 2017:70:1573-1583.

151. Lewalter T, Brachmann J, Akin I, Sievert H, Geist V, Zeymer U, Erkapic D, Mudra H, Pleger S, Hochadel M, Senges J. Abstract 17170: Occlusion of left atrial appendage in patients with atrial fibrillation: clinical results from the LAARGE registry. Circulation. 2017;136:A17170.

152. Rillig A, Tilz RR, Lin T, Fink T, Heeger CH, Arya A, Metzner A, Mathew S, Wissner E, Makimoto H, Wohlmuth P, Kuck KH, Ouyang F. Unexpectedly high incidence of stroke and left atrial appendage thrombus formation after electrical isolation of the left atrial appendage for the treatment of atrial tachyarrhythmias. Circ Arrhythm Electrophysiol. 2016;9:e003461.

153. Di Biase L, Burkhardt JD, Mohanty P, Mohanty S, Sanchez JE, Trivedi C, Güneş M, Gökoğlan Y, Gianni C, Horton RP, Themistoclakis S, Gallinghouse GJ, Bailey S, Zagrodzky JD, Hongo RH, Beheiry S, Santangeli P, Casella M, Dello
Russo A, Al-Ahmad A, Hranitzky P, Lakkireddy D, Tondo C, Natale A. Left atrial appendage isolation in patients with longstanding persistent AF undergoing catheter ablation: BELIEF trial. J Am Coll Cardiol. 2016;68:1929-40.

154. Di Biase L, Natale A, Romero J. Thrombogenic and arrhythmogenic roles of the left atrial appendage in atrial fibrillation. Circulation. 2018;138: 2036-50.

155. Kim YG, Shim J, Oh SK, Lee KN, Choi JI, Kim YH. Electrical isolation of the left atrial appendage increases the risk of ischaemic stroke and transient ischaemic attack regardless of postisolation flow velocity. Heart Rhythm. 2018;15:1746-53.

156. Calvo N, Salterain N, Arguedas H, Macias A, Esteban A, García de Yébenes M, Gavira JJ, Barba J, García-Bolao I. Combined catheter ablation and left atrial appendage closure as a hybrid procedure for the treatment of atrial fibrillation. Europace. 2015;17:1533-40.

157. Fassini G, Conti S, Moltrasio M, Maltagliati A, Tundo F, Riva S, Dello Russo A, Casella M, Majocchi B, Zucchetti M, Russo E, Marino V, Pepi M, Tondo C. Concomitant cryoballoon ablation and percutaneous closure of left atrial appendage in patients with atrial fibrillation. Europace. 2016;18:1705-10. 158. Wintgens L, Romanov A, Phillips K, Ballesteros G, Swaans M, Folkeringa R, Garcia-Bolao I, Pokushalov E, Boersma L. Combined atrial fibrillation ablation and left atrial appendage closure: long-term follow-up from a large multicentre registry. Europace. 2018;20:1783-9.

159. Phillips KP, Pokushalov E, Romanov A, Artemenko S, Folkeringa RJ, Szili-Torok T, Senatore G, Stein KM, Razali O, Gordon N, Boersma LVA. Combining Watchman left atrial appendage closure and catheter ablation for atrial fibrillation: multicentre registry results of feasibility and safety during implant and 30 days follow-up. Europace. 2018;20:949-55.

160. Kuwata S, Vierecke J, Gloekler S, Maisano F, Meier B, Nietlispach F. Left atrial appendage closure for "primary primary" prevention during percutaneous closure of septal defects in patients with large atria but no atrial fibrillation. Cardiol J. 2018;25:179-87.

161. Tilz RR, Potpara T, Chen J, Dobreanu D, Larsen TB, Haugaa KH, Dagres N. Left atrial appendage occluder implantation in Europe: indications and anticoagulation post-implantation. Results of the European Heart Rhythm Association Survey. Europace. 2017;19:1737-42.

162. Fountain RB, Holmes DR, Chandrasekaran K, Packer D, Asirvatham S, Van Tassel R, Turi Z. The PROTECT AF (WATCHMAN Left Atrial Appendage System for Embolic PROTECTion in Patients with Atrial Fibrillation) trial. Am Heart J. 2006;151:956-61.

163. Bosche LI, Afshari F, Schone D, Ewers A, Mugge A, Gotzmann M. Initial Experience With Novel Oral Anticoagulants During the First 45 Days After Left Atrial Appendage Closure With the Watchman Device. Clin Cardiol. 2015;38:720-4.

164. Enomoto Y, Gadiyaram VK, Gianni C, Horton RP, Trivedi C, Mohanty S, Di Biase L, Al-Ahmad A, Burkhardt JD, Narula A, Janczyk G, Price MJ, Afzal MR, Atoui M, Earnest M, Swarup V, Doshi SK, van der Zee S, Fisher R, Lakkireddy DR, Gibson DN, Natale A, Reddy VY. Use of non-warfarin oral anticoagulants instead of warfarin during left atrial appendage closure with the Watchman device. Heart Rhythm. 2017;14:19-24.

165. Kirchhof P, Benussi S, Kotecha D, Ahlsson A, Atar D, Casadei B, Castella M, Diener HC, Heidbuchel H, Hendriks J, Hindricks G, Manolis AS, Oldgren J, Popescu BA, Schotten U, Van Putte B, Vardas P; ESC Scientific Document Group. 2016 ESC Guidelines for the management of atrial fibrillation developed in collaboration with EACTS. Eur Heart J. 2016;37:2893-962.

166. Lip GYH, Banerjee A, Boriani G, Chiang CE, Fargo R, Freedman B, Lane DA, Ruff CT, Turakhia M, Werring D, Patel S, Moores L. Antithrombotic Therapy for Atrial Fibrillation: CHEST Guideline and Expert Panel Report. Chest. 2018;154:1121-201

167. Block PC, Burstein S, Casale PN, Kramer PH, Teirstein P, Williams DO, Reisman M. Percutaneous left atrial appendage occlusion for patients in atrial fibrillation suboptimal for warfarin therapy: 5-year results of the PLAATO 
(Percutaneous Left Atrial Appendage Transcatheter Occlusion) Study. JACC Cardiovasc Interv. 2009;2:594-600.

168. Krumsdorf U, Ostermayer S, Billinger K, Trepels T, Zadan E, Horvath K, Sievert $\mathrm{H}$. Incidence and clinical course of thrombus formation on atrial septal defect and patient foramen ovale closure devices in 1,000 consecutive patients. J Am Coll Cardiol. 2004;43:302-9.

169. Park JW, Bethencourt A, Sievert H, Santoro G, Meier B, Walsh K, LopezMinguez JR, Meerkin D, Valdes M, Ormerod O, Leithauser B. Left atrial appendage closure with Amplatzer cardiac plug in atrial fibrillation: initial European experience. Catheter Cardiovasc Interv. 2011;77:700-6.

170. Weise FK, Bordignon S, Perrotta L, Konstantinou A, Bologna F, Nagase T, Chen S, Chun KRJ, Schmidt B. Short-term dual lantiplatelet therapy after interventional left atrial appendage closure with different devices. EuroIntervention. 2018;13:e2138-46.

171. Chen S, Weise FK, Chun KJ, Schmidt B. Antithrombotic strategies after interventional left atrial lappendage closure: an update. Expert Rev Cardiovasc Ther. 2018;16:675-8.

172. Tzikas A, Gafoor S, Meerkin D, Freixa X, Cruz-Gonzalez I, Lewalter T, Saw J, Berti S, Nielsen-Kudsk JE, Ibrahim R, Lakkireddy D, Paul V, Arzamendi D, Nietlispach F, Worthley SG, Hildick-Smith D, Thambo JB, Tondo C, Aminian A, Kalarus Z, Schmidt B, Sondergaard L, Kefer J, Meier B, Park JW, Sievert H, Omran H. Left atrial appendage occlusion with the AMPLATZER Amulet device: an expert consensus step-by-step approach. EuroIntervention. 2016;11:1512-21.

173. Thakkar J, Vasdeki D, Tzikas A, Meier B, Saw J. Incidence, Prevention, and Management of Periprocedural Complications of Left Atrial Appendage Occlusion. Interv Cardiol Clin. 2018;7:243-52.

174. Masoudi FA, Calkins H, Kavinsky CJ, Drozda JP Jr, Gainsley P, Slotwiner DJ, Turi ZG. 2015 ACC/HRS/SCAI Left Atrial Appendage Occlusion Device Societal Overview. J Am Coll Cardiol. 2015;66:1497-513.

175. Kavinsky CJ, Kusumoto FM, Bavry AA, Bailey SR, Ellenbogen KA, Hess PL, Lustgarten DL, Moussa ID, Spies C. SCAI/ACC/HRS Institutional and Operator Requirements for Left Atrial Appendage Occlusion. J Am Coll Cardiol. 2016;67:2295-305.

176. Badhwar V, Rankin JS, Damiano RJ Jr, Gillinoy AM, Bakaeen FG, Edgerton JR, Philpott JM, McCarthy PM, Bolling SF, Roberts HG, Thourani VH, Suri RM, Shemin RJ, Firestone S, Ad N. The Society of Thoracic Surgeons 2017 Clinical Practice Guidelines for the Surgical Treatment of Atrial Fibrillation. Ann Thorac Surg. 2017;103:329-341.

177. Kanderian AS, Gillinov AM, Pettersson GB, Blackstone E, Klein AL. Success of surgical left atrial appendage closure: assessment by transesophageal echocardiography. J Am Coll Cardiol. 2008;52:924-9.

178. Katz ES, Tsiamtsiouris T, Applebaum RM, Schwartzbard A, Tunick PA, Kronzon I. Surgical left atrial appendage ligation is frequently incomplete: a transesophageal echocardiographic study. J Am Coll Cardiol. 2000;36: $468-71$.

179. Garcia-Fernandez MA, Perez-David E, Quiles J, Peralta J, Garcia-Rojas I, Bermejo J, Moreno M, Silva J. Role of left atrial appendage obliteration in stroke reduction in patients with mitral valve prosthesis: a transesophageal echocardiographic study. J Am Coll Cardiol. 2003;42:1253-8.

180. Lee RL, Vassallo P, Kruse J, Malaisrie SC, Rigolin V, Andrei AC, McCarthy P. A randomized, prospective pilot comparison of three atrial appendage elimination techniques: internal ligation, stapled excision, and surgical excision. J Thorac Cardiovasc Surg. 2016;152:1075-80.

181. Cullen MW, Stulak JM, Li Z, Powell BD, White RD, Ammash NM, Nkomo VT. Left atrial appendage patency at cardioversion after surgical left atrial appendage intervention. Ann Thorac Surg. 2016;101:675-81.

182. Healey JS, Crystal E, Lamy A, Teoh K, Semelhago L, Hohnloser SH, Cybulsky I, Abouzahr L, Sawchuck C, Carroll S, Morillo C, Kleine P, Chu V, Lonn E, Connolly SJ. Left Atrial Appendage Occlusion Study (LAAOS): results of a randomized controlled pilot study of left atrial appendage occlusion during coronary bypass surgery in patients at risk for stroke. Am Heart $J$. 2005; 150:288-93.

183. Ando M, Funamoto M, Cameron DE, Sundt TM 3rd. Concomitant surgical closure of left atrial appendage: A systematic review and meta-analysis. J Thorac Cardiovasc Surg. 2018;156:1071-1080.e2.

184. Yao X, Gersh BJ, Holmes DR Jr, Melduni RM, Johnsrud DO, Sangaralingham LR, Saha ND, Noseworthy PA. Association of Surgical Left Atrial Appendage Occlusion With Subsequent Stroke and Mortality Among Patients Undergoing Cardiac Surgery. JAMA. 2018;319:2116-26.

185. Friedman DJ, Piccini JP, Wang T, Zheng J, Malaisrie SC, Holmes DR, Suri RM, Mack MJ, Badhwar V, Jacobs JP, Gaca JG, Chow SC, Peterson ED, Brennan JM. Association Between Left Atrial Appendage Occlusion and Readmission for Thromboembolism Among Patients with Atrial Fibrillation Undergoing Concomitant Cardiac Surgery. JAMA. 2018;319:365-74.

186. Friedman PA, Asirvatham SJ, Dalegrave C, Kinoshita M, Danielsen AJ, Johnson SB, Hodge DO, Munger TM, Packer DL, Bruce CJ. Percutaneous epicardial left atrial appendage closure: preliminary results of an electrogram guided approach. J Cardiovasc Electrophysiol. 2009;20:908-15.

187. Bruce CJ, Asirvatham SJ, McCaw T, Hong E, Berhow S, Ammash NM, Friedman PA. Novel percutaneous left atrial appendage closure. Cardiovasc Revasc Med. 2013;14:164-7.

188. Salzberg SP, Plass A, Emmert MY, Desbiolles L, Alkadhi H, Grünenfelder J, Genoni M. Left atrial appendage clip occlusion: early clinical results. J Thorac Cardiovasc Surg. 2010;139:1269-74.

189. Starck CT, Steffel J, Emmert MY, Plass A, Mahapatra S, Falk V, Salzberg SP. Epicardial left atrial appendage clip occlusion also provides the electrical isolation of the left atrial appendage. Interact Cardiovasc Thorac Surg. 2012;15:416-8.

190. Bartus K, Bednarek J, Myc J, Kapelak B, Sadowski J, Lelakowski J, Yakubov SJ, Lee RJ. Feasibility of closed-chest ligation of the left atrial appendage in humans. Heart Rhythm. 2011;8:188-93.

191. Cruz-Gonzalez I, Fuertes-Barahona M, Moreno-Samos JC, GonzalezFerreiro R, Lam YY, Sanchez PL. Left atrial appendage occlusion: the current device landscape and future perspectives. Intervent Cardiol Clin. 2018;7: 253-65.

192. https://www.clinicaltrials.gov/ct2/show/NCT03568890? $\mathrm{recrs}=\mathrm{ab} \& \mathrm{cond}=$ left + atrial + appendage + closure \& rank $=6$

193. https://www.clinicaltrials.gov/ct2/show/NCT02928497? cond=asaptoo\&rank=1

194. https://clinicaltrials.gov/ct2/show/NCT02830152

195. https://www.clinicaltrials.gov/ct2/show/NCT02426944? cond=prague$17 \&$ rank $=1$

196. https://www.clinicaltrials.gov/ct2/show/NCT03445949? cond=safeLAAC\&rank $=1$

197. https://www.clinicaltrials.gov/ct2/show/NCT03463317? recrs=ab\&cond= left+atrial + appendage + closure \& $r a n k=10$

198. https://www.clinicaltrials.gov/ct2/show/NCT03642509

199. https://www.clinicaltrials.gov/ct2/show/NCT02879448? cond=amulet\&dr aw $=1 \&$ rank $=1$

200. https://www.clinicaltrials.gov/ct2/show/NCT03399851?recrs=ab\&cond= swiss-apero\&rank $=1$

201. https://www.clinicaltrials.gov/ct2/show/NCT03434015?cond=fLAAC\& rank=1

202. https://www.clinicaltrials.gov/ct2/show/NCT02702271?term=FLX\& rank $=2$

203. https://clinicaltrials.gov/ct2/show/NCT03273322

204. https://clinicaltrials.gov/ct2/show/NCT03173534 
205. https://clinicaltrials.gov/ct2/show/NCT03088098?recrs=abd\&cond=Aort ic + Valve + Stenosis\&draw $=3$ \& rank $=188$

206. Meier B, Blaauw Y, Khattab A, Lewalter T, Sievert H, Tondo C, Glikson M. EHRA/EAPCI expert consensus statement on catheter-based left atrial appendage occlusion. Europace. 2014;16:1397-416.

207. Meier B, Blaauw Y, Khattab A, Lewalter T, Sievert H, Tondo C, Glikson M. EHRA/EAPCI expert consensus statement on catheter-based left atrial appendage occlusion. EuroIntervention. 2015;10:1109-25.

\section{Supplementary data}

Supplementary Figure 1. Tenting of the transseptal needle in 2D and 3D echocardiography.

Supplementary Figure 2. 3D reconstruction of the left atrium and interatrial septum from computed tomography. Demonstration of the trajectory of the WATCHMAN access sheath (WAS) depending on the TSP location (anterior superior versus inferior posterior).

Supplementary Figure 3. Axial (transverse) view of computed tomography demonstrating the anterolateral orientation of the LAA as well as the implanted WATCHMAN device (incidentally, note small peri-device leak to illustrate both the appendage and WATCHMAN orientation).

Supplementary Figure 4. Sagittal view of computed tomography demonstrating the superior anterior orientation of the left atrial appendage as well as the implanted WATCHMAN device.

Supplementary Figure 5. Orientation of the WATCHMAN access sheath with respect to the fossa ovalis and LAA.

Supplementary Figure 6. Orientation of the TSP system determines the location of the puncture.

Supplementary Figure 7. Demonstration of how pulling the transseptal system down may allow more inferior puncture but at the same time also may change the location from anterior to posterior.

Supplementary Figure 8. Demonstration of how a very anterior oriented appendage may require a far posterior TSP for adequate alignment.

Supplementary Figure 9. Short-axis view of the transoesophageal echocardiogram with a very posterior puncture location for a very anterior appendage orientation.

Supplementary Figure 10. Transoesophageal echocardiography demonstrating a very posterior orientation of the appendage.

Supplementary Figure 11. Very posterior orientation of the appendage requiring a more anterior TSP or access through a patent foramen ovale.

Supplementary Figure 12. Traditional long-axis view of the interatrial septum by transoesophageal echocardiography demonstrating an inferior orientation of the transseptal system (marked in yellow).

Supplementary Figure 13. Traditional short-axis view of the interatrial septum by transoesophageal echocardiography demonstrating a posterior orientation of the transseptal system (marked in yellow).

Supplementary Figure 14. WATCHMAN instructions for use sizing chart.
Supplementary Figure 15. WATCHMAN double-curve access sheath.

Supplementary Figure 16. 45/45 TorqVue sheath.

Supplementary Figure 17. Instructions for use sizing chart for the Amulet device.

Supplementary Figure 18. Flushing of the Amulet device.

Supplementary Figure 19. Fluoroscopic step-by-step Amulet deployment.

Supplementary Figure 20. Amulet release criteria.

Supplementary Figure 21. Demonstration of the Amulet fixation hooks with respect to the lobe.

Supplementary Figure 22. Demonstration of different Amulet implantation techniques.

Movie 1 (corresponding to Supplementary Figure 1). Tenting of the transseptal needle in 2D and 3D echocardiography.

Movie 2 (corresponding to Supplementary Figure 3). Anterolateral orientation of the LAA.

Movie 3 (corresponding to Supplementary Figure 4). Superioranterior orientation of the LAA.

Movie 4. 3D movie of the appendage and heart and fossa.

Movie 5 (corresponding to Supplementary Figure 7). Anterior posterior by pulling down CT trimmed final.

Movie 6a. Demonstration of difficulty with transseptal sheath advancement through the interatrial septum.

Movie 6b. A balloon is advanced across the septum for dilatation.

Movie 7a. Balloon across the interatrial septum.

Movie 7b. The balloon across the interatrial septum is deflated and, during deflation, the transseptal sheath is advanced over the balloon across the interatrial septum.

Movie 8 (corresponding to Figure 12). WATCHMAN tips fluoro1. Movie 9 (corresponding to Figure 13). WATCHMAN tips fluoro2. Movie 10 (corresponding to Supplementary Figure 15). WATCHMAN double-curve access sheath.

Movie 11 (corresponding to Figure 14). WATCHMAN tips fluoro4.

Movie 12. Demonstration of fluid-to-fluid connection between the WATCHMAN access sheath and delivery catheter as well as advancing of the delivery catheter tip to the tip of the WATCHMAN access sheath.

Movie 13. Delivery catheter into the WATCHMAN access sheath (WAS)

Movie 14a. Demonstration of WATCHMAN device deployment.

Movie 14b. WATCHMAN fluoro slow deployment. Demonstration of WATCHMAN device deployment.

Movie 15. Tug test.

Movie 16. WATCHMAN device release. 
Movie 17. Demonstration of how counter-clockwise rotation of the WAS will typically allow more anterior orientation (shown in the RAO/CAU view fluoroscopically and $135^{\circ}$ view by transoesophageal echocardiography).

Movie 18 (corresponding to Supplementary Figure 18). Flushing of the loading system.

Movie 19 (corresponding to Figure 19). Fluid-to-fluid connection as the loading catheter and delivery sheath are connected to minimise air entrapment and embolisation.

Movie 20 (corresponding to Figure 20). Advancing the Amulet device via the delivery cable.
Movie 21 (corresponding to Figure 21 and Supplementary Figure 19). Step-by-step Amulet deployment with deployment of the lobe.

Movie 22. Deployment of the Amulet disc.

Movie 23. Amulet tug test.

Movie 24. Demonstration of Amulet implantation via the sandwich technique.

The supplementary data are published online at: https://EuroIntervention.pcronline.com/ doi/10.4244/EIJY19M08_01 


\section{Supplementary data}

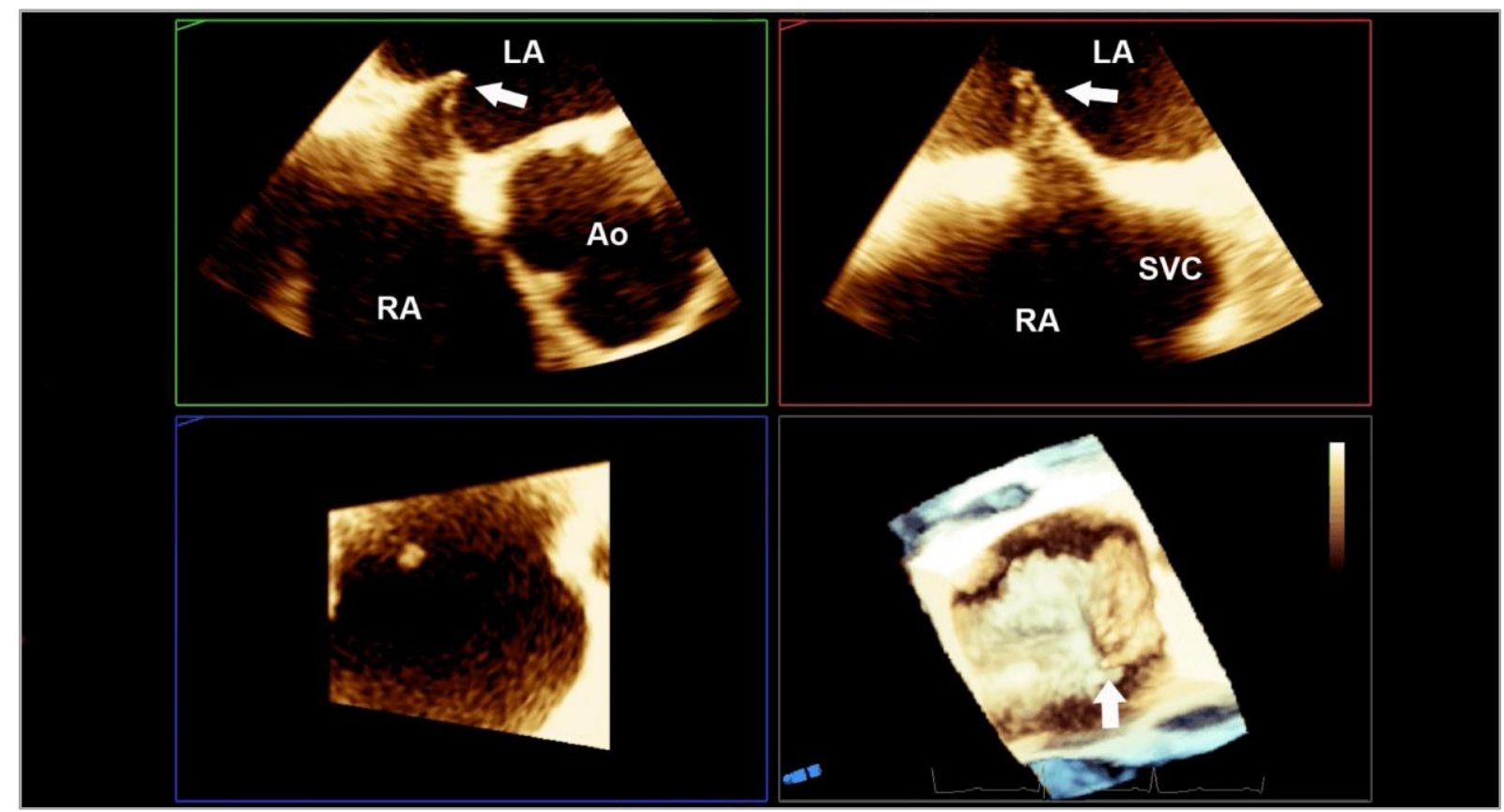

Supplementary Figure 1. Tenting of the transseptal needle in 2D and 3D echocardiography. Ao: aorta; LA: left atrium; RA: right atrium; SVC: superior vena cava; white arrows point towards the tenting of the transseptal system 


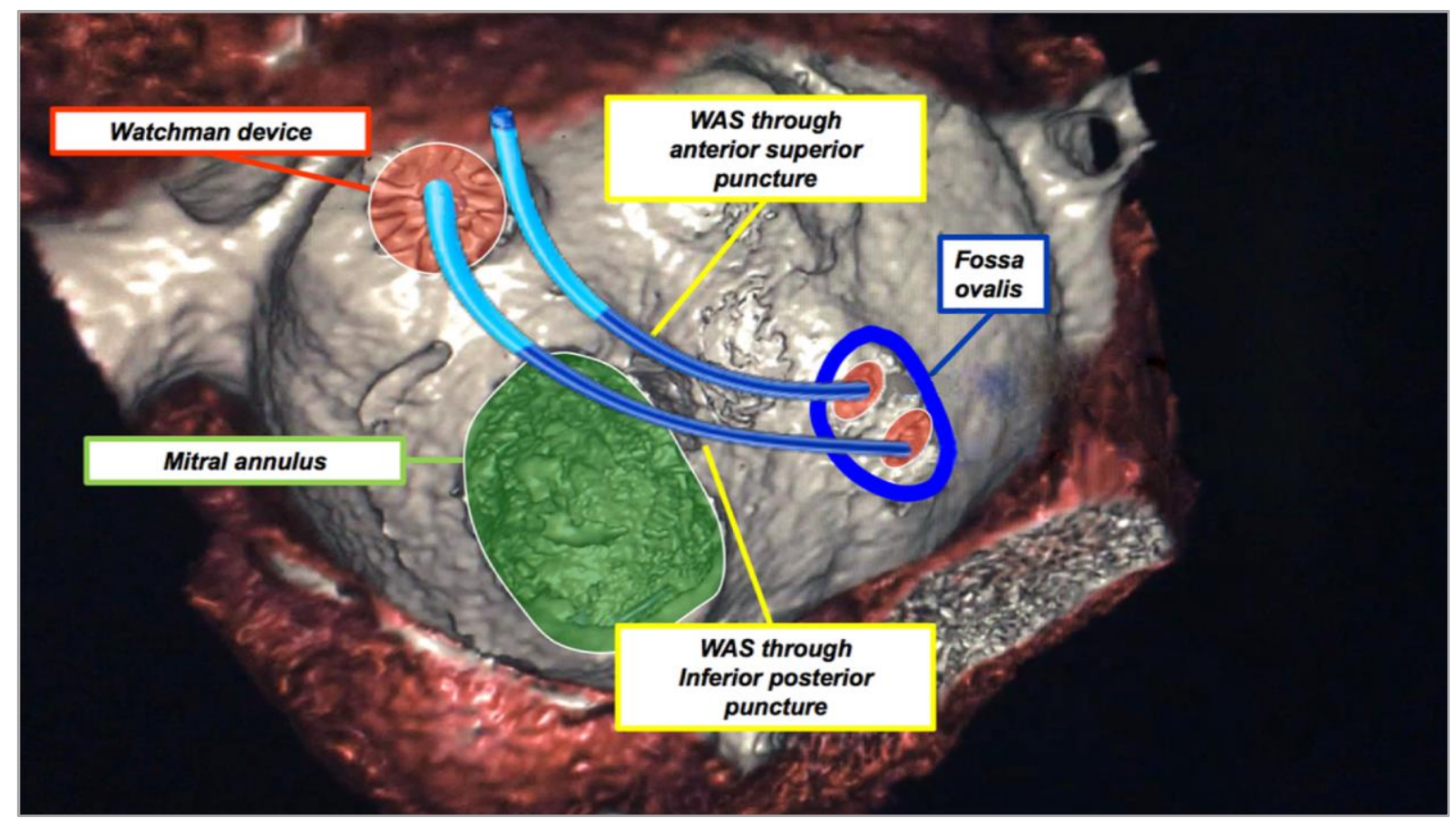

Supplementary Figure 2. 3D reconstruction of the left atrium and interatrial septum from computed tomography. Demonstration of the trajectory of the WATCHMAN access sheath (WAS) depending on the transseptal puncture location (anterior superior versus inferior posterior). 


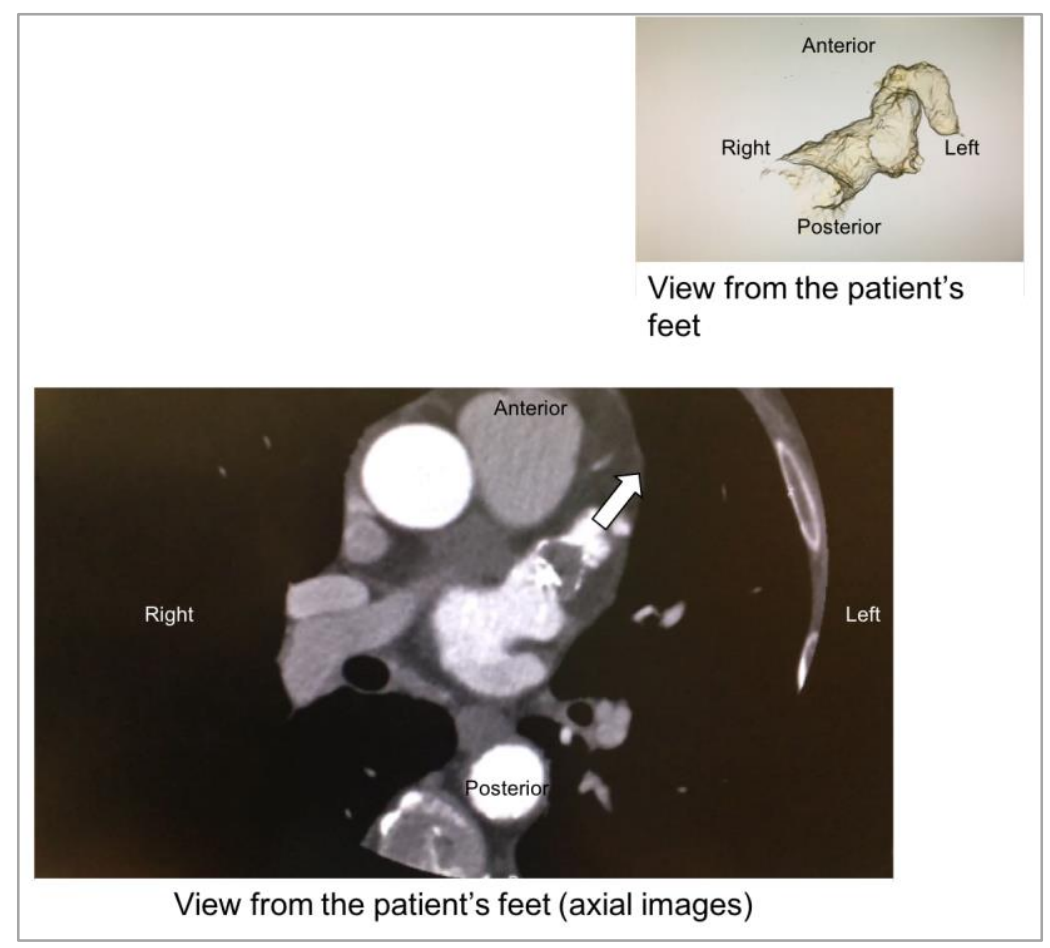

Supplementary Figure 3. Axial (transverse) view of computed tomography demonstrating the anterolateral orientation of the LAA as well as the implanted WATCHMAN device (incidentally, note small peri-device leak to illustrate both the appendage and WATCHMAN orientation). Upper right panel demonstrates the corresponding 3D reconstruction of the appendage with a view from the patient's foot (corresponding with the axial computed tomography images). LAA: left atrial appendage 


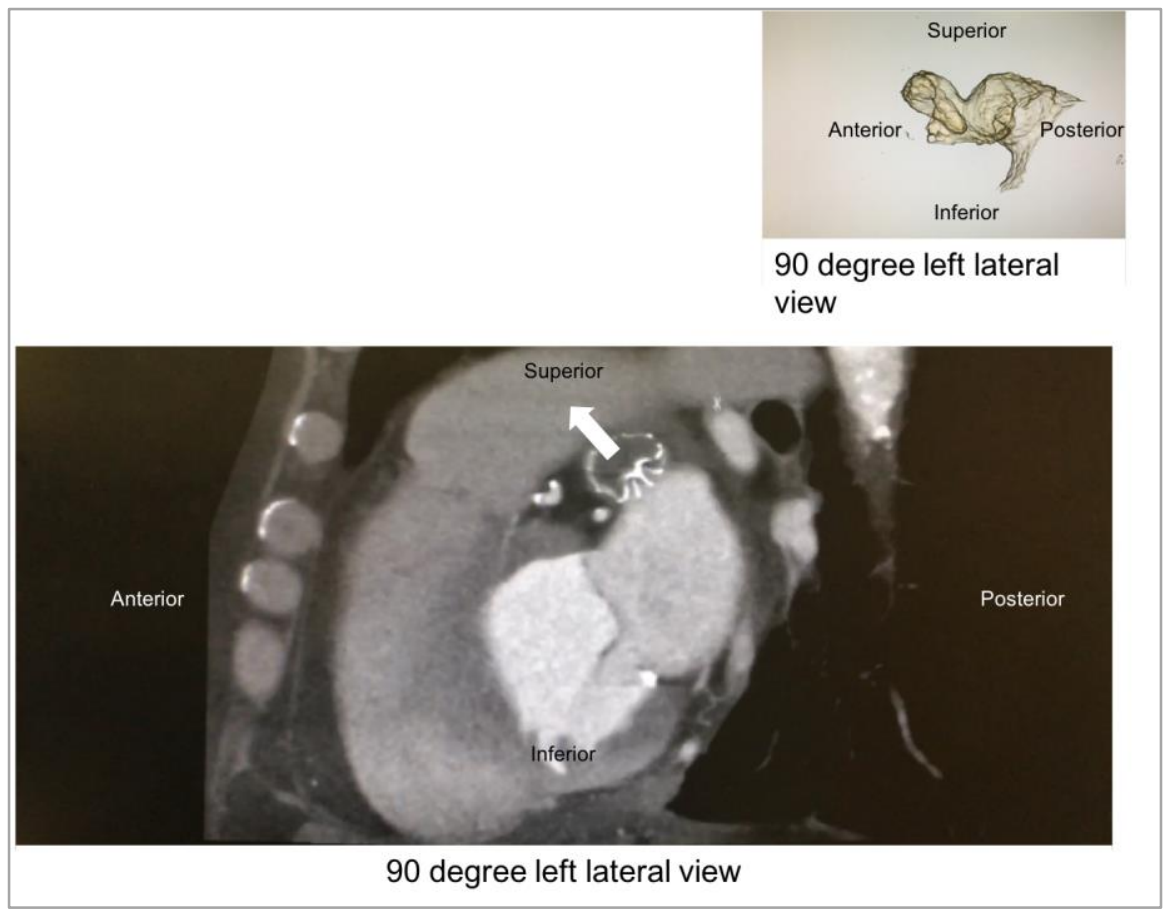

Supplementary Figure 4. Sagittal view of computed tomography demonstrating the superior anterior orientation of the left atrial appendage as well as the implanted WATCHMAN device. Upper right panel demonstrates the corresponding 3D reconstruction of the appendage with a view from the patient's left side (corresponding with the sagittal computed tomography images). LAA: left atrial appendage 


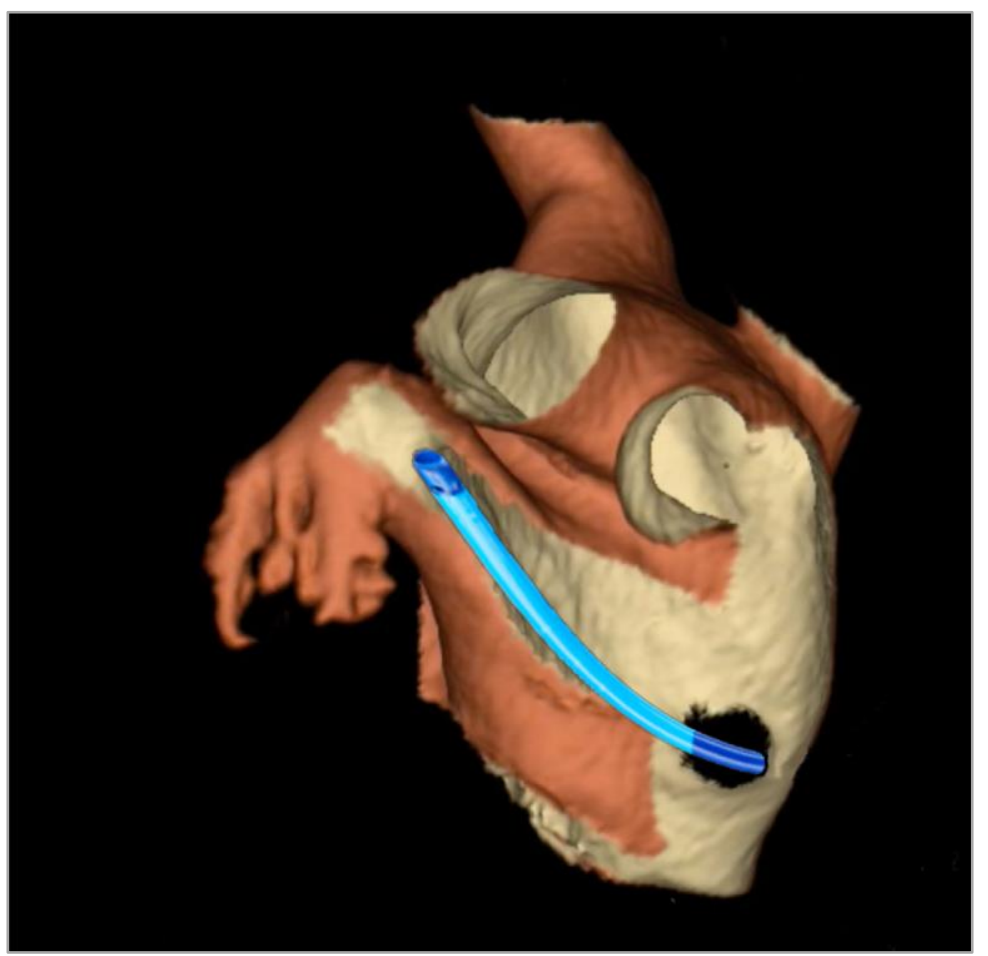

Supplementary Figure 5. Orientation of the WATCHMAN access sheath with respect to the fossa ovalis and LAA. 


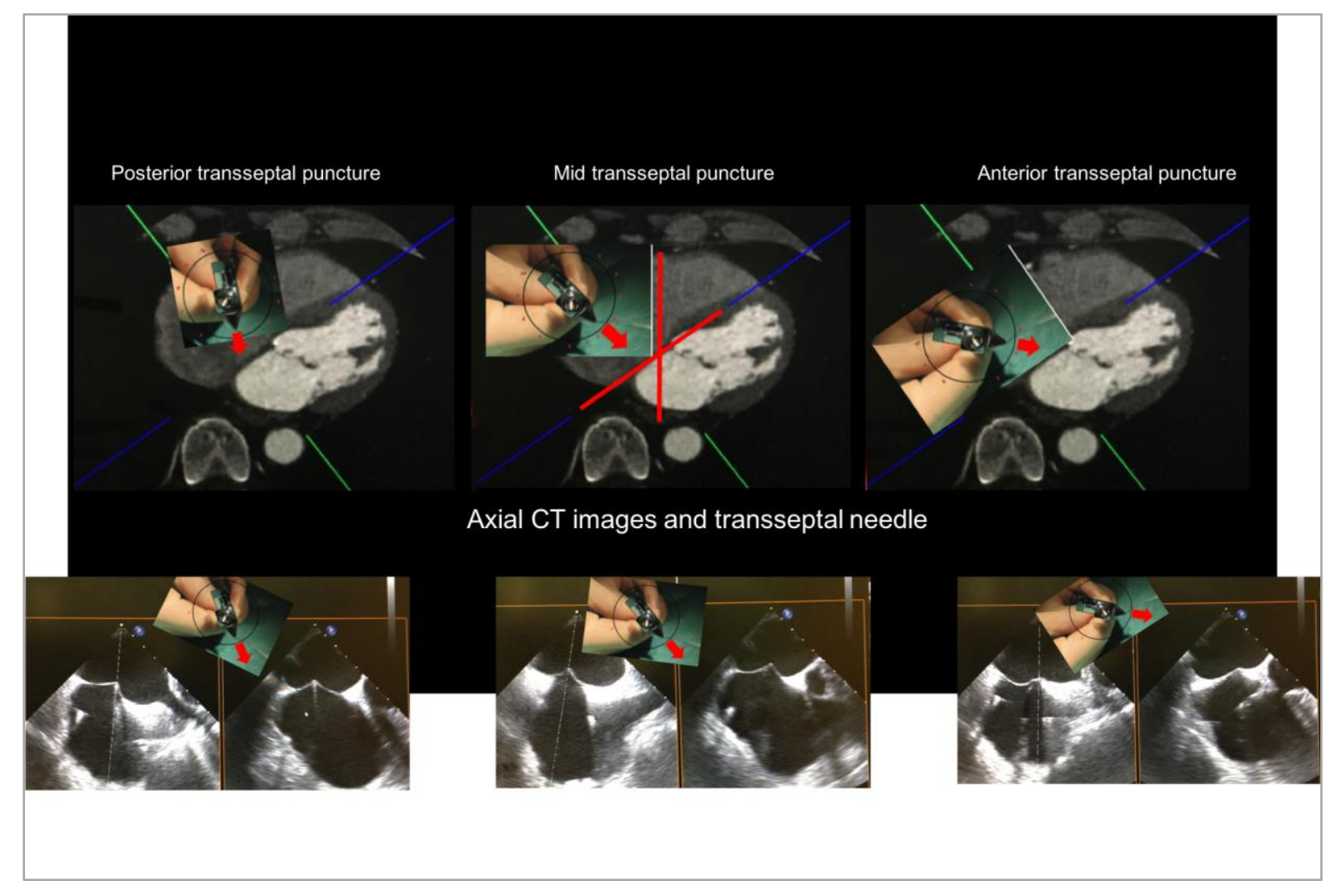

Supplementary Figure 6. Orientation of the transseptal puncture system determines the location of the puncture. CT: computed tomography 


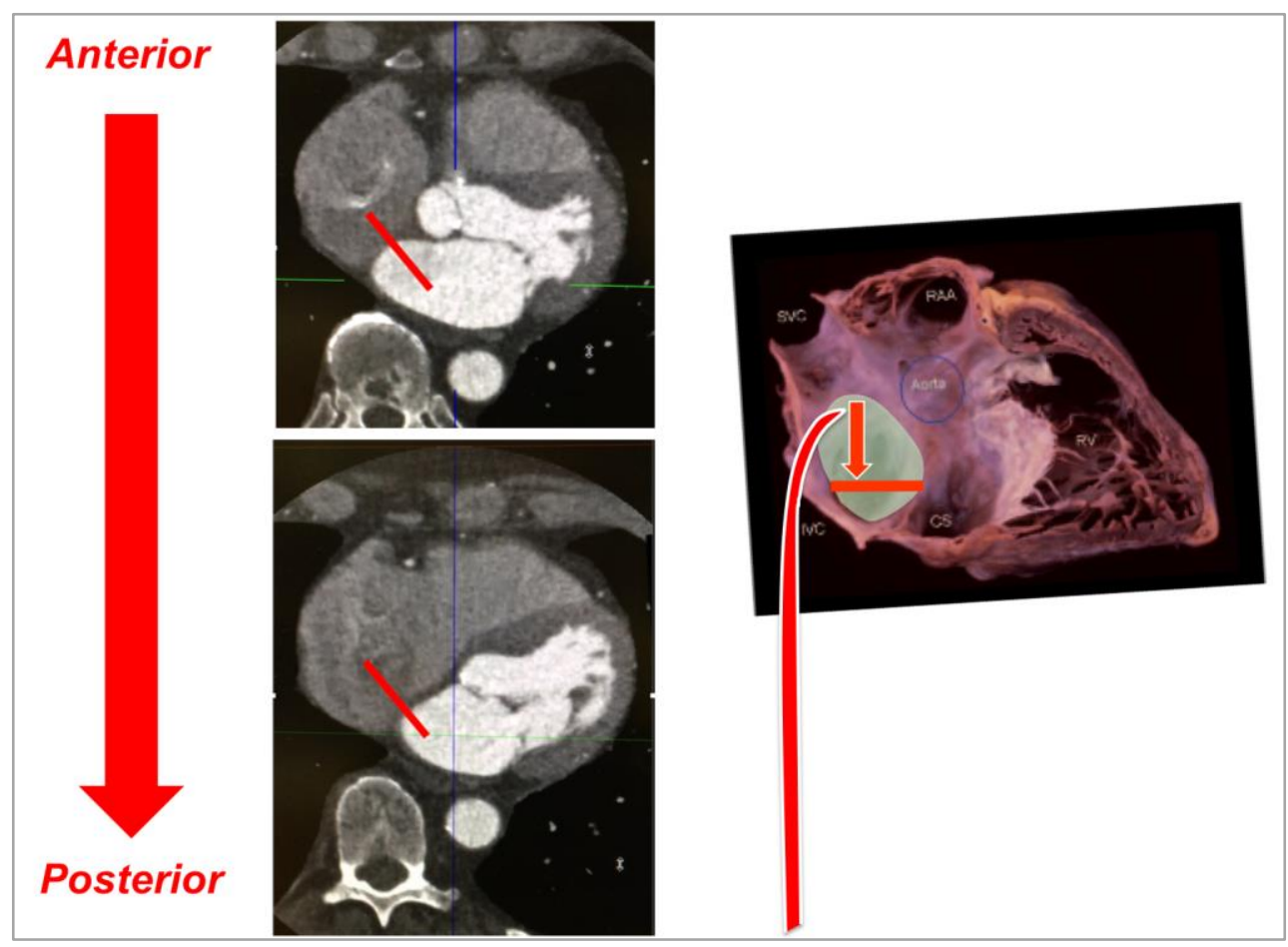

Supplementary Figure 7. Demonstration of how pulling the transseptal system down may allow more inferior puncture but at the same time also may change the location from anterior to posterior. 


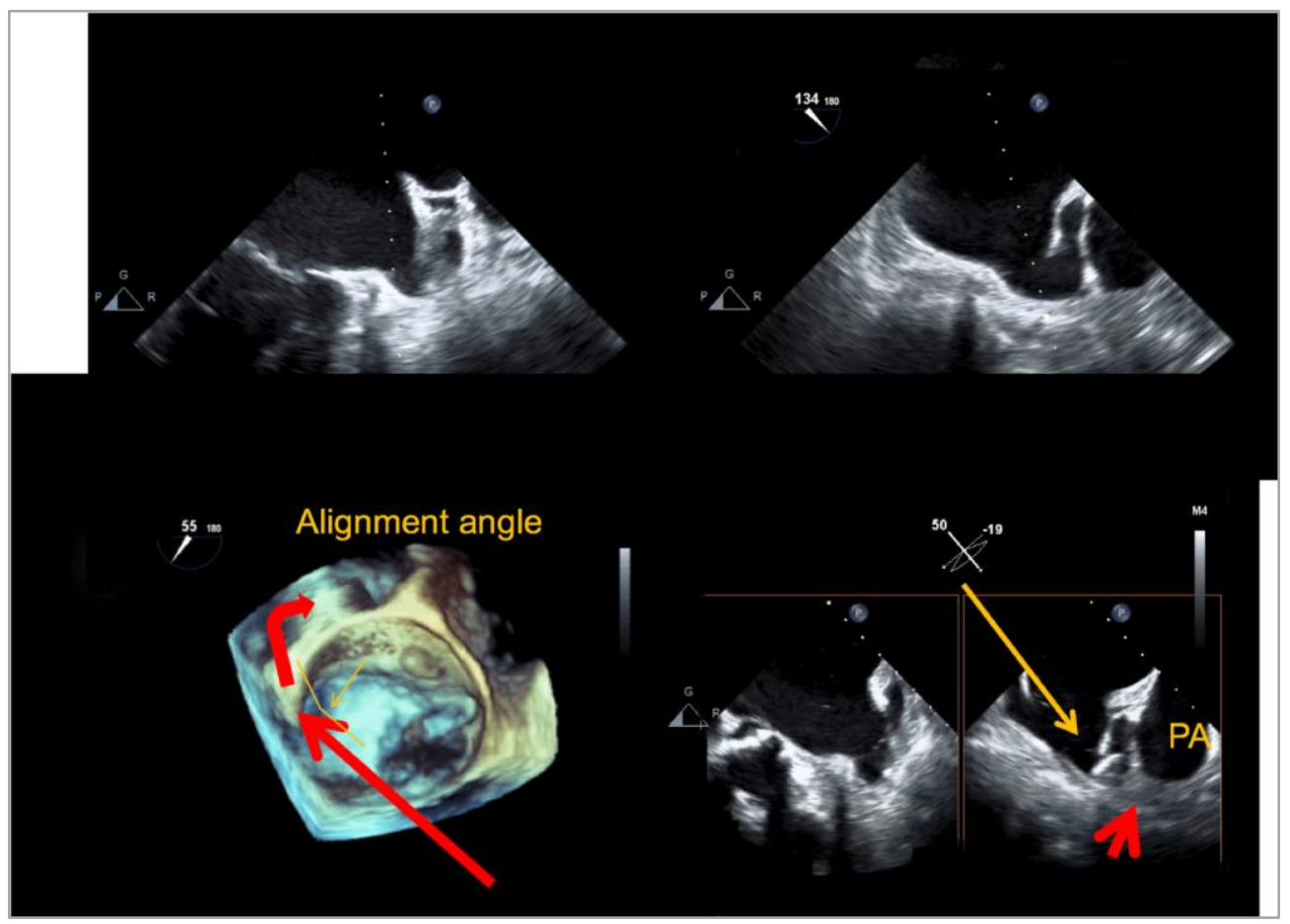

Supplementary Figure 8. Demonstration of how a very anterior oriented appendage may require a far posterior transseptal puncture for adequate alignment. Straight red arrow shows the optimal puncture location, angled red arrow shows the appendage orientation. PA: pulmonary artery 


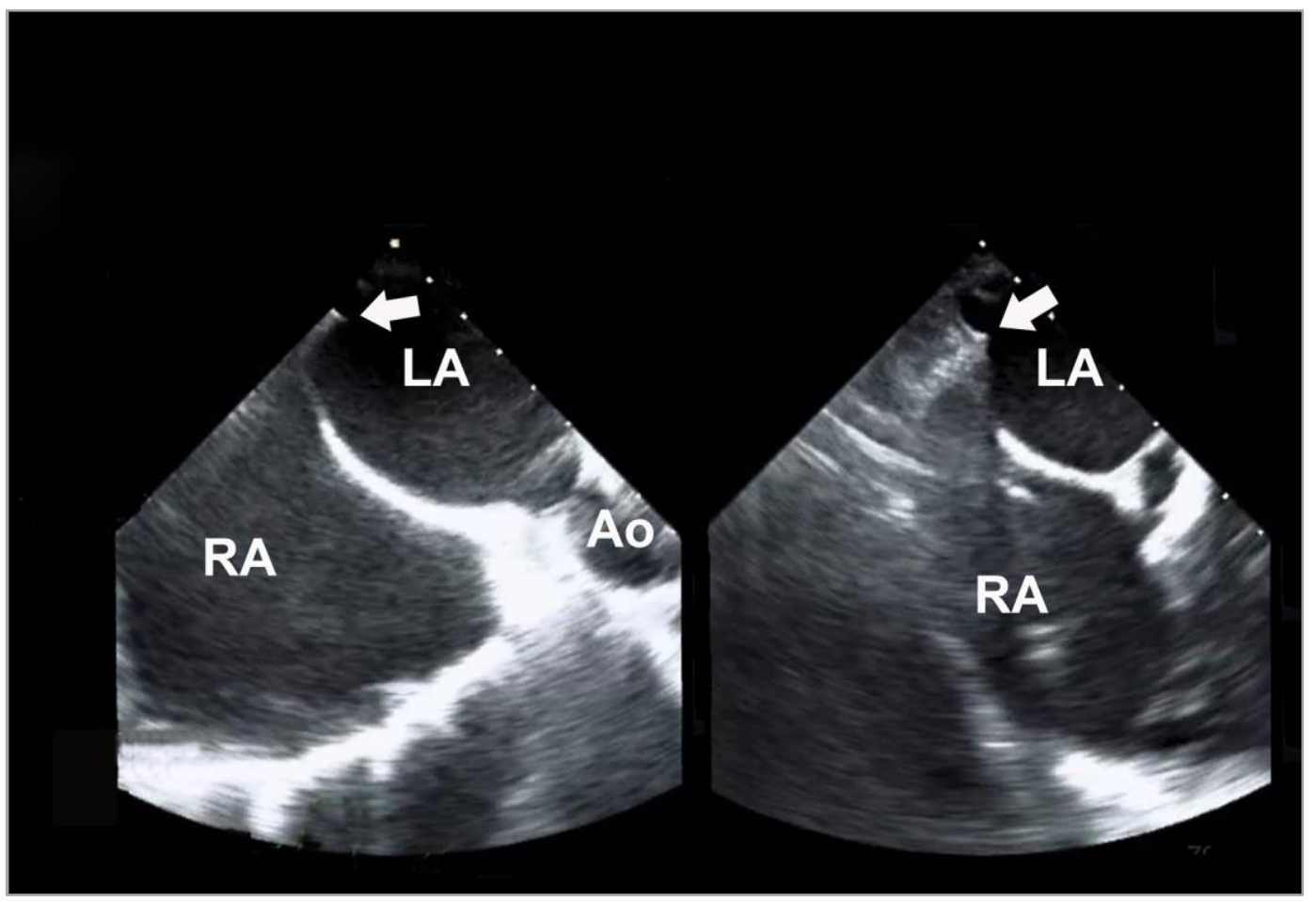

Supplementary Figure 9. Short-axis view of the transoesophageal echocardiogram with a very posterior puncture location for a very anterior appendage orientation. 


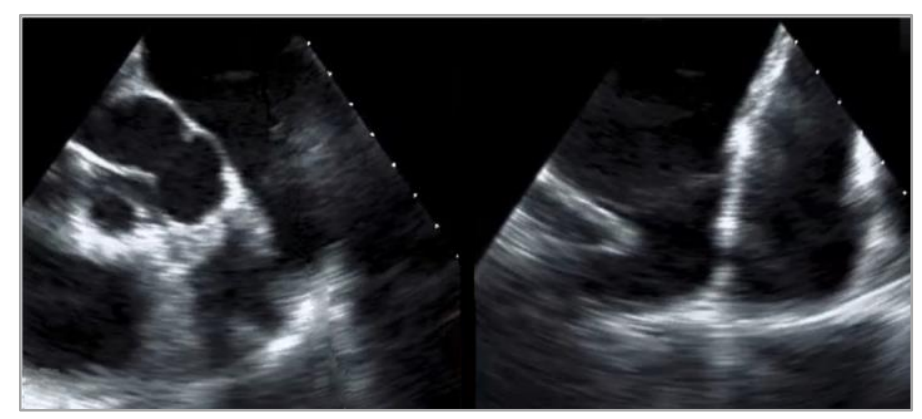

Supplementary Figure 10. Transoesophageal echocardiography demonstrating a very posterior orientation of the appendage. 


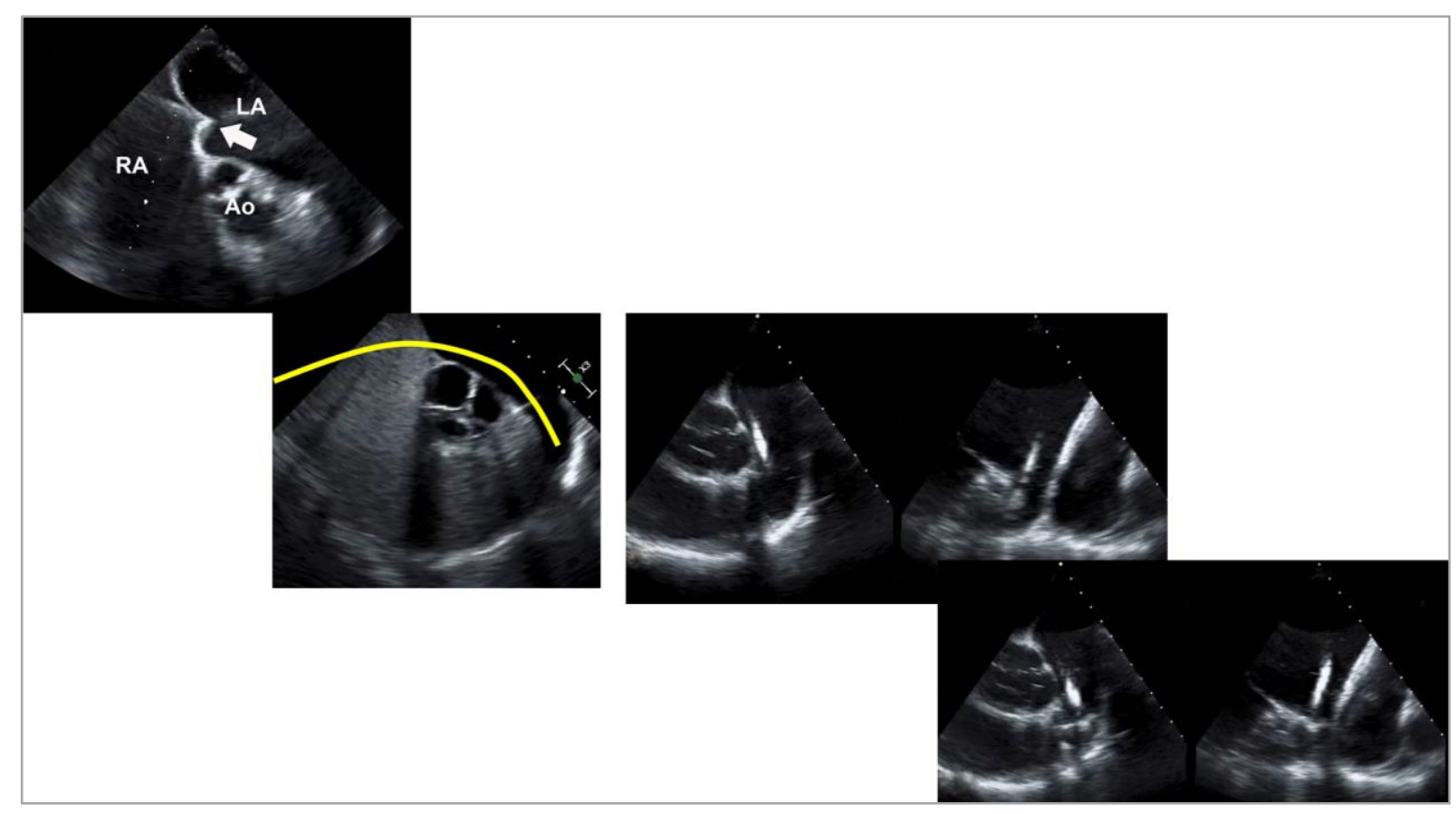

Supplementary Figure 11. Very posterior orientation of the appendage requiring a more anterior transseptal puncture or access through a patent foramen ovale. 


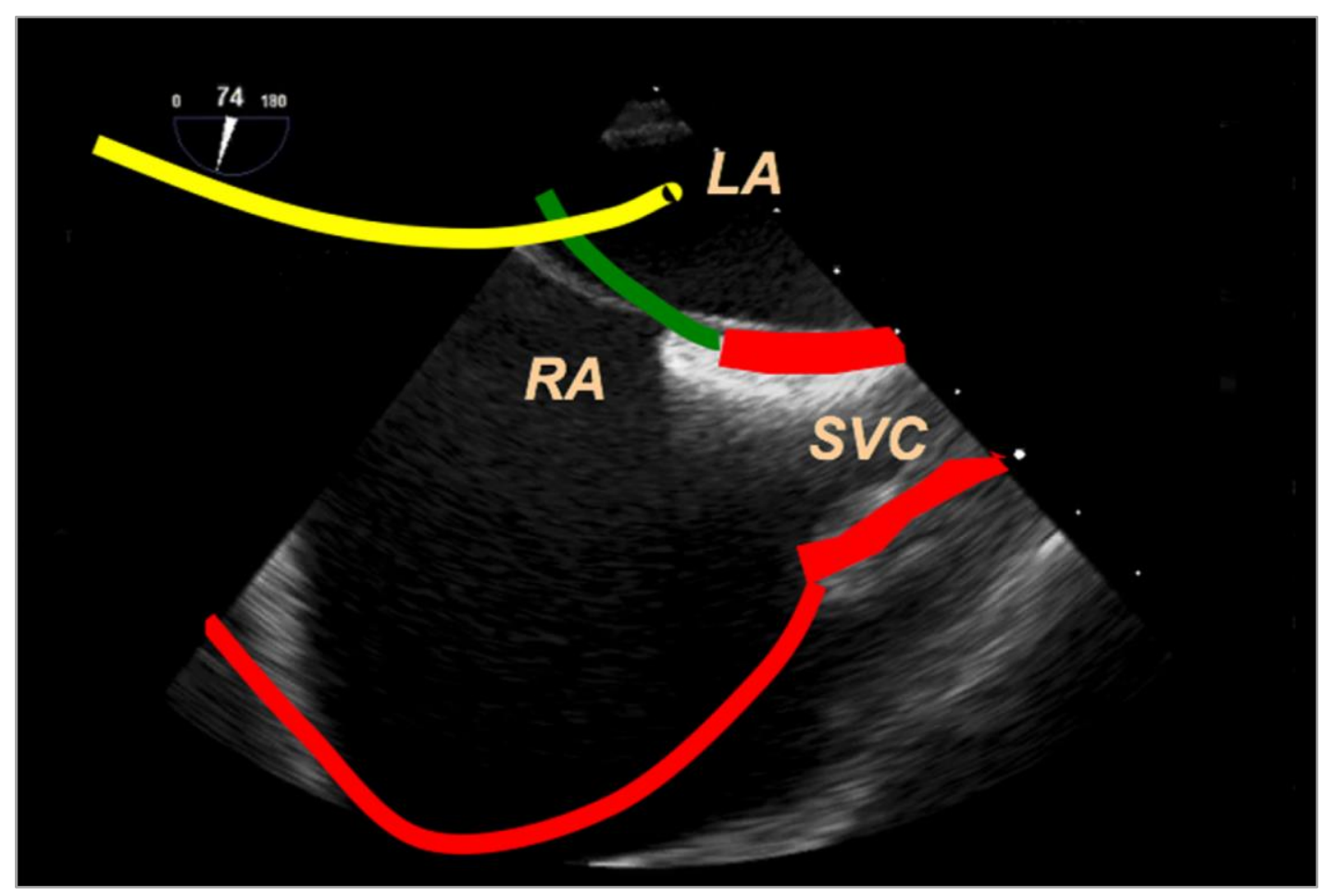

Supplementary Figure 12. Traditional long-axis view of the interatrial septum by transoesophageal echocardiography demonstrating an inferior orientation of the transseptal system (marked in yellow).

LA: left atrium; RA: right atrium; SVC: superior vena cava 


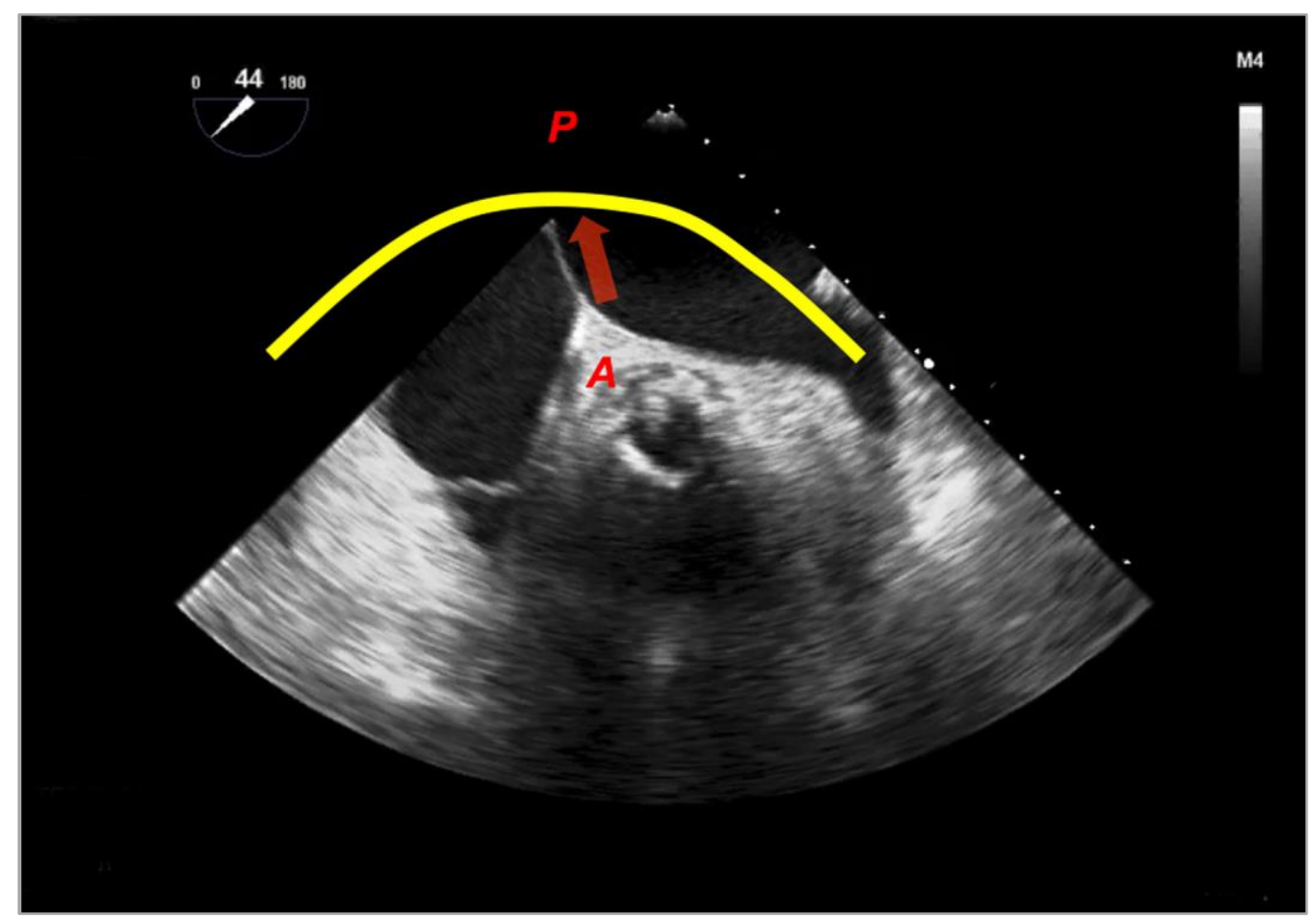

Supplementary Figure 13. Traditional short-axis view of the interatrial septum by transoesophageal echocardiography demonstrating a posterior orientation of the transseptal system (marked in yellow).

A: anterior; P: posterior 


\begin{tabular}{|c|c|c|c|}
\hline $\begin{array}{c}\text { Maximum } \\
\text { LAA Ostium }\end{array}$ & $\begin{array}{c}\text { Device Size } \\
\text { (uncompressed } \\
\text { diameter) }\end{array}$ & Maximum & Minimum (8\%) \\
\hline $17-19 \mathrm{~mm}$ & $21 \mathrm{~mm}$ & $168 \mathrm{~mm}$ & $193 \mathrm{~mm}$ \\
\hline $20-22 \mathrm{~mm}$ & $24 \mathrm{~mm}$ & $192 \mathrm{~mm}$ & $221 \mathrm{~mm}$ \\
\hline $23-25 \mathrm{~mm}$ & $27 \mathrm{~mm}$ & $21.6 \mathrm{~mm}$ & $248 \mathrm{~mm}$ \\
\hline $26-28 \mathrm{~mm}$ & $30 \mathrm{~mm}$ & $240 \mathrm{~mm}$ & $276 \mathrm{~mm}$ \\
\hline $29-31 \mathrm{~mm}$ & $33 \mathrm{~mm}$ & $264 \mathrm{~mm}$ & $304 \mathrm{~mm}$ \\
\hline
\end{tabular}

Supplementary Figure 14. WATCHMAN instructions for use sizing chart. 


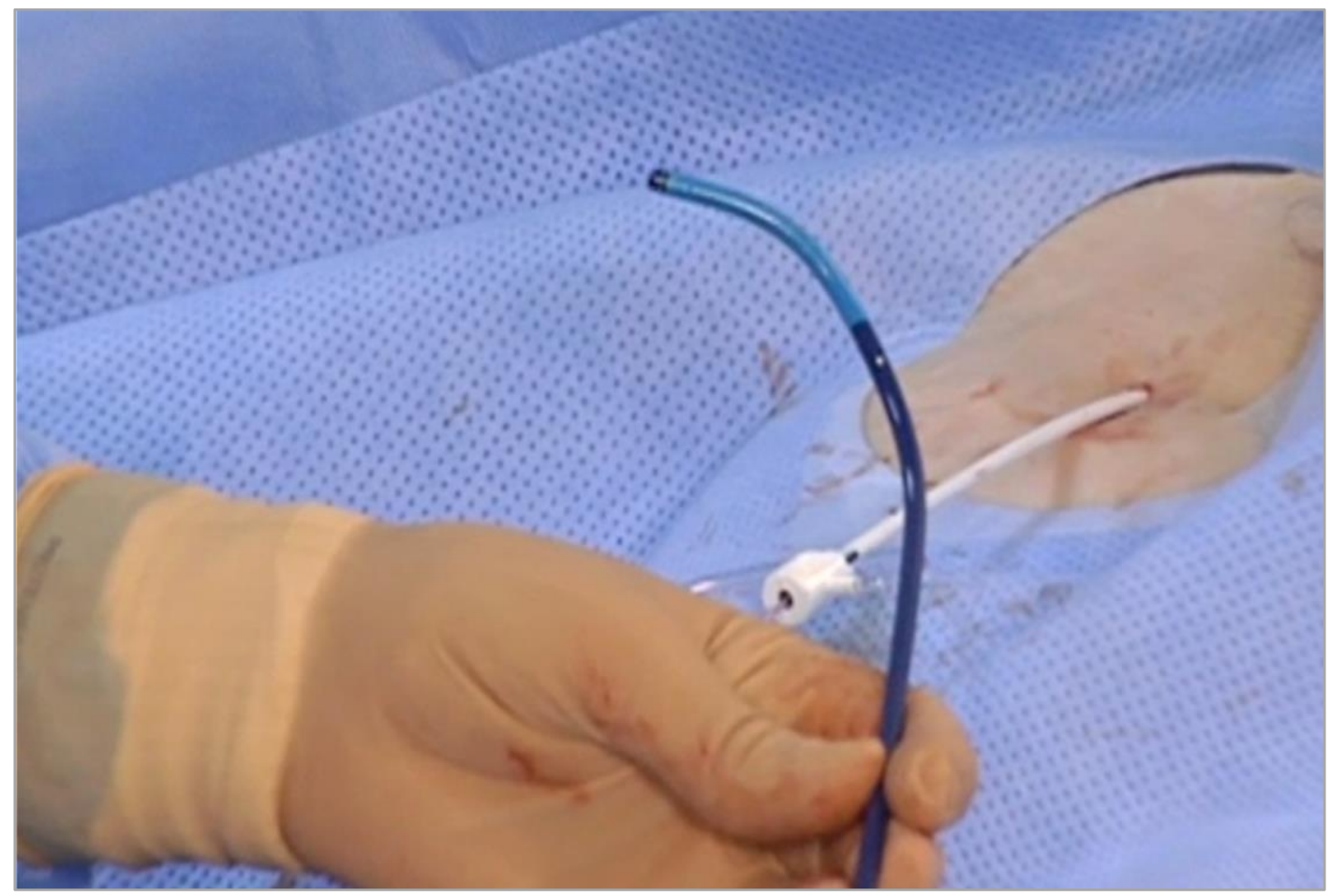

Supplementary Figure 15. WATCHMAN double-curve access sheath. 


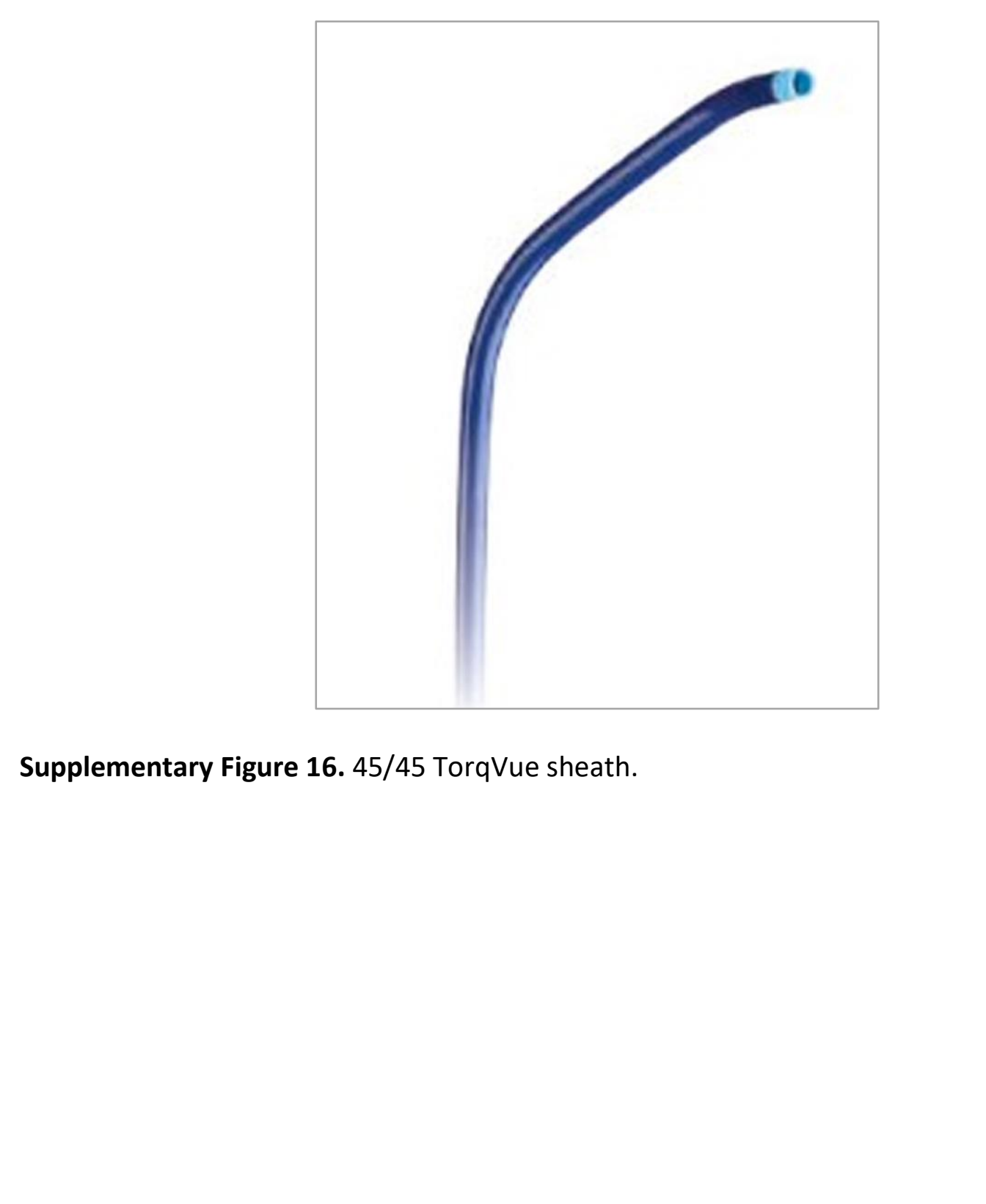




\begin{tabular}{|c|c|c|c|c|c|}
\hline \multicolumn{4}{|c|}{$\begin{array}{l}\text { AMPLATZER }{ }^{\mathrm{TM}} \text { Amulet }^{\mathrm{TM}} \\
\text { Left atrial appendage occluder }\end{array}$} & \multirow[t]{2}{*}{$\begin{array}{l}\text { Disc } \\
\text { diameter }\end{array}$} & Device \\
\hline \multicolumn{4}{|c|}{ Device dimensions and sizing chart } & & Lobe length \\
\hline $\begin{array}{l}\text { Maximum landing } \\
\text { zone width (mm) }\end{array}$ & $\begin{array}{l}\text { Device size } \\
(\mathrm{mm})\end{array}$ & $\begin{array}{l}\text { Lobe length } \\
(\mathrm{mm})\end{array}$ & $\begin{array}{c}\text { Minimum LAA } \\
\text { depth (mm) }\end{array}$ & $\begin{array}{c}\text { Disc diameter } \\
(\mathrm{mm})\end{array}$ & $\begin{array}{c}\text { Sheath } \\
\text { diameter }\end{array}$ \\
\hline $11.0-13.0$ & 16 & 7.5 & $\geq 10$ & 22 & \multirow{5}{*}{$\begin{array}{c}12 \mathrm{Fr} \\
\text { or } \\
14 \mathrm{Fr} \text { (with adaptor) }\end{array}$} \\
\hline $13.0-15.0$ & 18 & 7.5 & $\geq 10$ & 24 & \\
\hline $15.0-17.0$ & 20 & 7.5 & $\geq 10$ & 26 & \\
\hline $17.0-19.0$ & 22 & 7.5 & $\geq 10$ & 28 & \\
\hline $19.0-22.0$ & 25 & 10 & $\geq 12$ & 32 & \\
\hline $22.0-25.0$ & 28 & 10 & $\geq 12$ & 35 & \multirow{3}{*}{$14 \mathrm{Fr}$} \\
\hline $25.0-28.0$ & 31 & 10 & $\geq 12$ & 38 & \\
\hline $28.0-31.0$ & 34 & 10 & $\geq 12$ & 41 & \\
\hline
\end{tabular}

Supplementary Figure 17. Instructions for use sizing chart for the Amulet device. 


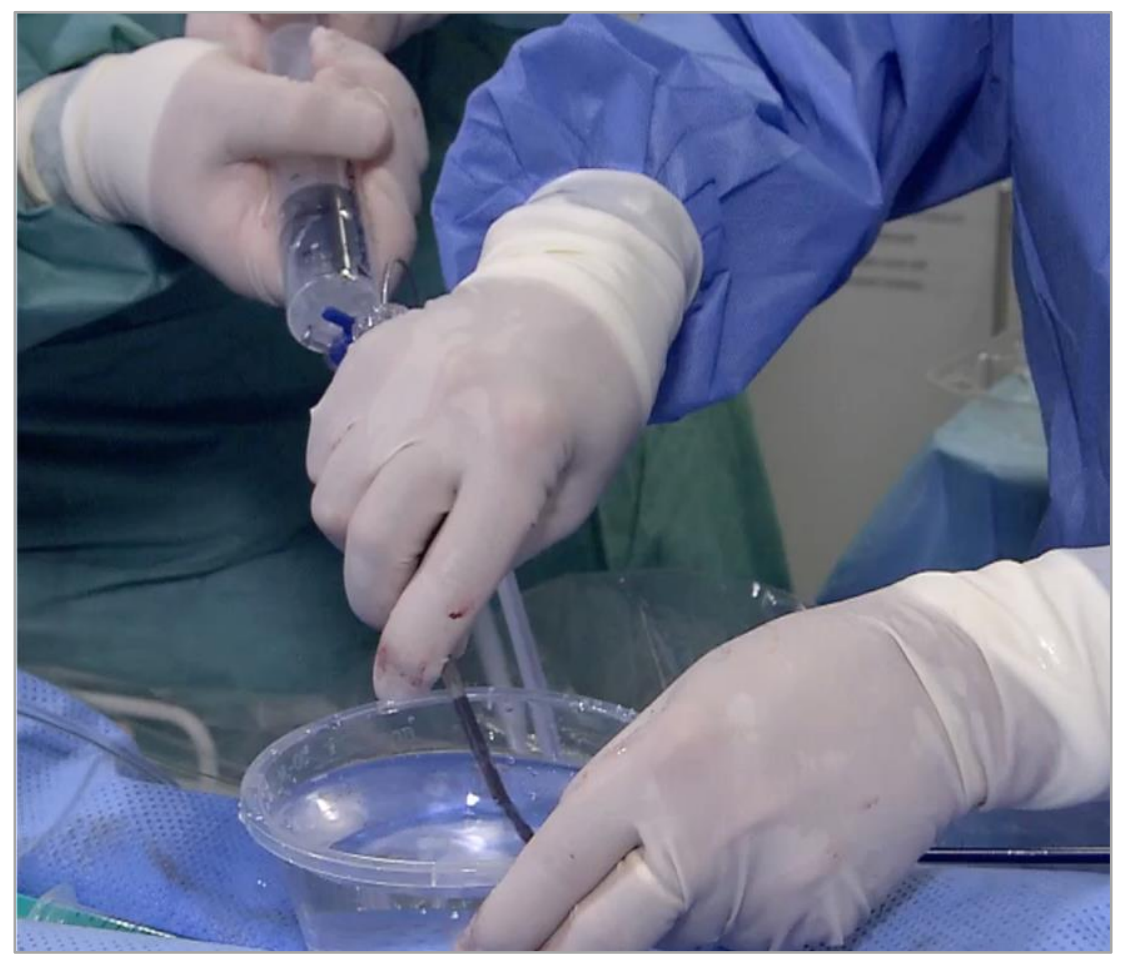

Supplementary Figure 18. Flushing of the Amulet device. 


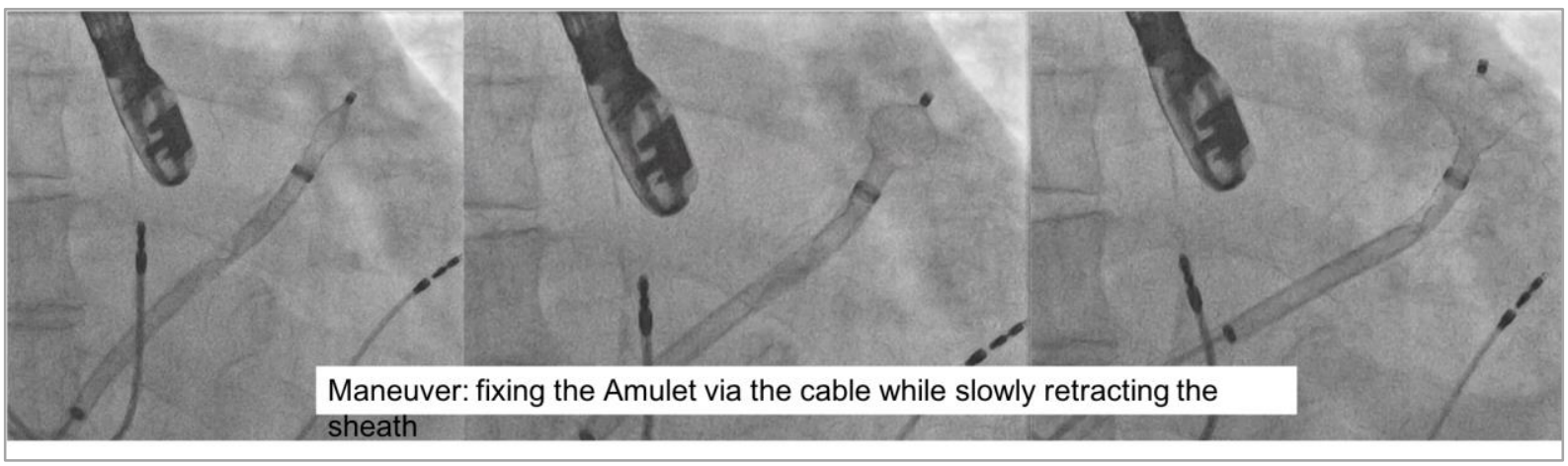

Supplementary Figure 19. Fluoroscopic step-by-step Amulet deployment. 


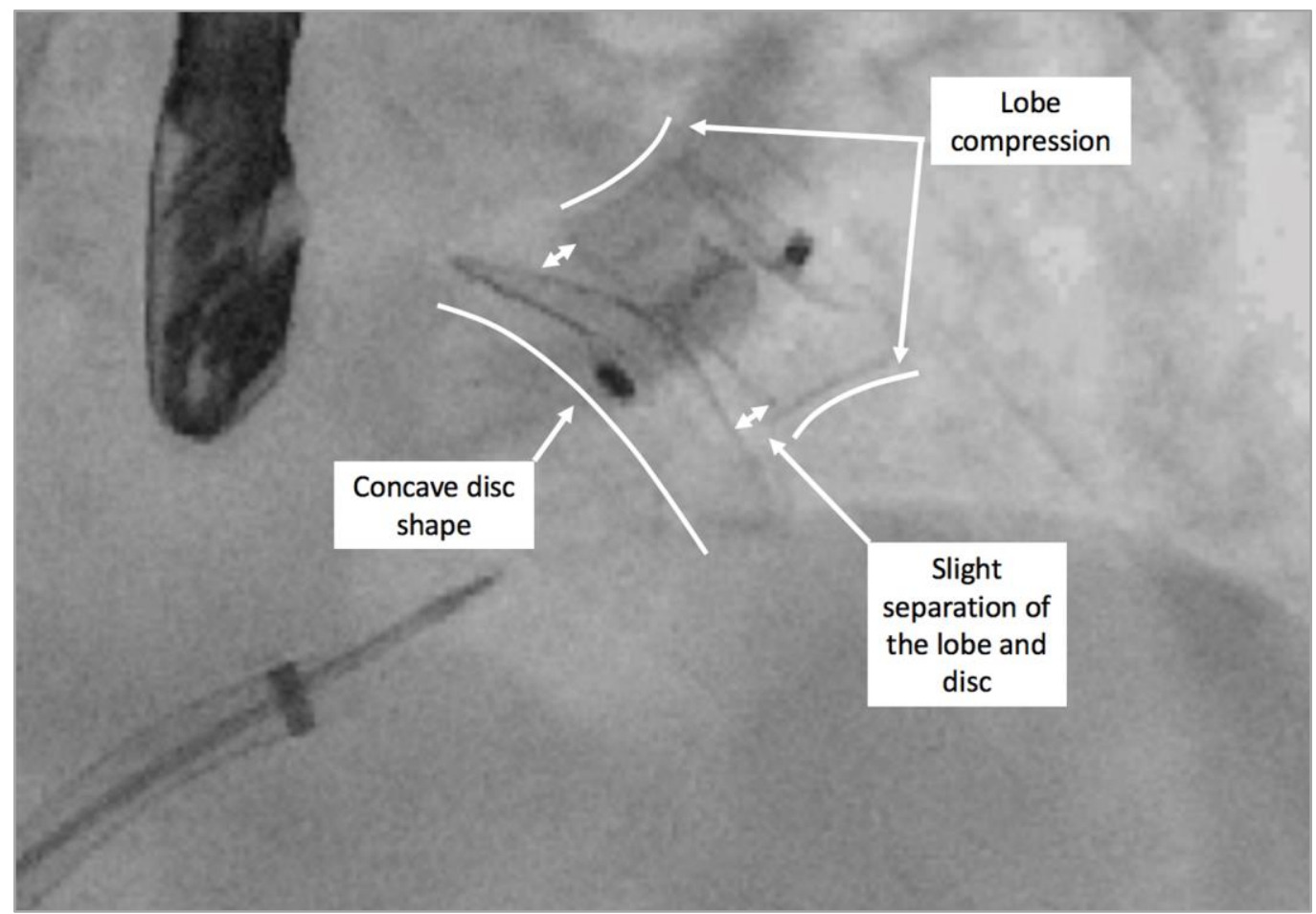

Supplementary Figure 20. Amulet release criteria. 


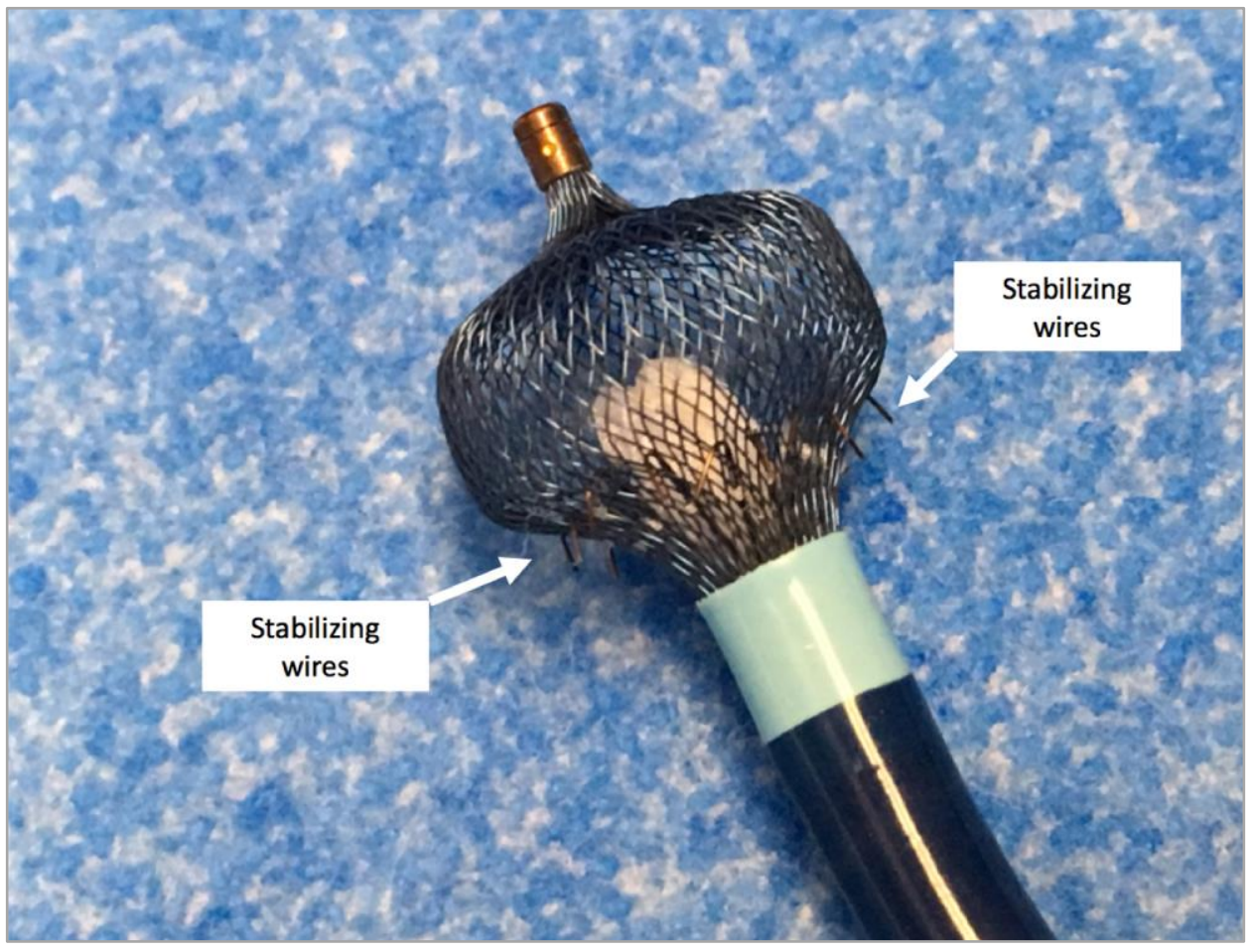

Supplementary Figure 21. Demonstration of the Amulet fixation hooks with respect to the lobe. 


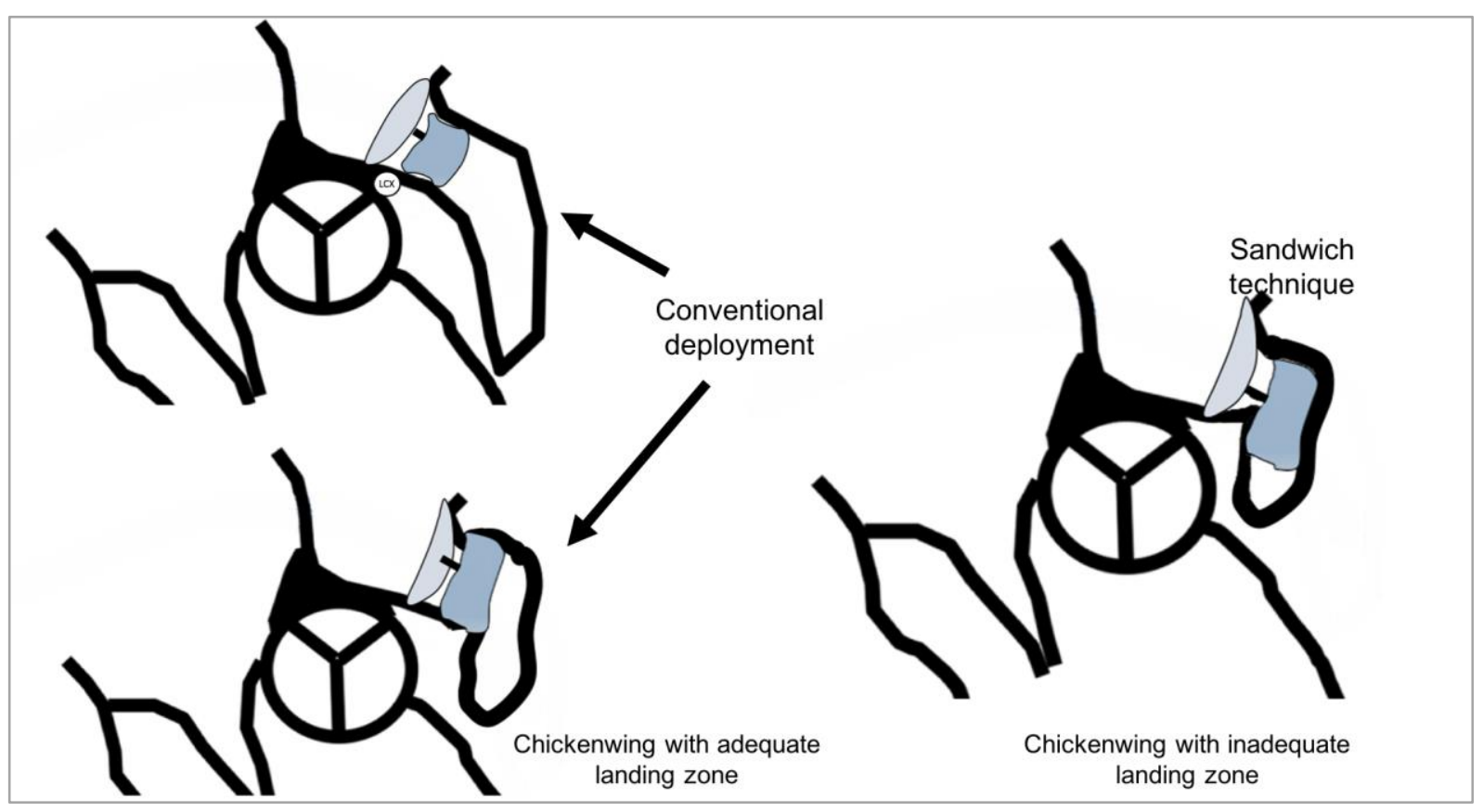

Supplementary Figure 22. Demonstration of different Amulet implantation techniques. 